\title{
Der Deutsche Corporate Governance Kodex 2020
}

\section{- Grundsatz- und Praxisprobleme -}

Prof. Dr. Dr. Dr. h.c. mult. KLaus J. Hopt, M.C.J. (New York University), Hamburg*

und

Prof. Dr. Patrick C. Leyens, LL.M. (London), Graz***

I. Vom Deutschen Corporate Governance Kodex (DCGK) 2017 über den DCGK-E 2018 und den DCGK-E 2019 zum DCGK 2020 . . . . . . . . . . . 930

1. Der DCGK 2017: Reformbedarf nur in Einzelheiten . . . . . . . . . . . 930

2. Der DCGK-E 2018: Einwände und Gegenvorschläge . . . . . . . . . . . 932

3. Der DCGK-E 2019: Wesentliche Änderungen gegenüber dem DCGK 2017932

II. Der DCGK 2020 und "good corporate governance" . . . . . . . . . . . . . . 934

1. Definition der Corporate Governance, Zielsetzung und Adressaten

(DCGK Teil 1 und Teil 2 Präambel) . . . . . . . . . . . . . . . . . . 934

2. Die internationale Corporate Governance Code-Landschaft:

Einigkeit in den Grundsätzen, Vielfalt im Detail . . . . . . . . . . . . . . . 943

3. Die Corporate Governance-Leitlinien der wichtigsten Stimmrechtsberater und institutionellen Investoren . . . . . . . . . . . . . . . . . . . . 945

4. Die Grundsätze im DCGK 2020 . . . . . . . . . . . . . . . . . . . . . . . . . . 948

III. Der Aufsichtsrat, insbesondere Unabhängigkeit und Interessenkonflikte, $\mathrm{Zu}$ sammenarbeit sowie Funktions- und Arbeitsweise . . . . . . . . . . . . . . . 950

1. Leitung und Überwachung (DCGK Teil 2 A und B) . . . . . . . . . . . . . . 950

2. Zusammensetzung und Unabhängigkeit (DCGK Teil 2 C) . . . . . . . . 954

3. Interessenkonflikte bei Vorstand und Aufsichtsrat (DCGK Teil 2 E) . . . . 965

4. Funktions- und Arbeitsweise des Aufsichtsrats, insbesondere Zusammenarbeit mit dem Vorstand und Abschlussprüfer,

Information, Ausschüsse (DCGK Teil 2 D) . . . . . . . . . . . . . . 967

IV. Die Vergütung von Vorstand und Aufsichtsrat . . . . . . . . . . . . . . . . . . . . . 974

1. Vergütung des Vorstands (DCGK Teil 2 G I) . . . . . . . . . . . . . . . . . . 974

2. Vergütung des Aufsichtsrats (DCGK Teil 2 G II) . . . . . . . . . . . . . . . 986

3. Zwischenergebnis zur Vergütung von Vorstand und Aufsichtsrat . . . . . . 989

* Direktor em. und Professor am Max-Planck-Institut für ausländisches und internationales Privatrecht in Hamburg.

** Professor an der Karl-Franzens-Universität Graz und (ehrenamtl.) an der Erasmus Universiteit Rotterdam. 
V. Transparenz und externe Berichterstattung (DCGK Teil 2 F) . . . . . . . . . 990

1. Überführung des Corporate Governance Berichts in die Erklärung zur Unternehmensführung sowie weitere externe Berichterstattung . . . . . . 990

2. Gleichbehandlung der Aktionäre bei Informationen . . . . . . . . . . . . 992

VI. Zusammenfassung und Thesen . . . . . . . . . . . . . . . . . . . . 994

Die Regierungskommission Deutscher Corporate Governance Kodex hat ein vollständig neugefasstes Kodexwerk vorgelegt, das ab 2020 gelten soll. Im Einklang mit internationalen Vorstellungen soll künftig die Mehrheit der Anteilseignervertreter im Aufsichtsrat von Vorstand und Gesellschaft unabhängig sein, hingegen sollen schon zwei von einem Kontrollaktionär unabhängige Mitglieder ausreichen. Zur Vorstandsvergütung, dem zweiten großen Reformanliegen, empfieblt der Kodex ein Modell mit weitgehenden Vorgaben zu Inhalt, Ablauf und Überprüfung. Zu begrüßen ist der Wegfall des Corporate Governance Berichts und die Aufwertung der Erklärung zur Unternehmensführung zum zentralen Berichtsinstrument. Bei Kritik im Einzelnen ist die Neufassung des DCGK international anschlussfähig und die Kodexregulierung nicht zuletzt durch das offen gefübrte Konsultationsverfabren gestärkt.

The Government Commission "German Corporate Governance Code" has adopted a completely revised version of the German Corporate Governance Code which will come into force in 2020. In line with international standards, the revised Code recommends that the majority of the shareholder representatives on the supervisory board should be independent of the management board and the corporation. Yet only two of them shall be independent of controlling shareholders. Regarding the remuneration of members of the management board, which was the second major reform theme, the revised Code foresees a remuneration model with far-reaching terms on substance and procedure. It is an improvement that the earlier recommendation for an additional corporate governance report has been deleted. Instead, the revised Code strengthens the statutory corporate governance statement, which will henceforth become the new central reporting instrument. While details are open to criticism, the revised Code lives up to internationally agreed standards. Moreover, the code has considerably benefited from the transparency of the consultation process which preceded the revision.

\section{Vom Deutschen Corporate Governance Kodex (DCGK) 2017 über den DCGK-E 2018 und den DCGK-E 2019 zum DCGK 2020}

\section{Der DCGK 2017: Reformbedarf nur in Einzelheiten}

Der Deutsche Corporate Governance Kodex (DCGK) von 2002, bisher in der Fassung von 2017 mit Regeln für die über 400 inländischen börsennotierten Unternehmen, hat in Literatur und Praxis breite Aufmerksamkeit gefunden. ${ }^{1} \mathrm{Ob}$ schon selbst kein Recht und auch ohne unmittelbare Rechtswirkung, hat er vom Gesetzgeber mit dem in $\ 161 \mathrm{AktG}$ niedergelegten Grundsatz „comply or ex-

1 Statt aller Kremer/Bachmann/Lutter/v. Werder, Hrsg., Deutscher Corporate Governance Kodex, Kommentar, 7. Aufl., 2018 (zit. Autor, in: Kodexkomm.). Derzeit sind 439 deutsche Unternehmen im regulierten Markt der Frankfurter Wertpapierbörse gelistet (https://www.boerse-frankfurt.de/equities/search, letzter Zugriff: 16.8.2019). 
plain “2 einen Anreiz zur Befolgung und eine Legitimationsgrundlage erhalten, ${ }^{3}$ die durch die Rechtsprechung zur Anfechtbarkeit von Entlastungsbeschlüssen der Hauptversammlung entgegen mancher Kritik ${ }^{4}$ weiter akzentuiert worden sind. In der Praxis werden die Empfehlungen mit Unterschieden im Einzelnen weithin befolgt. ${ }^{5}$ Die Reformdiskussion zum DCGK $2017^{6}$ hat im Wesentlichen beanstandet, der DCGK sei durch Gesetzeswiedergabe überfrachtet, hinsichtlich Mitbestimmung, Konzernrecht und einzelnen Gesellschaftsformen lückenhaft und zur Unabhängigkeit von Aufsichtsratsmitgliedern und zur Vergütung von Vorstandsmitgliedern überholungsbedürftig. Diskussionen gab es ferner zum ehrbaren Kaufmann, zum Investorendialog, zur Rolle der Hauptversammlung bei Übernahmeangeboten sowie zur Fremdevaluation. Auch sei der DCGK zu häufig geändert worden.

2 Umfassend Leyens, Großkomm. z. AktG, 5. Aufl., 2018, \$161, zu den zivilrechtlichen Wirkungen DERs., AcP 215 (2015), 611, 631 ff. Zum comply or explain Europäische Kommission, Empfehlung vom 9.4.2014, ABlEU L 109/43. Rechtsvergleichung bei ECODA/ Mazars, Corporate Governance Compliance and Monitoring Systems across the EU, 2015; im Europäischen Privatrecht LeYENs, ZEuP 2016, 388.

3 Die verschiedentlich geäußerten Zweifel an der Verfassungsmäßigkeit, Nachweise bei KocH, in: Hüffer/Koch, Komm. z. AktG, 13. Aufl., 2018, \$161 Rdn. 4, sind unbegründet, Bachmann, in: Kodexkomm., aaO (Fn. 1), Rdn. 82 ff; Hopt, FS Hoffmann-Becking, 2013, S. 563, 569ff m.w.N.); Wegmann, FS Schmidt-Preuß, 2018, S. 477, 520: verfassungsrechtlich sicherer Boden. Dahingestellt bei FleIsCHER, in: Spindler/Stilz, Komm. z. AktG, 4. Aufl., 2019, \$ 93 Rdn. 46.

4 St. Rspr. seit BGHZ 180, 9 Tz 18 (Kirch/Deutsche Bank) und BGHZ 182, 272 Tz. 16 (Umschreibungstopp); zuletzt einschränkend zur Aufsichtsratswahl BGH 9.10.2018 NZG 2019, 262 (Mologen) m. krit. Anm. u.a. Bayer, JZ 2019, 677; Habersack, NJW 2019, 669; Scholz, ZIP 2019, 407; E. VetTer, NZG 2019, 379. Nachweise zur kontroversen Diskussion bei LeYens, aaO (Fn. 2), $\ 161$ AktG Rdn. 468 ff. Kritik bei HaberSACK, Gutachten E, 69. DJT 2012, Bd. 1, S. E66f und These 10, allerdings auch für Anfechtbarkeit von Wahlbeschlüssen, wenngleich unter Hinweis auf Reformbedürftigkeit des Beschlussmängelrechts. Für Ausschluss der Anfechtbarkeit (nur) von Wahlbeschlüssen Leyens, Referat, in: ebd., Bd. II/1, S. N21 ff, N24 und Thesen 10f, diese angenommen in Beschlüssen 10 a), 10 b), S. N88.

5 Zahlen für 2017 bei v Werder/Danilow, DB 2018, 1997. Das gilt sicher, was die formale Akzeptanz angeht formell, aber nicht unbedingt auch für eine effektive, „gelebte“ Akzeptanz, v. WeRDER, FS Baums 2017, S. 1395, 1401, zur Überprüfung ist Deutschland im Vergleich zu anderen Mitgliedstaaten ausgesprochen liberal, ebenda S. $1402 \mathrm{ff}$. Aber für die Aufsichtsräte hat die konkrete Ausgestaltung der Vorstandsvergütung durch den DCGK den stärksten Gestaltungseinfluss, Arbeitskreis Deutscher Aufsichtsrat E. V./HengelerMueller, Aufsichtsratsstudie 2019 Vergütung im Mittelpunkt, September 2019, B.3.

6 Zur Reformdiskussion vor dem DCGK-E 2018 Bachmann, aaO (Fn. 3), Rdn. 85 ff. Mit Fällen aus der Praxis Strenger, FS Seibert, 2019, S. 903. 


\section{Der DCGK-E 2018: Einwände und Gegenvorschläge}

Anders als der DCGK 2017 ist der DCGK-E 2018 vom 6.11.2018 unter der Ägide des neuen Kommissionsvorsitzenden Nonnenmacher in einem Konsultationsverfahren mit mehr als 120 Stellungnahmen auf geballte Kritik gestoßen. ${ }^{7}$ Diese gipfelten in der Forderung, den DCGK ganz abzuschaffen, ${ }^{8}$ ein aus internationaler Sicht ${ }^{9}$ nicht nachvollziehbarer Vorschlag, dem das Bundesjustizministerium zu Recht eine klare Absage erteilt hat. Die Zusammensetzung der DCGK-Kommission wurde als nicht demokratisch legitimiert und nicht repräsentativ kritisiert. ${ }^{10}$ Inhaltliche Kritik richtete sich vor allem gegen den Grundsatz „apply and explain“, die starren, der praktischen Vielfalt nicht gerecht werdenden Vergütungsempfehlungen, ${ }^{11}$ die Regeln zur Bestell- bzw. Amtsdauer für Vorstände und Aufsichtsräte, und die deutlich verschärfte Unabhängigkeit für Aufsichtsräte. Die DCGK-Kommission hat deshalb am 9.5.2019 einen neuen Entwurf (DCGK-E 2019) vorgelegt, der einigen Kritikpunkten Rechnung getragen hat - vor allem Streichung des zunächst vorgeschlagenen „apply and explain“, Überarbeitung der Empfehlungen zur Vorstandsvergütung und Rücknahme der Beschränkung der Bestelldauer für Aufsichtsratsmitglieder auf nicht länger als drei Jahre.

\section{Der DCGK-E 2019: Wesentliche Änderungen gegenüber dem DCGK 2017}

\section{a) Änderungen in der Sache}

Der DCGK 2019 enthält gegenüber dem DCGK 2017 erhebliche Änderungen. ${ }^{12}$ In der Sache ganz neu ist die Gestaltung der Regelung zur Vorstandsver-

7 Stellungnahmen abrufbar auf der Homepage der DCGK-Kommission www.dcgk.de (letzter Zugriff: 9.8.2019); Übersicht bei FоскEnвROск, Handelsblatt 20.2.2019, Nr. 36, S. $14 \mathrm{f}$.

8 Vgl. aus der Praxis mit markigen, an die Zeit des rheinischen Kapitalismus erinnernden Sprüchen z. B. Kley, Audit Committee Quarterly IV/2018, 30; mit Eingaben an die Bundesjustizministerin Vereinigung der Aufsichtsräte in Deutschland (VARD), März 2019. Rechtspolitisch aus der Wirtschaftswissenschaft z.B. Theisen, Kodex am Ende, Handelsblatt, 18.3.2019, Nr. 54 S. 29.

9 Deutschland würde sich damit international völlig isolieren, unten II. 2. Auch LutTer, Audit Committee Quarterly IV/2018, 33: nicht ernsthaft diskutabel; SIMON, Handelsblatt 25.4.2109, Nr. 80, S. 48.

10 International finden sich ganz unterschiedliche Gremien als Verfasser der Corporate Governance Kodizes, dazu rechtsvergleichend BECKER/v. WERDER, AG 2016, 761, 764.

11 Bericht bei Kramarsch/Siepmann/Dörrwächter, Der Aufsichtsrat 2019, 66.

12 Tabellarische Übersicht in Audit Committee Institute e.V., DCGK - Folgen für Aufsichtsräte. Zum DCGK-E 2019 u.a. v. WERDER, DB 2019, 1721; RUBNER/FISCHER, NZG 2019, 961 (Unabhängigkeit des Aufsichtsrats). 
gütung. Erheblich verschärft sind die Regeln über die Unabhängigkeit von Aufsichtsratsmitgliedern. Empfohlen werden striktere zeitliche Schranken für Vorstandsmandate. Neu ist auch die Aufnahme von allgemeinen Grundsätzen neben den Empfehlungen und Anregungen und als Grundlage für diese, allerdings nunmehr ohne "apply and explain“ wie noch im DCGK-E 2018. Es bleibt also bei der aktienrechtlichen Berichtspflicht allein zu den Empfehlungen. Diese werden noch auf das ARUG II $^{13}$ abgestimmt.

\section{b) Änderung in der Form}

Neu sind die der Präambel vorangestellten Allgemeinen Erläuterungen. Die wichtigsten formalen Erleichterungen sind die Vereinfachung der Berichterstattung durch Aufgehen des Corporate Governance Berichts in der Erklärung zur Unternehmensführung nach $\$ 289 \mathrm{f}$ HGB (im Folgenden: EzU) und der Verzicht auf die bisherigen, breiten, unpräzisen und teils sogar irreführenden Gesetzeswiederholungen. ${ }^{14}$ Die dadurch erreichte Verschlankung - nunmehr 64 Empfehlungen und Anregungen ${ }^{15}$ - wird allerdings durch 25 neue Grundsätze und Vorgaben zur weiteren Erläuterung in der EzU ${ }^{16}$ wieder relativiert. Im Vergleich zu vielen ausländischen Corporate Governance Kodizes ist der DCGK 2019 aber zu Recht deutlich kürzer. ${ }^{17}$ Die weitgehende Neugliederung, mit den Aufgaben im Zentrum statt an den Organen bzw. Adressaten der Aufgaben orientiert, ist hingegen keine Verbesserung. ${ }^{18}$ Sie hat zur Folge, dass die Organe wenig adressatenfreundlich oder transparent an ganz verschiedenen Stellen des Kodex angesprochen werden. ${ }^{19}$ Das macht die Gliederung nicht leicht nachvollziehbar, erschwert die Lesbarkeit und dient nicht dem Ziel der Transparenz des Kodex..$^{20}$ Unvermeidlich sind auf Dauer weitere Änderun-

13 Das ARUG II ist am 14.11.2019 vom Bundestag verabschiedet worden, BT-Drucks. 19/ 15153, Vorabfassung vom 13.11.2019.

14 So schon die Forderung von Hopt, FS Hoffmann-Becking, 2013, S. 563, $578 \mathrm{f} \mathrm{m}$. w. N.

15 v. Werder, DB 2019, 1721, 1723 zählt 121 Einzelempfehlungen und 7 Anregungen. Die Zahl der Anregungen hat gegenüber dem DCGK 2017 weiter abgenommen. Ganz verzichten sollte die Kommission auf Anregungen jedoch nicht, sie ermöglichen ein flexibleres Herantasten der DCGK-Kommission an neue Entwicklungen und künftige Standards, anders v. WERDER, DB 2019, 1721, 1723; DERS., FS Hommelhoff, 2012, S. 1299, $1316 \mathrm{ff}$.

16 Aufzählung bei v. Werder, DB 2019, 1721, 1724.

17 v. Werder, DB 2019, 41, 42; auch, aber mit Vorsicht, Becker/v. Werder, AG 2016, 761, 766.

18 Dezidiert z.B. Strenger, FS Seibert, S. 903, 917.

19 Vgl. die Kritik von VGR, Stellungnahme zum DCGK-E 2018, I 2, der nur zum Teil Rechnung getragen ist.

20 So wird die Unabhängigkeit der Aufsichtsratsmitglieder im DCGK-E 2019 unter C II behandelt, dann folgen unter D. die Arbeitsweise und dann unter E. Interessenkonflikte von Vorstand und Aufsichtsrat. Die Vergütung von Vorstand und Aufsichtsrat folgt un- 
gen, aber nicht mehr so häufig wie bisher. ${ }^{21}$ Der endgültige DCGK 2020 wird sich bis auf Anpassungen an das ARUG II (wesentliche Änderung in $\$ \int 87$ a Abs. 1 Nr. 1, 87 Abs. 4 AktG: Festlegung einer Maximalvergütung der Vorstandsmitglieder durch den Aufsichtsrat, Herabsetzungsmöglichkeit durch die Hauptversammlung) gegenüber dem DCGK-E 2019, wie zu hören, nicht mehr ändern und soll ab 2020 gelten. Deshalb wird im Folgenden vom DCGK 2020 gesprochen..

\section{Der DCGK 2020 und "good corporate governance"}

\section{Definition der Corporate Governance, Zielsetzung und Adressaten (DCGK Teil 1 und Teil 2 Präambel)}

\section{a) Definition der Corporate Governance}

Corporate Governance ist nach der Definition des DCGK 2020 “der rechtliche und faktische Ordnungsrahmen für die Leitung und Überwachung eines Unternehmens".22 Dies entspricht im Wesentlichen der Definition der Cadbury Commission („the system by which companies are directed and controlled“) $)^{23}$

ter $\mathrm{G}$ erst nach F. Transparenz und externe Berichterstattung, obschon gerade hinsichtlich der Vergütung Transparenz und Berichterstattung zentral sind (vgl. Grundsatz 23 Abs. 1, Grundsatz 25 zum Vergütungsbericht). Die Ausschüsse sind an verschiedener Stelle, zum Teil nur implizit (Vergütungsausschuss) geregelt. Der Begriff der Kontrolle ist nicht ausdrücklich geklärt.

21 Ursprünglich war sogar einmal die Rede von einem Zeitraum von fünf Jahren. Vgl. DCGK 2017 Präambel Abs. 15: „in der Regel einmal jährlich vor dem Hintergrund nationaler und internationaler Entwicklungen überprüft und bei Bedarf angepasst.“ Der DCGK ist seit den 16 Jahren seines Inkrafttretens zwölfmal geändert worden, NoNNENMACHER, Der Aufsichtsrat 1/2019, 11.

22 DCGK Teil 2 Präambel Abs. 1. Eine Definition ist durchaus sinnvoll, zumal Corporate Governance im Rahmen des Aktiengesetzes und seiner Kommentierungen bisher eher zögerlich aufgenommen worden ist, aber jetzt Норт/Rотн, Der Aufsichtsrat und Corporate Governance, Sonderausgabe aus dem Großkomm. z. AktG, $\int \mathbb{S} 95$ bis 116 AktG, Berlin 2019; auch DiEs., $\int 93$ AktG, 2015. Auch z.B. Kort, Großkomm. z. AktG, 5. Aufl., 2015, Vor $\$ 76$ Rdn. 35 ff; Koch, aaO (Fn. 3), \$76 AktG Rdn. 37-39 sowie zum Aufsichtsrat und zu $\$ 161$, auch Sachverzeichnis unter Corporate Governance; SPINDLER, Münchener Komm. z. AktG, 5. Aufl., 2019, Vor $\$ 76$ Rdn. 69 ff. Aus ökonomischer Sicht Gilson, From Corporate Law to Corporate Governance, in: Gordon/Ringe, eds., The Oxford Handbook of Corporate Law and Governance, 2018, p. 3, auch schon als ECGI Law Research Paper No. 324/2016.

23 Report of the Committee on the Financial Aspects of Corporate Governance (Sir Adrian Cadbury), Dezember 1992, Abschn. 2.5. Übernommen durch die Europäische Kommission Grünbuch Europäischer Corporate Governance-Rahmen, 5.4.2011, KOM (2011) 164 endg., S. 2. 
die heute international anerkannt ist, ${ }^{24}$ und bezieht zutreffend ein, dass es neben der internen eine externe Ebene der Corporate Governance gibt, also Einwirkungen auf die Unternehmensführung und -überwachung von außen. ${ }^{25}$ Die Präambel selbst gehört zum Kodextext und nimmt insoweit an der Natur desselben Teil. Wie bei Präambeln zu Rechtsakten, insbesondere europäischen, enthält sie wichtige Hinweise zu Ziel und Adressaten des eigentlichen Textes und kann zur Auslegung desselben, also der Empfehlungen und Anregungen, ${ }^{26}$ herangezogen werden. ${ }^{27}$ Die Allgemeinen Erläuterungen und die einzelnen $\mathrm{Be}-$ gründungen ${ }^{28}$ stellen dagegen keinen Kodextext dar. ${ }^{29}$ Anders als teilweise im Ausland hat die Kodexkommission auch keine Kompetenz, ihre Meinung dazu unmittelbar oder mittelbar durchzusetzen. Im Vergleich zur Guidance zum UK Corporate Governance Code $2018^{30}$ sind die Begründungen begrüßenswert schlank. ${ }^{31}$

\section{b) Zielsetzung des DCGK}

Der Kodex „will das Vertrauen der Anleger, der Kunden, der Belegschaft und der Öffentlichkeit in die Leitung und Überwachung deutscher börsennotierter Gesellschaften fördern“. ${ }^{32}$ Das ist als Oberziel zu begrüßen, auch wenn die Reihen-

24 Hорт, ZHR 175 (2011), 444, 448f.

25 Näher Норт, ZHR 175 (2011), 444, 450 und unten III. 1. c) a. E. Wohl enger Koch, aaO (Fn. 3), \$ 76 AktG Rdn. 37: „Führungsgrundsätze, die sich an die Gesellschaft wenden“. Zur Einberufung der Hauptversammlung bei Übernahmeangeboten als Wirkmechanismus der externen Corporate Governance ebenfalls unten III. 1. c).

26 Die von der Kommission formulierten Grundsätze sollen die Gesetzeslage kurz darstellen, Unschärfen sind dabei bewusst in Kauf genommen. Selbstverständlich sind diese Formulierungen unverbindlich, die Kommission will und kann nichts am Gesetz ändern. Aber die Formulierungen erlauben Rückschlüsse darauf, wie die Kommission das Gesetz versteht.

27 Leyens, aaO (Fn. 2), $\mathbb{1} 161$ AktG Rdn. 109. Zur Rechtsnatur und Bedeutung von Präambeln im europäischen Recht Krajewski/Rösslein, in: Grabitz/Hilf, Das Recht der Europäischen Union, 40. Aufl., 2009, Art. 253 EGV Rdn. 36f; Grundmann, Europäisches Gesellschaftsrecht, 2. Aufl., 2011, Rdn. 104.

28 Teil 1 und Teil 2 des DCGK 2020 mit Begründung.

29 Zutreffend Präambel DCGK 2020 mit Begründung Fn. 6.

30 Financial Reporting Council (FRC), The UK Corporate Governance Code 2018, dazu FRC, Guidance on Board Effectiveness, July 2018, 45 p.; dazu ausführlich Норт, FS Seibert, 2019, S. 389.

31 Auch VGR, aaO (Fn. 19), I1. Rechtsvergleichend Becker/v. Werder, AG 2016, 761, 766.

32 Präambel Abs. 3. Die Allgemeinen Erläuterungen fassen unter I. unscharf die „Zielsetzung der Überarbeitung des Kodex“ und darin die Zielsetzung des Kodex selbst unter I (1) und (2) zusammen. 
folge („Kunden“ vor „Belegschaft“) unter $\$ 76$ AktG wie teilweise im Ausland ${ }^{33}$ anders gesehen wird. ${ }^{34}$ Dieses Oberziel wird zweifach konkretisiert: es geht zum einen um Transparenz und Nachvollziehbarkeit und zum anderen um nationale und internationale Standards guter und verantwortungsvoller Unternehmensführung. ${ }^{35}$ Die zutreffendere Reihenfolge ist allerdings eher umgekehrt.

\section{aa) Gute Corporate Governance Standards}

Für einen Corporate Governance Kodex sind die Standards das Primäre, also was gute Corporate Governance ist. Der DCGK enthält laut seiner Präambel national und international anerkannte Standards. ${ }^{36}$ Die Standards werden wie bisher in Empfehlungen und Anregungen - nunmehr sehr begrüßenswert und benutzerfreundlich ausdrücklich als solche gekennzeichnet ${ }^{37}$ - niedergelegt, wobei bekanntlich nur für Empfehlungen („soll“) der Grundsatz comply or

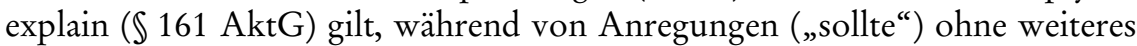
abgewichen werden kann. Die besonders wichtige, in den letzten Jahren auch von der Kodexkommission anerkannte „Abweichungskultur“ wird nur in der Sache angesprochen, ${ }^{38}$ die Verwendung des Begriffs selbst hätte als eine klarere Absage an das verbreitete bloße box ticking nahegelegen. ${ }^{39}$ Die „Grundsätze“ sollen wesentliche rechtliche Vorgaben verantwortungsvoller Unternehmens-

33 Sec. 172 (1) (a) und (b) UK Companies Act 2006; anders aber Business Roundtable (USA), Statement on the Purpose of a Corporation, 2019, kurze Berichte dazu auch in Handelsblatt 21.8.2019 Nr. 160, S. 14/15 und FAZ 21.8.2019 Nr. 193, S. 15.

$34 \mathrm{Koch}, \mathrm{aaO}$ (Fn. 3), $\$ 76$ AktG Rdn. 28: Aktionäre (Kapital), Arbeitnehmer (Arbeit) und Öffentlichkeit (Gemeinwohl). Die Reihenfolge „Aktionäre, Belegschaft und sonstige Stakeholder" findet sich auch in der Präambel Abs. 1 Satz 3. Wieder andere Formulierung in Grundsatz 21 „Anteilseigner und Dritte“.

35 Präambel Abs. 3 Satz 1 und 2. Ebenso Allgemeine Erläuterungen I (1) und (2). Die richtige Reihenfolge wäre umgekehrt: erst die Vorgaben dann die Information, so auch in der Sache Präambel Abs. 1, 2 und 3 Satz 2. Der Kodex spricht bald von „guter und verantwortungsvoller Unternehmensführung “ (Präambel Abs. 3 Satz 2) dann wieder nur von „verantwortungsvoller Unternehmensführung“ (Präambel Abs. 4 Satz 1), ohne dass klar wird, ob das dasselbe sein soll oder ob zwischen „gut“ (objektiv) und „verantwortungsvoll“ (Pflichtenmaßstab) unterschieden werden soll.

36 Nicht näher angesprochen ist, woher die Erkenntnis der beiden Standards kommt, auch wenn bekannt ist, dass die Kodexkommission sich im In- und Ausland breit informiert hat und ein gewisser Einfluss des UK Corporate Governance Code 2018 (Fn. 30) nicht zu verkennen ist. Offen bleibt auch, wie sich beide Arten zueinander verhalten, ob nur die Standards aufgenommen sind, die sowohl national als auch international anerkannt sind, also ein deckungsgleiches Minimum, oder welche bei Divergenzen vorgehen sollen.

37 Leyens, aaO (Fn. 2), $\mathbb{1} 161$ AktG Rdn. 95.

38 Präambel Abs. 4 Satz 5.

39 VGR, aaO (Fn. 19), I 3 Unterpunkt 4. Auch UK Code of Corporate Governance 2018, $\mathrm{aaO}$ (Fn. 30), p. 2 gegen boilerplate reporting und "tick-box approach". 
führung wiedergeben und dienen der Information, insbesondere gilt für sie anders als noch im DCGK-E 2018 nicht mehr das „apply and explain“.40

Der Kodex soll dazu beitragen, dass Vorstand und Aufsichtsrat die Gesellschaft im Unternehmensinteresse führen. ${ }^{41}$ Das Unternehmensinteresse wird als Sorge für den Bestand des Unternehmens und seine nachhaltige Wertschöpfung definiert, und zwar im Einklang mit den Prinzipien der sozialen Marktwirtschaft und unter Berücksichtigung der Belange der Aktionäre, der Belegschaft und sonstigen dem Unternehmen verbundenen Gruppen (stakeholder). ${ }^{42}$ Der DCGK 2020 übernimmt aus dem DCGK 2017 die Aussage: „Diese Prinzipien verlangen nicht nur Legalität, sondern auch ethisch fundiertes, eigenverantwortliches Verhalten (Leitbild des Ehrbaren Kaufmanns). ${ }^{43}$ Die Aufnahme dieses Leitbilds in den DCGK 2017 war bekanntlich kontrovers. Die ausdrückliche Unterscheidung zwischen Legalität und Legitimität und die Erinnerung der Unternehmensorgane an diese ist aber zumal in Zeiten der rücksichtslosen Ausnutzung des Gesetzestextes wie bei cum/cum und cum/ex richtig und wichtig, ${ }^{44}$ auch wenn speziell die Berufung auf das historische Leitbild eines Ehrbaren Kaufmanns nicht notwendig gewesen wäre. ${ }^{45}$

Was die Ergänzungen dazu in der Präambel Abs. 2 zusätzlich beitragen, wird nicht ganz klar. ${ }^{46}$ Die gesellschaftliche Verantwortung des Unternehmens und seiner Organe (dann nicht nur Vorstand und Aufsichtsrat, sondern auch die

40 Präambel Abs. 4 Satz 1. Zu den Grundsätzen unten II. 4.

41 Präambel Abs. 1 Satz 2.

42 Präambel Abs. 1 Satz 3, anders als zur Zielsetzung ist die Öffentlichkeit bzw. das Gemeinwohl hier unscharf nicht ausdrücklich angesprochen. Der Begriff stakeholder wird hier wie meist als Gegensatz zu shareholder benutzt, demgegenüber in der Theorie oft als beide umfassender Oberbegriff. DCGK 2020 Präambel Abs. 1 Satz 5 wie DCGK 2017 Präambel Abs. 2 Satz 2.

$44 \mathrm{Vgl}$. Wertekommission/TUM School of Management der Technischen Universität München, Führungskräftebefragung 2019, dort u. a. S. 22: Die Ergebnisse legen nahe, dass in vielen Unternehmen unethisches Verhalten bis zu einem gewissen Grad toleriert wird; S. 30: „neigt ein Viertel der Führungskräfte dazu, in bestimmten Situationen moralische Ansichten zurückzustellen und ethisch fragwürdig zu agieren“. Änliche Befunde für den Finanzbereich bei Cohn/Fehr/Maréchal, Business culture and dishonesty in the banking industry, Nature, vol. 516, 4 December 2014, p. 86. De lege lata zuletzt J. VeTTER, ZGR 2018, 338; HaRbarTh, ZGR 2018, 379.

45 Kritisch z.B. Fleischer, DB 2017, 2015; auch VGR, 12.12.2016, zu den Änderungen für 2017 Präambel Abs. 2; das Leitbild galt unter ganz anderen wirtschaftlichen und sozialen Voraussetzungen und Durchsetzungsmechanismen. Aber z.B. Mengers (Vorsitzender der Versammlung Eines Ehrbaren Kaufmanns zu Hamburg, VEEK) und E. Schweitzer (2013 Präsident der DIHK), IDW Life 1/2018, S. 4 und S. 7; auch Hüther, Ordnungspolitischer Einspruch, Moral als Unternehmenswert, Handelsblatt 30./31.5./ 1.6.2008 Nr. 103, S. 8. Weitergehend für Codes of Conduct/Ethics CalPERS, Governance \& Sustainability Principles, June 18, 2018, p. 31 et seq., zu CalPERS siehe Fn. 98.

46 So auch VGR, aaO (Fn. 19) unter II. 
Hauptversammlung) folgt eigentlich schon aus dem zum Unternehmensziel gehörenden Gemeinwohl. Jedoch ist die Betonung von Einzelaspekten der gesellschaftlichen Verantwortung des Unternehmens im Zuge der von Politik, aber auch institutionellen Investoren getriebenen ESG-Bewegung zunehmend üblich und entspricht mittlerweile auch bereits dem in Deutschland geltenden Recht. Überraschend und nicht nachvollziehbar ist jedenfalls die Hervorhebung nur der Sozial- und Umweltfaktoren ohne Erwähnung des gerade bei börsennotierten Gesellschaften maßgeblichen Kapitalmarkts und damit der Wirtschaft. ${ }^{47}$ Auch der Hinweis, dass die potentiellen Auswirkungen (allein?) dieser Faktoren ,auf die Unternehmensstrategie und operative Entscheidungen" erkannt und adressiert werden, versteht sich eigentlich von selbst, zumal

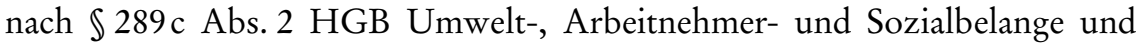
Weiteres in der nichtfinanziellen Erklärung der Kapitalgesellschaft zu beschreiben sind.

\section{bb) Transparenz und Nachvollziehbarkeit}

Zur Zielsetzung des Kodex gehören wie erwähnt auch Transparenz und Nachvollziehbarkeit der Standards. Laut Präambel Abs. 3 Satz 1 soll „das duale deutsche Corporate Governance System transparent und nachvollziehbar" gemacht werden. Die Allgemeinen Erläuterungen ${ }^{48}$ präzisieren dazu: den internationalen Anlegern das deutsche zweistufige System $^{49}$ sowie die Mitbestimmung im Aufsichtsrat verständlich machen. Ob internationale Anleger ihre Anlageentscheidung erst nach Einsicht in den deutschen Kodex treffen, ist natürlich mehr als fraglich. Aber gerade wenn der Kodex sich dies als Vorgabe nimmt, greift er gemessen an den selbstgesetzten Zielen und den internationalen Erwartungen zu kurz. Denn er lässt das einstufige System, das bei der Europäischen Aktiengesellschaft (SE) optional zur Verfügung steht, ganz außen vor und spricht die unternehmerische Mitbestimmung im Aufsichtsrat - anders als noch im DCGK 2017 - nur knapp in Grundsatz 10 an, ohne die eigentliche deutsche Besonderheit der quasiparitätischen Mitbestimmung in großen deutschen Unternehmen zu erläutern. Das ist vor allem deshalb misslich und für internationale Investoren kaum nachzuvollziehen, weil Teil C II mit der „Unabhängigkeit der Aufsichtsratsmitglieder" betitelt ist, dann aber die Empfehlung C.6 diese, auch in der Sache nicht überzeugend, auf die Anteilseignerseite beschränkt. Die Begründung zu diesem Teil der Empfehlung besagt lediglich, dass die Arbeitnehmervertreter nicht vom Aufsichtsrat vor-

47 Dagegen zutreffend gleich zu Anfang: „focus on financial markets“, CalPERS, aaO (Fn. 45), p. 3. Auch OECD Corporate Governance Factbook 2019, 49 jurisdictions covered, p. 14: promotion of transparent and well-functioning markets.

48 Allgemeine Erläuterungen unter I. (1).

49 Zur internationalen Konvergenz des ein- und des zweistufigen Systems zuletzt HopT, ZGR 2019, 507, $515 \mathrm{ff}$ m.w. N. 
zuschlagen sind, ohne auf die kontroverse Einschätzung ihrer Unabhängigkeit einzugehen. ${ }^{50}$

\section{c) Adressaten des DCGK}

Der Kodex richtet sich nur an börsennotierte Gesellschaften und Gesellschaften mit Kapitalmarktzugang i.S.v. $\$ 161$ Abs. 1 AktG. ${ }^{51}$ Dass damit allein deutsche Gesellschaften gemeint sind, ergibt sich wenig transparent nur aus der Zielsetzung des Kodex in der Präambel Abs. 3 Satz 2 und 3. Diese Ausklammerung ausländischer, in Deutschland notierter Gesellschaften ${ }^{52}$ führt jedoch zu einer kapitalmarktrechtlichen Ungleichbehandlung. Allerdings ist auch etwa nach dem schweizerischen Kodex ${ }^{53}$ Anknüpfungspunkt nicht der Ort der Börsennotierung, sondern das Gesellschaftsstatut, also der Sitzort. ${ }^{54}$ Internationalprivatrechtlich ist das aber, schon weil der Kodex keine Rechtsnorm ist, jedenfalls nicht vorgegeben. Der neue UK Corporate Governance Code 2018 ist demgegenüber insgesamt überzeugender auf alle Gesellschaften mit premium listing anwendbar, einerlei ob mit Sitz im Vereinigten Königreich oder außerhalb. ${ }^{55}$ Auch in Österreich sind an der Wiener Börse notierte EU- und EWR-Gesellschaften zur Anerkennung des Kodex aufgerufen. ${ }^{56}$ Für ausländische börsennotierte Gesellschaften hätte ihre Einbeziehung in den Kodex zur Folge, dass sie wegen der für sie und ihre Organe geltenden ausländischen Aktienrechte deutlich mehr an Abweichungen erklären müssten. Für die Anleger am Ort der Börsennotierung hätte das aber klare Informationsvorteile. Soweit der Kodex Erklärungen erst in der EzU empfiehlt, gehen diese für ausländische Gesellschaften, soweit sie dem deutschen Recht nicht unterfallen, insoweit ins Leere. ${ }^{57}$ Der DCGK unterscheidet auch nicht nach der Rechtsform der börsennotierten Ge-

50 Näher unten III. 2. b) bb).

51 Präambel Abs. 7 Satz 1. Auch unter $\ 161 \mathrm{AktG}$ ist anerkannt, dass nur deutsche Gesellschaften erklärungspflichtig sind, LEYENS, aaO (Fn. 2), $\$ 161$ AktG Rdn. 126 mit dem Hinweis, dass die Beschränkung auf deutsche Gesellschaften nicht zum kapitalmarktrechtlichen Kontext der Erklärungspflicht passt, aber mit dem aktienrechtlichen Schwerpunkt der DCGK-Empfehlung harmoniert.

52 Z.B. Unicredit S.p.A. Zweifelnd auch SÜnner, AG 2012, 265.

53 economieisuisse, Swiss Code of Best Practice for Corporate Governance, 2016, S. 6: schweizerische Publikumsgesellschaften.

54 Leyens, aaO (Fn. 2) , $\$ 161$ AktG Rdn. 126; v. Werder, in: Kodexkomm., aaO (Fn. 1), Präambel Rdn. 160.

55 UK Corporate Governance Code 2018, aaO (Fn. 30), Introduction, Application, p. 3.

56 Österreichischer Arbeitskreis für Corporate Governance, Österreichischer Corporate Governance Kodex, 2018, Präambel S. 12.

57 Da die EzU ihren Ursprung im Europarecht hat, kommen jedoch Erklärungspflichten nach dem Recht anderer Mitgliedstaaten in Betracht. 
sellschaft, gilt also ebenso wie $₫ 161 \mathrm{AktG}^{58}$ auch für die monistische Societas Europaea (SE) $)^{59}$ und nimmt die Besonderheiten der KGaA nicht in den Blick. ${ }^{60}$

In Präambel Abs. 7 Satz 2 ist nur noch die Rede davon, nicht kapitalmarktorientierten Gesellschaften „mögen die Empfehlungen und Anregungen des Kodex zur Orientierung dienen. "Der DCGK 2017 richtete sich zwar ebenfalls in erster Linie an börsennotierte Gesellschaften, sagte aber stärker: „Auch nicht kapitalmarktorientierten Gesellschaften wird die Beachtung des Kodex empfohlen." ${ }^{61}$ Diese Formulierung, eventuell klarstellend mit der Hinzufügung von „unter Beachtung ihrer Besonderheiten“, war besser. Die jetzige Formulierung nimmt sich zur Corporate Governance unnötig zurück.

Der DCGK 2020 weist in der Präambel richtigerweise darauf hin, dass für börsennotierte Kreditinstitute und Versicherungsunternehmen Besonderheiten nach dem jeweiligen Aufsichtsrecht gelten, die im Kodex nicht berücksichtigt sind. ${ }^{62}$ Nach $\ 161$ AktG waren Kreditinstitute und Versicherungen unter dem DCGK 2017 offenbar gehalten, in solchen Fällen Abweichungen zu erklären, ${ }^{63}$ was schon damals nicht einleuchtete. Nunmehr stellt die Präambel klar, dass die Empfehlungen des Kodex nur insoweit gelten, als keine gesetzlichen Bestimmungen entgegenstehen ${ }^{64}$ mit der Folge, dass es dann insoweit auch nicht zu einer Abweichung kommt, über die nach $\$ 161 \mathrm{AktG}$ berichtet

58 Leyens, aaO (Fn. 2), $\$ 161$ AktG Rdn. 128.

59 Demgegenüber vom Österreichischen Corporate Governance Kodex, aaO (Fn. 56), Präambel S. 11, ausdrücklich angesprochen, sinngemäße Geltung.

60 Moniert auch von VGR, aaO (Fn. 19), II; Johannsen-Roth/Kießling, FS Marsch-Barner, 2018, S. 273. Für die KGaA gilt $\$ 289 \mathrm{f}$ Abs. 1 und $2 \mathrm{HGB}$ zur EzU entsprechend, so $\$ 289 \mathrm{f}$ Abs. 3 HGB. Ausführlich Vollertsen, Corporate Governance der börsennotierten KGaA, 2019; zur Corporate Governance der Kapitalgesellschaft \& Co. KGaA HABersack, ZIP 2019, 1453. Glass Lewis, 2019 Guidelines Germany, aaO (Fn. 98), p. 10 et seq. hält die KGaA für die Corporate Governance wenig geeignet und trägt deshalb in der Regel Vorschläge, eine AG in eine KGaA umzuwandeln, nicht mit, berücksichtigt aber etwa bei den Anforderungen an die Unabhängigkeit die Besonderheiten der KGaA. Für Frankreich AFEP/MEDEF, Code de gouvernement d'entreprise des sociétés côtées, 2018, \24.1.3.

61 DCGK 2017 Präambel Abs. 13 Satz 2.

62 Präambel Abs. 8, auch schon DCGK 2017 Präambel Abs. XIV. Tatsächlich ist die Corporate Governance von Banken und Versicherungen eine andere als die von Unternehmen sonst, näher Hopt, ZGR 2017, 438 und statt vieler Busch/FerRarini/van Solinge, eds., Governance of Financial Institutions, Oxford 2019. Die Besonderheiten ergeben sich aus CRD IV, KWG und VAG u.a.

63 Leyens, aaO (Fn. 2), \161 AktG Rdn. 330 ff.

64 Empfehlung F.4 beschränkt sich auf die Angabe nicht anwendbarer Bestimmungen „auf Grund vorrangiger gesetzlicher Bestimmungen“. Indessen gründen sich auch alle regulatorischen Anforderungen der Bank-, Versicherungs- und ähnlichen Aufsichten auf das Gesetz, sodass auch diese miterfasst sind. 
werden müsste. ${ }^{65}$ Der Kodex empfiehlt aber in Empfehlung F.4, die Abweichungen in der EzU anzugeben, und adressiert dabei richtiger als nach dem Wortlaut der Präambel alle spezialgesetzlich regulierten Gesellschaften. Die Frage, ob neben dem DCGK etwa ein spezieller Bankenkodex wie in den Niederlanden sinnvoll wäre, jedenfalls aber dass es dazu eine kontroverse Diskussion gibt, hätte in der Begründung zu Präambel Abs. 8 angesprochen werden können. ${ }^{66}$

Der Kodex richtet sich an Vorstand und Aufsichtsrat. ${ }^{67}$ Über die Hauptversammlung berichtet zwar Grundsatz 8, die dazu ausgesprochenen Empfehlungen A.4 und A.5 richten sich jedoch an den Hauptversammlungsleiter und den Vorstand. ${ }^{68}$ Das leuchtet ein, wenn man Corporate Governance eng auf die Leitung und Überwachung beschränkt, ${ }^{69}$ aber der Kodex spricht in der Präambel Abs. 2 davon, dass die Gesellschaft „und ihre Organe“ sich ihrer gesellschaftlichen Verantwortung bewusst zu sein haben. Das betrifft nach Wortlaut und Sinn auch die Hauptversammlung. ${ }^{70}$ Rechtsvergleichend fällt auf, dass etwa der französische Kodex auch von Pflichten kontrollierender Mehrheitsaktionäre gegenüber seinen Mitaktionären spricht. ${ }^{71}$

Ausdrücklich klargestellt ist in Präambel Abs. 5, dass der Kodex nicht nur die Gesellschaft selbst, sondern auch ihre Konzernunternehmen betrifft, dies im Sinne von $\mathbb{1} 18$ Abs. $1 \mathrm{AktG}^{72}$. Der Kodex wählt dazu die Formulierung „Unternehmen“ statt „Gesellschaft“, was dann an mehreren Stellen der Fall ist. ${ }^{73}$

65 Dazu und zur Empfehlung F.4 näher Hopt, WM 2019, 1771.

66 Für einen zusätzlichen eigenen Bankenkodex mit dem Vorteil eines signaling für die einzelne Bank und die in die öffentliche Diskussion geratene Bankwirtschaft insgesamt Hopt, A Plea for a Bankers' Code of Conduct, in: Kenadjian/Dombret, eds., Getting the Culture and the Ethics Right, Towards a New Age of Responsibility in Banking and Finance, Berlin/Boston 2016, p. 75; auch kurz DERs., Audit Committee Quarterly III/ 2015, 20. Für einen Berufseid für Banker wie den hippokratischen Eid für Ärzte ähnlich wie in den Niederlanden Cohn/Fehr/Maréchal, aaO (Fn. 44), at 88.

67 Präambel Abs. 1 Satz 2.

68 Unten II. 1. c), III. 1. c).

69 Vgl. die Definition oben II. 1. a). Allerdings überwacht auch die Hauptversammlung.

70 Unter $\ 161$ AktG sind nur der Vorstand und der Aufsichtsrat erklärungspflichtig. Auch an die Hauptversammlung gerichtete Empfehlungen, etwa zu Vergütungsfragen, wären vorstellbar, sind aber durch $\$ 161 \mathrm{AktG}$ nicht erfasst und auch international unüblich.

71 AFEP/MEDEF, Code de gouvernement d'entreprise des sociétés côtées, 2018, \2.4. Zu den mit Kontrollaktionären zusammenhängenden Fragen erst unten bei der Unabhängigkeit, III. 2. b) ee). Zum Minderheitenschutz unten Fn. 183.

72 Ebenso v. Werder, in: Kodexkomm., aaO (Fn. 1), Präambel Rdn. 157, mit Beispielen von konzernbezogenen Regelungen des DCGK 2017. Vgl. Szabó/Sorensen, Corporate Governance Codes and Corporate Groups, ECFR 2018, 697.

73 Z.B. außer in der Präambel in Grundsatz 1 und 2 mit Empfehlung A.1, Grundsatz 5 mit Empfehlung A.2, Grundsatz 6, Grundsatz 13, Grundsatz 16 und Empfehlungen G.2 G.5 zur Vorstandsvergütung und Empfehlungen G.15 und G.16 zu konzerninternen 
Die jeweilige börsennotierte Konzerngesellschaft hat auch über Abweichungen von konzernbezogenen Empfehlungen zu berichten und dies zu begründen. Eine einzige, konzerneinheitliche Erklärung ist nicht vorgesehen,${ }^{74}$ unterschiedliche Erklärungen sind denkbar.

Die institutionellen Anleger ${ }^{75}$ werden im Kodex in der Präambel Abs. 6 Satz 2 besonders angesprochen, ${ }^{76}$ allerdings anders als etwa noch im niederländischen Kodex $2008^{77}$ rein feststellend und dabei auch ohne eine Trennung, wie sie die unterschiedlichen Geschäftsmodelle der passiv verwaltenden, aktiven und aktivistischen Investoren nahegelegt hätten. Bei der Aussage, von ihnen werde erwartet, dass sie ihr Eigentumsrecht aktiv und verantwortungsvoll auf der Grundlage von transparenten und die Nachhaltigkeit berücksichtigenden Grundsätzen ausüben, bleibt offen, ob das eine Erwartung der Kodexkommission ist oder eine Aussage über Kapitalmarkt und Öffentlichkeit oder eine solche über die geltende Gesetzeslage. ${ }^{78}$

Die Stimmrechtsberater und die kontroverse Frage eines eigenen Stewardship Code wie prototypisch im Vereinigten Königreich ${ }^{79}$ wird angesichts der Regelung der Stimmrechtsberater im ARUG II in $\$ 134 \mathrm{~d}$ AktG-E i.d.F. ARUG II nicht angesprochen, doch wäre das angesichts ihrer Bedeutung am Kapitalmarkt in der Präambel durchaus vorstellbar gewesen, zumal ein solcher Kodex auch im

und -externen Aufsichtsratsmandaten. Grundsatz 10 Satz 4 und Grundsatz 19 Satz 1 sprechen vom Unternehmensinteresse, Grundsatz 22 von der EzU. Grundsatz 21 mit Empfehlung F.2 erwähnt den Konzernabschluss und den Konzernlagebericht.

74 Vgl. aber Leyens, aaO (Fn. 2), $\mathbb{1} 161$ AktG Rdn. 136 m. w. N.

75 Die institutionellen Anleger, Stimmrechtsberater und Vermögensverwaltung werden im ARUG II geregelt, $\int \mathbb{S} 134 \mathrm{a}-134 \mathrm{~d}$ AktG.

76 Offen bleibt, ob damit institutionelle Anleger in einem weiteren Sinne einschließlich der Vermögensverwalter (Fonds) gemeint sind oder sich der Kodex damit der Definition des institutionellen Anlegers in $\$ 134$ a Abs. 1 Nr. 1 AktG-E i.d.F. ARUG II anschließt, die nur Versicherungsunternehmen umfasst, dort eigene Definitionen für Vermögensverwalter und Stimmrechtsberater. Zu den institutionellen Investoren und zum Agenturkapitalismus Leyens, ZGR 2019, 544, 554f; Rock, Institutional Investors in Corporate Governance, in: Gordon/Ringe, aaO (Fn. 22), p. 363 et seq.

77 Dutch Corporate Governance Code 2008, IV.4 Responsibility of institutional investors mit drei best practice provisions. Im Code 2016 nur noch in der Präambel: "Institutional investors are responsible to the ultimate beneficiary owners for the careful and transparent assessment of how to exercise their rights as shareholders of the company."

78 Nunmehr $\mathbb{1} 134 \mathrm{~d}$ AktG i.d.F. ARUG II zu Offenlegungspflichten der Stimmrechtsberater mit einer comply or explain-Verpflichtung im Hinblick auf einen „näher bezeichneten Verhaltenskodex“. Vgl. auch $\$ 134$ c AktG i.d.F. ARUG II zu Offenlegungspflichten von institutionellen Anlegern und Vermögensverwaltern.

79 UK Stewardship Code 2020. Zum Entwurf eines revidierten UK Stewardship Code 2019 Financial Reporting Consultation des Financial Reporting Council vom Januar/ März 2019 mit über 100 Stellungnahmen siehe frc.org.uk. 
ARUG II erwähnt wird. ${ }^{80}$ Angesichts der maßgeblichen Rolle der Intermediäre am Kapitalmarkt wird man sich künftig Gedanken machen müssen über das $\mathrm{Zu}$ sammenspiel von DCGK-Regeln für Vorstand und Aufsichtsrat und künftiger eigener Kodexregeln für verschiedene Intermediäre am Kapitalmarkt. ${ }^{81}$

\section{Die internationale Corporate Governance Code-Landschaft: Einigkeit in den Grundsätzen, Vielfalt im Detail}

Heutzutage haben außer den EU-Mitgliedstaaten nahezu alle Industrienationen neben ihrer aktien- und kapitalmarktrechtlichen Corporate Governance-Regulierung ${ }^{82}$ eigene Corporate Governance Kodices, so namentlich das Vereinigte Königreich, Frankreich, Niederlande, Belgien, Italien, Spanien, Portugal und auch die Schweiz. ${ }^{83}$ In den USA existieren mehrere Kodexwerke von unterschiedlich starkem Einfluss, ohne dass dort eine gesetzliche Erklärungspflicht vorgesehen wäre. Eine herausgehobene Rolle spielt der UK Corporate Governance Code, derzeit von Juli 2018. ${ }^{84}$ Von internationaler Bedeutung sind auch die G20/OECD Principles of Corporate Governance 2015, die allerdings viel

$80 \rrbracket 134$ d Abs. 1 AktG i.d.F. ARUG II. Gegen eine Stewardship Kodex in Deutschland z.B. Fleischer/Strothotte, AG 2011, 221. Vgl. auch Fleischer, ZGR 2010, 155, $164 \mathrm{ff}$ und AG 2012, 2. Zum von der ESMA veranlassten Verhaltenskodex aber ZeTZsCHe/PreINER, AG 2014, 685.

81 Zum Ganzen Leyens, Informationsintermediäre des Kapitalmarkts: Private Marktzugangskontrolle durch Abschlussprüfung, Bonitätsrating und Finanzanalyse, 2017. Der Kodex berichtet nur in Grundsatz 17 über die Rolle der Abschlussprüfer, die folgenden Empfehlungen D.9. - D.11 richten sich allein an den Aufsichtsrat bzw. den Prüfungsausschuss, unten III. 4. c). Ratingagenturen und Finanzanalysten sind überhaupt nicht angesprochen.

82 OECD Corporate Governance Factbook 2019, aaO (Fn. 47); Hорт, ZHR 175 (2011), 444 und IDEM, Comparative Corporate Governance: The State of the Art and International Regulation, The American Journal of Comparative Law 59 (2011) 1-73; FLECKNER/HOPT, eds., Comparative Corporate Governance, Cambridge 2013, mit 24 Länderberichten; Jung/STIEGLeR, in: Jung/Krebs/Stiegler, Hrsg., Gesellschaftsrecht in Europa, 2018, \33 Europäische Corporate Governance, mit Länderberichten zu USA, Großbritannien, Österreich, Frankreich, Italien und Niederlande und zu den Vorgaben der EU; Gelter, Comparative Corporate Governance: Old and New, in Choudbury/Petrin, eds., Understanding the Modern Company: Corporate Governance and Theory, Cambridge 2017, p. 57.

83 Vgl. die Sammlung bei ECGI von über 80 Kodizes; Autorité Des marchés Financiers, Comparative study: corporate governance codes in 10 European countries, 2016; auch Allen \& Overy, Corporate Governance, Comparative Study, 13.7.2017 für das Belgische Corporate Governance Committee. Übersicht bei Becker/v. Werder, AG 2016, 761. Auch Gerner-Beuerle, Diffusion of Regulatory Innovations: The Case of Corporate Governance Codes, Journal of Institutional Economics (JITE) 13 (2017) 271.

UK Corporate Governance Code 2018, aaO (Fn. 30). 
weiter ausholen und neben den Aktionären und dem Board auch institutionelle Investoren und andere Intermediäre sowie andere Stakeholder erfassen.$^{85}$ Während es im Detail eine große Vielfalt gibt, besteht Einigkeit in den allgemeinen Grundsätzen. ${ }^{86}$ Der UK Code enthält beispielsweise 18 Principles zu fünf Bereichen: 1. Board Leadership and Company Purpose, 2. Division of Responsibilities, 3. Composition, Succession and Evaluation, 4. Audit, Risk and Internal Control, 5. Remuneration. ${ }^{87}$ Die Rolle des Board ist "to promote the long-term sustainable success of the company, generating value for shareholders and contributing to wider society". Dabei sind sorgfältige und wirksame Kontrollen, die das Management der Risiken ermöglichen, und die Unternehmenskultur wichtig. ${ }^{88}$ Besondere Anforderung werden an den Vorsitzenden des Board gestellt, er sollte bei seiner Ernennung unabhängig sein, was sich an einem Negativ-Kriterienkatalog misst. ${ }^{89}$ Der Board soll eine angemessene Mischung von executive und non-executive (and in particular, independent non-executive) directors haben, und zwar sollten, abgesehen vom Vorsitzenden, wenigsten die Hälfte der Mitglieder des Board nach dessen Beurteilung unabhängig sein. ${ }^{90}$ Die Verantwortlichkeiten von Board und Exekutive sind klar zu trennen. Dem audit committee und dem remuneration committee sollten ausschließlich independent non-executive directors angehören, beidesmal ohne dass der chairman of the board Mitglied ist; der Vorsitzende des remuneration committee sollte schon 12 Monate einem solchen committee angehört haben; das nomination committee sollte mehrheitlich mit independent non-executive directors besetzt werden. ${ }^{91}$ Alle Direktoren sollten jährlich zur Wahl stehen..$^{92}$ In den FTSE 350-Gesellschaften sollte mindestens alle drei Jahre eine Evaluation unter Heranziehung eines external evaluator stattfinden. ${ }^{93}$ Drei Principles und 10 ausführliche Provisions regeln die Vergütung.

Auch Corporate Governance Kodizes aus anderen Ländern, beispielsweise Frankreich, Niederlande, Italien oder den USA, stellen besondere Anfor-

85 OECD (2015), G20/OECD Principles of Corporate Governance, Paris, abrufbar unter: www.oecd.org/corporate/principles-corporate-governance.htm (letzter Zugriff: 19.10.2019). Darin wird aber grundsätzlich nicht zwischen gesetzlichen Bestimmungen und solchen nur in Corporate Governance Kodizes unterschieden.

86 Dieser Abschnitt beschränkt sich auf einen allgemeinen Überblick, Detailvergleiche erfolgen weiter unten zu den konkreten Fragen.

87 Dazu im Einzelnen Hopt, FS Seibert, S. 395.

88 Principle B und C sowie Provisions 1 und 2 sowie Principles M, N und O; Financial Reporting Council, Guidance on Board Effectiveness, July 2018, Nos. 21-26.

89 Principle F mit Provisions 9 und 10.

90 Principle G mit Provisions 10 und 11.

91 Provision 24 für das audit committee, Provision 32 für das remuneration committee und Provision 17 für das nomination committee.

92 Provision 18.

93 Provision 21. 
derungen hinsichtlich der Professionalisierung (Aus- und Fortbildung, Erfahrung, Ressourcen, Ausschüsse und Evaluation, aber auch Zeitaufwand, Sitzungsteilnahme, Mehrfachmandate und Mandatslaufzeit) und vor allem auch an die Unabhängigkeit von Board- und Ausschussmitgliedern. ${ }^{94}$ Wichtig ist die Pflege der Unternehmenskultur, wozu die Beziehungen zu den Aktionären und anderen Stakeholdern und vielfach der Dialog mit den Investoren gehören. ${ }^{95}$

\section{Die Corporate Governance-Leitlinien der wichtigsten Stimmrechtsberater und institutionellen Investoren}

Der Kodex spricht die institutionellen Investoren nur in der Präambel kurz und die Stimmrechtsberater überhaupt nicht an. ${ }^{96}$ In der Kritik zum DCGKE 2018 ist verschiedentlich behauptet worden, der DCGK habe neben den Corporate Governance-Leitlinien der wichtigsten Stimmrechtsberater und institutionellen Investoren keine Funktion und auf Dauer auch keine Überlebenschance mehr. ${ }^{97}$ Das ist ein ernst zu nehmender Einwand. Denn die Stimmrechtsberater haben international und auch in Deutschland mittlerweile einen erheblichen Einfluss ${ }^{98}$ und sind nicht zuletzt deswegen im ARUG II ausdrücklich geregelt. ${ }^{99}$ Dasselbe gilt für die institutionellen Investoren, ${ }^{100}$ die bei ihren Abstimmungen auch unabhängig von den Stimmrechtsberatern ihre eigene Corporate Governance-Politik haben und verfolgen. ${ }^{101}$ Das bedeutet, dass der DCGK mit seinen Empfehlungen in der Tat in einer gewissen Kon-

94 Mit kodexvergleichenden Nachweisen Becker/v. Werder, AG 2016, 761. Detailangaben erfolgen auch hier erst weiter unten zu den konkreten Fragen.

95 Becker/v. Werder, AG 2016, 761, 772 ff. Dazu unten III. 1. b).

96 Näher oben II. 1. c).

97 U.a. Kley, aaO (Fn. 8), S. 31. Widersprüche bezüglich der Vorstandsvergütung sieht auch Dörrwächter, DB 2018, 2977, 2980. Vgl. auch v. Werder, DB 2019, 41, 42.

98 International Shareholder Services (ISS) und Glass Lewis geben mithilfe ihrer Leitlinien Stimmrechtsempfehlungen für über 40.000 bzw. 20.000 Hauptversammlungen, HeInen/Koch, Audit Committee Quarterly IV/2018, 8, 9. CalPERS (The California Public Employees' Retirement System) ist der größte amerikanische Pensionsfonds.

99 Oben II. 1. c) a.E.

100 Institutionelle Investoren stellen die überwiegende Mehrheit der Aktionäre im DAX, 2017 circa 60 \%, darunter deutsche mit circa 10 \% der Aktien; siehe Arbeitskreis Leitlinien für eine nachhaltige Vorstandsvergütung, Juli 2019, S. 5, dazu auch Fn. 102, auch LeYens, ZGR 2019, 544, $554 \mathrm{ff}$. Für die Aufsichtsräte ist bei der Vorstandsvergütung, abgesehen vom DCGK (dazu oben Fn. 5), die Akzeptanz durch die institutionellen Investoren besonders wichtig, gefolgt vom Betriebsrat; Arbeitskreis Deutscher AufSichtsrat E. V./HengelerMueller, aaO (Fn. 5), B.2.

101 Heinen, Die Rolle institutioneller Investoren und Stimmrechtsberater in der deutschen Corporate Governance, Diss. rer. pol., Mainz 2018. 
kurrenz zu diesen neueren Akteuren am Kapitalmarkt steht. ${ }^{102}$ Die DCGKKommission ist sich dieser Konkurrenzsituation natürlich sehr wohl bewusst, was in der Präambel jedenfalls kurz hätte angesprochen werden können. ${ }^{103}$

Die Stimmrechtsberater und institutionellen Investoren haben, wie schon angesichts des Wettbewerbs zwischen ihnen nicht anders zu erwarten, teilweise ganz unterschiedliche Strategien und Vorstellungen über die zu beachtende gute Corporate Governance, ${ }^{104}$ auch wenn sie länderspezifische Besonderheiten berücksichtigen. ${ }^{105}$ Das gilt bekanntlich schon bei der Zielsetzung der Gesellschaft, die der Vorstand verfolgen soll, shareholder value oder stakeholder value. ${ }^{106}$ Zur Unabhängigkeit von Direktoren verlangt ISS Unabhängigkeit auch von einem significant shareholder, während Glass Lewis dazu für den Aufsichtsrat und den Nominierungsausschuss etwas großzügiger ist. ${ }^{107}$ Andere wie Bundesverband Investment und Asset Management e.V. (BVI), DEKA, Allianz Global Investors und DWS Investment GmbH verwenden ebenfalls

102 Daneben gibt es auch spezielle „Leitlinien für eine nachhaltige Vorstandsvergütung“, die ein privater Arbeitskreis im Juli 2018 vorgestellt hat und die deutlich weniger weit gehen als der DCGK 2020. Aufgegriffen in Glass Lewis, 2019 Proxy Paper, Guidelines, An Overview of the Glass Lewis Approach to Proxy Advice, Germany, www.glasslewis.com, p. 1 et seq. 13 .

103 Aus Gesprächen mit Mitgliedern der DCGK-Kommission ist aber klar, dass sich diese der Konkurrenzsituation sehr wohl bewusst sind und dass bei der Neufassung auch durchaus daran gedacht wurde.

104 Leitlinien von Stimmrechtsberatern und ausgewählten Investoren mit Blick auf den Aufsichtsrat u.a., Audit Committee Quarterly IV/2018, 16-19 mit Tabellen zu ISS, Glass Lewis, IVOX Glass Lewis, Deka, Allianz Global Investors, DWS Investment $\mathrm{GmbH}$. Auch die Indexfonds (die drei größten sind BlackRock, Vanguard und State Street) nehmen auf die Corporate Governance der Unternehmen Einfluss KaHAN/ Rock, Index Funds and Corporate Governance: Let Shareholders be Shareholders, ECGI Law Working Paper No. 467/2019, August 2019. Das sieht auch die DCGKKommission; Nonnenmacher, WPg 2018, 709, 710.

105 ISS, Continental Europe Proxy Voting Guidelines, 6.12.2018, https://www.issgovernance.com, mit Berücksichtigung nationaler Besonderheiten, mehrfach auch solcher in Deutschland, zu ISS siehe auch Fn. 98; Glass Lewis, 2019 Guidelines Germany, aaO (Fn. 98). Unter den institutionellen Investoren z. B. CalPERS, aaO (Fn. 45), Governance \& Sustainability Principles, June 18, 2018. Zum Folgenden auch Langenbucher, Audit Quarterly IV/2018, 6.

106 Z.B. ISS, aaO (Fn. 105), p. 25, spricht zwar auch environmental and social issues an, aber: „the overall principle guiding all vote recommendations focuses on how the proposal may enhance or protect shareholder value in either the short-term or long-term". International Норт, ZHR 175 (2011), 444, 476ff. Demgegenüber CalPERS, aaO (Fn. 45), p. 3: „ESG in investing“. Zum Streit unter deutschem Recht KorT, aaO (Fn. 22), \ 76 AktG Rdn. 52 ff; КосH, aaO (Fn. 3), \ 76 AktG Rdn. 29 ff.

107 ISS, aaO (Fn. 105), p. 13; Glass Lewis, 2019 Guidelines Germany, aaO (Fn. 98), p. 6: "However, we generally accept the presence of representatives of significant shareholders in proportion to their equity or voting stake in the company." 
unterschiedliche Gründe für Nichtunabhängigkeit. ${ }^{108}$ Während $\ 100$ Abs. 2 Nr. 4 AktG für den Wechsel in den Aufsichtsrat eine zweijährige Karenzzeit (cooling-off) für Vorstandsmitglieder börsennotierter Gesellschaften vorsieht, stehen Glass Lewis ehemaligen Vorstandsmitgliedern und ISS jedenfalls ehemaligen Vorstandsvorsitzenden im Aufsichtsrat generell kritisch gegenüber. ${ }^{109}$ Allianz Global Investors (AGI) hält zahlenmäßig nur einen ehemaligen Vorstand für akzeptabel, DEKA und Deutsche Asset Management (DAM) dagegen zwei. Bei der Zahl der Aufsichtsratsmandate, die ein Aufsichtsratsmitglied wahrnimmt, werden teils fünf, teils sechs akzeptiert, ${ }^{110}$ wobei ein Aufsichtsratsvorsitz teils doppelt zählt, ${ }^{111}$ ein Vorstandsamt teils sogar dreifach ${ }^{112}$. Auch bei der Vergütung finden sich erhebliche Unterschiede. Die Aufsichtsratsvergütung (bzw. non-executive director compensation) darf nach ISS, Deka und AGI nur eine Fixvergütung sein. DAM sieht das zwar als Grundsatz an, akzeptiert aber Ausnahmen. Glass Lewis ist hier großzügiger und verlangt nur, dass die fixen Vergütungsanteile überwiegen.

Der DCGK hat im Verhältnis zu diesen Kapitalmarktakteuren den Vorteil des $\$ 161$ AktG. Die deutschen börsennotierten Gesellschaften wollen Abweichungsbegründungen möglichst vermeiden, wie aus der Praxis zu hören und wie die hohen Befolgungsquoten nahelegen. ${ }^{113}$ Andererseits zwingt die Präsenz der genannten Akteure in den Hauptversammlungen zur Berücksichtigung ihrer Leitlinien. In einer Mehrzahl von Punkten scheinen sich jedoch die Empfehlungen des DCGK 2020 und die Leitlinien der Stimmrechtsberater und institutionellen Investoren im Wesentlichen zu entsprechen. ${ }^{114}$ Dann mag man über die jeweilige Kausalität spekulieren. Aber für die Reputation und den allgemeinen Einfluss des DCGK ist das sekundär. In anderen Punkten geht der DCGK weniger weit, ${ }^{115,}{ }^{116}$ was nicht verwunderlich ist, weil der Einfluss ausländischer,

108 Tabelle in Audit Committee Quarterly IV/2018, 16.

109 Glass Lewis, 2019 Guidelines Germany, aaO (Fn. 98), p. 7; ISS, aaO (Fn. 105), p. 9; Tabelle Audit Committee Quarterly IV/2018, 16.

$110 \mathrm{Zu}$ den Unterschieden im Detail Tabelle Audit Committee Quarterly IV/2018, 16.

111 Z.B. Glass Lewis, 2019 Guidelines Germany, aaO (Fn. 98), p. 7.

112 ISS, aaO (Fn. 105), p.9/10.

113 Oben I. 1. Fn. 5.

114 So nehmen z. B. Glass Lewis, 2019 Guidelines Germany, aaO (Fn. 98), p. 2 et seq. laufend Bezug auf den DCGK, die summary changes for the 2019 Germany Policy Guidelines berücksichtigen aber noch nicht den DCGK-E 2019.

115 Glass Lewis, 2019 Guidelines Germany, aaO (Fn. 98), p. 1: “generally less prescriptive than in many other European countries, with a strong emphasis on corporate flexibility".

116 Wenn im Folgenden auf weitergehende internationale Leitlinien oder Empfehlungen hingewiesen wird, wird damit nicht jeweils impliziert, dass diese ohne weiteres eine bessere Corporate Governance darstellen und schon gar nicht, dass damit die Übernahme derselben in den DCGK befürwortet wird. 
insbesondere anglo-amerikanischer Akteure groß ist und dort oft andere Aktionärsstrukturen (dispersed ownership) und Kapitalmarktgegebenheiten vorherrschen. ${ }^{117}$ Dabei ist aber zu berücksichtigen, dass manche Stimmrechtsberater den Besonderheiten des deutschen Kapitalmarkts durch eigene Guidelines für Kontinentaleuropa, so etwa ISS, ${ }^{118}$ oder sogar spezieller Deutschland, so z.B. Glass Lewis, ${ }^{119}$ Rechnung tragen. Wenn danach die Unterschiede zu den international als "good corporate governance“ angesehenen Grundsätzen ${ }^{120}$ wesentliche Punkte betreffen, kann sich das negativ auf die Reputation des DCGK auswirken. Sollten Empfehlungen des DCGK in einzelnen Punkten weiter gehen als solche Guidelines, mag das Kritik bei den Betroffenen auslösen, doch bleibt stets die Möglichkeit der begründeten Nichtbefolgung.

\section{Die Grundsätze im DCGK 2020}

Eine wesentliche Neuerung im DCGK 2020 sind die Grundsätze, 25 an der Zahl. Der DCGK-E 2018 hatte noch in Empfehlung A.19 vorgesehen, dass Aufsichtsrat und Vorstand erläutern, auf welche Weise sie die Grundsätze des Kodex anwenden (apply and explain) und dies unter Hinweis auf internationale Vorbilder, insbesondere den UK Corporate Governance Code 2018, näher begründen. ${ }^{121}$ Unter dem Eindruck massiver Kritik in der Konsultation hat die Kommission diese Empfehlung jedoch fallen gelassen. Nunmehr heißt es in der Präambel Abs. 4 Satz 1 nur noch: „Die Grundsätze geben wesentliche rechtliche Vorgaben verantwortungsvoller Unternehmensführung wieder und dienen hier der Information der Anleger und weiterer Stakeholder."

Der Verzicht auf das apply and explain gemäß Empfehlung A.19 ist angesichts der schon jetzt weit reichenden Publizitätsanforderungen in der EzU nach $\$ 289 \mathrm{f} \mathrm{HGB}$, der tendenziellen Überregulierung durch Berichtspflichten und vor allem auch der Unklarheit, was mit der Empfehlung über die zwingend vorgeschriebene EzU hinaus bewirkt werden soll, ${ }^{122}$ sicher zu begrü-

117 Dazu z.B. CalPERS, aaO (Fn. 45).

118 Z.B. ISS, aaO (Fn. 105).

119 Z.B. Glass Lewis, 2019 Guidelines Germany, aaO (Fn. 98): diese sollen die Glass Lewis' Continental Europe Policy Guidelines ergänzen, ebenda einleitend p. 1. Im Vergleich dazu Glass Lewis, 2018 Proxy Paper, Guidelines, An Overview of the Glass Lewis Approach to Proxy Advice, United States.

120 Oben II. 1. a), 2.

121 DCGK-E 2018 C. Begründung II 1 S. 40f. Diese Erläuterung hätte auch die Anregungen betroffen.

122 Nach der Begründung zu Empfehlung A.19 des DCGK-E 2018 hätte sich diese Erläuterung „weitgehend“ mit den „relevanten Angaben zu Unternehmensführung“ bzw. der „Beschreibung der Arbeitsweise von Vorstand und Aufsichtsrat sowie der Zusam- 
ßen. ${ }^{123}$ Allerdings funktioniert das apply and explain im Vereinigten Königreich $^{124}$ offenbar problemlos, wird auch von den UK Listing Rules verlangt ${ }^{125}$ und ist offenbar auch in der Praxis akzeptiert. Das liegt sicher zum einen daran, dass dort nur eine einzige Erklärung verlangt wird. ${ }^{126}$ Ein weiterer Grund mag sein, dass die Berichterstattung vom Financial Reporting Council (FRC) und den Unternehmen insgesamt pragmatischer gehandhabt wird. Dabei hilft auch, dass anders als in Deutschland ein laufender Kontakt zwischen den Unternehmen und dem FRC stattfindet, in dem Unklarheiten besprochen werden können. Das steht in der Tradition von Takeover Code und Takeover Panel. ${ }^{127}$

Für die jetzigen 25 Grundsätze im DCGK 2020 wird ihre Funktion neben den Empfehlungen und Anregungen nicht völlig klar. Einerseits sollen sie nur der Information über ohnehin geltende rechtliche Vorgaben dienen, andererseits aber doch „Basis für die daraus abgeleiteten Empfehlungen und Anregungen “128 sein. Indessen sind schon die Grundsätze, wie sie von der DCGKKommission formuliert sind, keine verbindliche Konkretisierung der rechtlichen Vorgaben, dazu hätte die Kommission keine Kompetenz, noch kann sie aus der daraus vorgenommenen Ableitung eine verbindliche Konkretisierung der rechtlichen Vorgaben in Anspruch nehmen. Die Aufgabe des Kodex besteht vermittelt durch $\ 161$ AktG lediglich darin, einen einheitlichen Bezugspunkt für die Berichterstattung über best practice zu liefern und zu dieser Empfehlungen aufzustellen. Wenn dem so ist, mag man sogar die Notwendigkeit einer zusätzlichen Information durch Grundsätze, die nur die unverbindliche Lesart rechtlicher Vorgaben durch die DCGK-Kommission wiedergibt, ${ }^{129}$ bezweifeln.

mensetzung und Arbeitsweise ihrer Ausschüsse“ in der EzU gemäß $\ 289 \mathrm{f}$ Abs. 2 Nr. 2 und 3 HGB gedeckt.

$123 \mathrm{Zu}$ den gegen Empfehlung A.19 sprechenden Gründen ausführlich VGR, aaO (Fn. 19), I 4.

124 Der UK Corporate Governance Code 2018, aaO (Fn. 30) verzichtet auf die bisherige Trennung in Main Principles, Supporting Principles und Code Provisions, fokussiert aber auf die Anwendung der Principles und dem Reporting darüber. Introduction on Reporting on the Code, p. 2. Dazu Hopt, FS Seibert, 2019, S. 389, 391.

125 UK Listing Rule 9.8.6 (5), danach wird eine Befolgungs- bzw. begründete Nichtbefolgungserklärung aber nur für die Code Provisions gefordert, dazu LeYens, aaO (Fn. 2), \$161 AktG Rdn. 99.

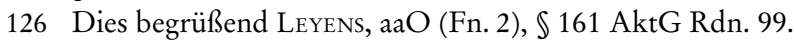

127 Норт, FS Rittner, 1991, S. 187.

128 DCGK 2020, Allgemeine Erläuterungen II 1.

129 Vgl. Leyens, FS E. Vetter, 2019, S. 397, 411 am Beispiel von Grundsatz 22 zur Berichterstattung. 
III. Der Aufsichtsrat, insbesondere Unabhängigkeit und Interessenkonflikte, Zusammenarbeit sowie Funktions- und Arbeitsweise

\section{Leitung und Überwachung (DCGK Teil $2 A$ und B)}

\section{a) Leitung durch den Vorstand}

Der DCGK-Text beginnt in Teil 2 A und B mit der Leitung und Überwachung sowie der Besetzung des Vorstands. ${ }^{130}$ Die Grundsätze über diese Kerninhalte des Aktienrechts zu den drei Organen und ihren Funktionen wirken einigermaßen eklektisch, immerhin weisen Grundsatz 4 über die Bedeutung eines geeigneten und wirksamen internen Kontroll- und Risikomanagementsystems und Grundsatz 5 zur Compliance auf zentrale aktienrechtliche Verantwortungsbereiche des Vorstands hin. Dass dem Aufsichtsrat hierbei wegen $\$ 107$ Abs. 3 Satz 2 und $\$ 171$ Abs. 1 Satz 2 AktG eine wichtige Überwachungsaufgabe zukommt, wird dann beim Aufsichtsrat merkwürdigerweise nicht mehr eigens angesprochen. Bei der Empfehlung A.2 zur Compliance-Verantwortung des Vorstands wird die Etablierung eines Whistleblowing-Systems mit geschützten Hinweisen auf Rechtsverstöße im Unternehmen und - insoweit aber nur Anregung („sollte“) - mit Öffnung auch für Dritte empfohlen. ${ }^{131}$ Ein Hinweis auf die zwischenzeitig erlassene Europäische Richtlinie zum Whistleblowing und die anstehende Umsetzung ${ }^{132}$ sowie die Problematik des Whistleblowing von Nicht-Unternehmensangehörigen ${ }^{133}$ hätte nahe gelegen.

130 Demgegenüber hat der DCGK 2017 nach der Präambel mit den Aktionären und der Hauptversammlung begonnen, was inhaltlich (die Aktionäre betrauen Vorstand und Aufsichtsrat mit der Leitung und Überwachung) und formal überzeugender war, oben I. 2. b). Merkwürdig ist als erste Empfehlung A.1 Diversität bei der Besetzung von Führungsfunktionen im Unternehmen, während die vorrangige Diversität für Vorstand und Aufsichtsrat erst in Empfehlung B.1 und C.1 Satz 2 kommt.

131 Schon DCGK 2017, damals neu. Auch CalPERS, aaO (Fn. 45), p. 32: employee, supplier or other stakeholder.

132 Richtlinie (EU) des Europäischen Parlaments und des Rates zum Schutz von Personen, die Verstöße gegen das Unionsrecht melden, COM/2018/218 final, beschlossen vom Rat am 7.10.2019; dazu Federmann U. A., DB 2019, 1665; ausführlich Fest, 720. Hinweisgeber-Richtlinie, in Franzen/Gallner/Oetker, Hrsg., Komm. z. Europäischen Arbeitsrecht, 3. Aufl., 2020, S. 2047.

133 Der UK Code of Corporate Governance 2018, aaO (Fn. 30), Provision 6 sieht das nur für die Arbeitnehmer und, wenn sie wollen, anonym vor. Zum Ganzen Hopt, ZGR 2020, Heft 2/3 (Symposiumsheft). 


\section{b) Überwachung durch den Aufsichtsrat}

Hierzu gibt es merkwürdigerweise ${ }^{134}$ als Einziges die Anregung A.3. über den Investorendialog des Aufsichtsrats. Dieser Dialog mit Investoren über aufsichtsratsspezifische Themen ist kontrovers, ${ }^{135}$ aber entspricht der internationalen Praxis wie auch der vieler großer DAX-Unternehmen ${ }^{136}$ und kann bei Beachtung seiner Grenzen und in Abstimmung mit dem Vorstand im Unternehmensinteresse liegen. Die Anregung ist deshalb zu Recht in den DCGK 2017 Ziffer 5.2. Abs. 2 aufgenommen und im DCGK 2020 beibehalten worden. Für den DCGK 2017 war ursprünglich sogar eine diesbezügliche Empfehlung angedacht, was von Investoren weiterhin gefordert wird. ${ }^{137}$ Überraschend ist nur das Fehlen einer Begründung, zumal die Grenzen des Investorendialogs - Insiderrecht und Ad-hoc-Publizität, aktienrechtliche Verschwiegenheitspflicht und vor allem der Grundsatz der Gleichbehandlung der Aktionäre - für seine rechtliche und praktische Akzeptanz zentral sind. ${ }^{138}$ Das ist umso erstaunlicher als die Gleichbehandlung der Aktionäre bei der Information in Grundsatz 20 und Empfehlung F.1 ohne Bezugnahme besonders angesprochen ist. ${ }^{139}$

\section{c) Hauptversammlung}

Die Hauptversammlung wird im Kodex nur kurz durch Grundsatz 8 und zwei Anregungen adressiert. ${ }^{10}$ Grundsatz 8 gibt ein paar summarische Informationen zur aktienrechtlichen Funktion der Hauptversammlung. ${ }^{141}$ Beide Anre-

134 Zum board und zur Überwachung durch ihn gibt es eine Fülle empirischer und theoretischer Beiträge, ausführlich Adams, Boards, and the Directors Who Sit on Them, ECGI Finance Working Paper No 515/2017, Juy 2017.

135 M.w.N. zuletzt Норт, ZGR 2019, 507, 525 ff; ausführlicher Hорт/Rotн, aaO (Fn. 22), \$111 AktG Rdn. 567ff, $\$ 107$ AktG Rdn. 97, $155 \mathrm{ff}$; Holle, ZIP 2019, 1895; allgemeiner LANDSITTEL, Investorenkommunikation, 2019.

136 Hopt/Roth, aaO (Fn. 22), $\$ 111$ AktG Rdn. 571, 573; Hirt/Hopt/Mattheus, AG 2016, 725, 728; Schilha/Theusinger, NZG 2019, 521, 527 „in der Praxis aufgenommen“; E. VetTer, NZG 2018, 899; Befragung 2017, Tietz/Hammann/Hoffmann, Der Aufsichtsrat 5/2019, S. 69. Rechtsvergleichend Becker/v. Werder, AG 2016, 761, 773, 774: deutliches Regelungsgefälle zwischen den ausländischen Kodizes und dem damals noch schweigenden DCGK 2015.

137 DVFA, Stellungnahme zum DCGK-E 2018, unter 2); M. Schmidt/STrenger, BörsenZeitung Nr. 233, 4.12.2018, S. 8 .

138 Leyens, aaO (Fn. 2), $₫ 161$ AktG Rdn. 88b; DERs., ZGR 2019, 544, 577.

139 Unten V. 2.

140 Zur Frage der Adressierung des Kodex auch an die Hauptversammlung oben II. 1. c).

141 Grundsatz 8 Satz 4 nimmt auf $\$ 120$ a AktG i. d. F. ARUG II zu den Aufgaben der Hauptversammlung bezüglich der Vorstandsvergütung (say on pay u. a.) Bezug. Im Rechtsausschuss am 5.6.2019 äußerten sich die Sachverständigen kontrovers zu dem im RegE zum 
gungen sind zu Recht aus dem DCGK 2017 beibehalten. ${ }^{142}$ Die Anregung A.4 zur Dauer der Hauptversammlung, möglichst nicht mehr als vier bis sechs Stunden, adressiert die überlange Dauer der deutschen Hauptversammlungen, die international nicht verstanden wird und, wie aus der Praxis zu hören, sogar ein Hemmnis für die Gewinnung nichtdeutscher Vorstands- und Aufsichtsratsmitglieder sein kann. ${ }^{143}$

Die weitere Anregung A.5 zur Einberufung einer außerordentlichen Hauptversammlung im Falle eines Übernahmeangebots ist richtig und nachdrücklich zu begrüßen. ${ }^{144}$ Sie lässt allerdings offen, ob die Aktionäre nur darüber beraten oder auch über gesellschaftsrechtliche Maßnahmen wie Verteidigungsmaßnahmen der Gesellschaft beschließen sollen. Über die Annahme des Übernahmeangebots entscheidet nicht die Hauptversammlung, sondern jeder einzelne Aktionär. Die Befassung der Hauptversammlung mildert das Koordinationsproblem der Aktionäre ab und erschwert zugleich eigennützige Verteidigungsmaßnahmen des Vorstands. ${ }^{145}$ Dadurch wird die Funktion von Übernahmeangeboten als einem von mehreren ${ }^{146}$ Wirkmechanismen der externen Corporate Governance gestärkt. ${ }^{147}$

ARUG II vorgesehenen, nur beratenden say on pay. 2017 gab es zu den zur Abstimmung vorgeschlagenen Vergütungssystemen durchschnittlich über $30 \%$ Gegenstimmen, Arbeitskreis Leitlinien für eine nachhaltige Vorstandsvergütung, aaO (Fn. 102), S. 5.

142 Anregung A.4 wie DCGK 2017 Anregung 2.2.4 Satz 2; Anregung A.5 wie DCGK 2017 Anregung 3.7 Abs. 3.

143 Die Anregung begrüßend auch Leyens, ZGR 2019, 544, 558 m.w.N.

144 Zuletzt Норт, ZGR 2019, 507, $533 \mathrm{ff}$ m.w.N.

145 Die Kritik an der Anregung aus der Unternehmenspraxis war, da den Verhaltensspielraum der Vorstände einschränkend, erwartbar. Umgekehrt wird teilweise sogar eine Empfehlung gefordert sowie unabhängiger Expertenrat zur Vorbereitung der Stellungnahme nach $\ 27$ WpÜG (fairness opinion). Vgl. dazu The Panel on Takeovers and Mergers, The City Code on Takeovers and Mergers, Ziff. 3.1, abrufbar unter: www. thetakeoverpanel.org.uk; HoPT, ZHR 166 (2002), 383, 420; LEYENs, Information des Aufsichtsrats, 2006, S. 408, 413, 435 mit Formulierungsvorschlag zum DCGK, S. 435 f; abwägend Fleischer, FS Hopt, 2010, S. 2753, 2770.

146 Die Intermediäre am Kapitalmarkt (oben II. 1.c) a. E. bei Fn. 81) haben ebenfalls eine externe Corporate Governance-Funktion; LEYENS, aaO (Fn. 81), S. $29 \mathrm{ff}, 165 \mathrm{ff}$ und passim.

147 Hopt, ZHR 175 (2011), 444, 450 und schon DERs., ZHR 166 (2002), 383, 385, 421f, $424 \mathrm{ff}$. Ausführlich Норт, Takeover Defenses in Europe: A Comparative, Theoretical and Policy Analysis, Columbia Journal of European Law 20 (2014) 249, auch in DERs., Europäisches Übernahmerecht, 2013, S. $69 \mathrm{ff}$, insbesondere zum Markt für Unternehmenskontrolle, S. 77 ff. Ähnlich НABERSACK, ZHR 181 (2017), 603, 614ff, 629: strenges Verhinderungsverbot mit alleinigem Recht der Aktionäre, aus diesem hinaus zu optieren. Auch Davies/Hopt/Ringe, in: Kraakman et al., eds., The Anatomy of Corporate Law, 3 d ed., Oxford 2017, p. 205, 215 et seq. Empirisch zu negativen Effekten von antitakeover provisions Rowoldt/STARke, The Role of Governments in Hostile Takeovers - Evidence from Regulation, Anti-Takeover Provisions and Government Interventions, International Review of Law and Economics 47 (2016) 1. 


\section{d) Vorstandsbesetzung}

Die Empfehlung B.1 zur Diversität im Vorstand nimmt über die in $\$ 289 \mathrm{f}$ Abs. 2 Nr. 6 HGB genannten Kriterien zutreffend auch das der Internationalität auf. ${ }^{148}$ Die Empfehlung B.2 zur langfristigen Nachfolgeplanung ist auch international als gute Corporate Governance anerkannt. ${ }^{149}$ Die Empfehlungen B.3 und B.4 über die Vorstandsbestellung auf längstens drei Jahre, dies ohne Umgehung durch Wiederbestellung, entsprechen, wie richtig gesagt wird, verbreiteter Praxis, was diese aber noch nicht ohne weiteres zum allgemeinen Standard guter Corporate Governance macht. Im angelsächsischen Raum ist der Standard sogar die jährliche Wiederwahl. ${ }^{150}$ Dies geht auf die dort einflussreicheren institutionellen Investoren und die durch Streubesitz gekennzeichnete Aktionärsstruktur zurück, bei der es vorrangig um den Agenturkonflikt zwischen Vorstand und Aktionären geht, zu dessen Lösung kurze Amtszeiten geboten sein können. In Deutschland wird die Aktionärsstruktur demgegenüber traditionell durch Konzerne und Familien bestimmt. ${ }^{151}$ Maßgeblich ist dann der Agenturkonflikt nicht zwischen Vorstand und Aktionären, sondern zwischen dem kontrollierenden Aktionär und den Minderheitsaktionären. ${ }^{152}$ Eine gewisse ${ }^{153}$ Stärkung der Stellung des Vorstands wie durch eine fünfjährige Bestelldauer widerspricht deshalb hier gerade nicht guten Corporate Governance Standards. Für die Empfehlung einer best practice ist jedoch entscheidend, ob eine hinreichende Verallgemeinerbarkeit angenommen werden kann, was fraglich ist angesichts von DAX 30-Gesellschaften mit Streubesitz, z.B. Deutsche Bank oder Deutsche Börse, ${ }^{154}$ überwiegender Prä-

148 Siehe dazu die Begründungen zu den Empfehlungen A.1, B.1 und C.1 mit dem Hinweis, dass zur Diversität außer Alter, Geschlecht, Bildungs- und Berufshintergrund, wie in $\$ 289 \mathrm{f}$ Abs. $2 \mathrm{Nr}$. 6 HGB angesprochen, auch Internationalität gehört. Die dreimalige Wiederholung deutet erneut auf das Gliederungsproblem hin (oben I. 3. b).

149 CalPERS, aaO (Fn. 45), p. 20 et seq.: 14. CEO Succession Plan, 15. Director Succession Plan.

150 UK Corporate Governance Code, aaO (Fn. 30), Provision 18, heute mehr oder weniger akzeptiert, Норт, FS Seibert, 2019, S. 389, 400f. Vgl. CalPERS, aaO (Fn. 45), p. 11: Annual Director Elections, jedenfalls mindestens alle drei Jahre.

151 Zum Abschied vom deutschen rheinischen Kapitalismus Ringe, Changing Law and Ownership Patterns in Germany: Corporate Governance and the Erosion of Deutschland AG, The American Journal of Comparative Law 63 (2015)493; auch schon von HeIN, Die Rezeption US-amerikanischen Gesellschaftsrechts in Deutschland, 2008, S. $376 \mathrm{ff}$.

$152 \mathrm{Zu}$ den drei Agenturkonflikten im Aktienrecht KraAkman et AL., aaO (Fn. 147), p. 29 et seq.

153 Der kontrollierende Aktionär kann dem Vorstand in der Hauptversammlung das Vertrauen entziehen, dann kann der Aufsichtsrat nach $\$ 84$ Abs. 3 Satz 2 AktG den Vorstand vorzeitig abberufen.

154 Deutsche Bank Streubesitz ca. 77 \% bei 5 Paketaktionären; Deutsche Börse Streubesitz ca. $60,5 \%, 94 \%$ institutionelle Investoren. 
senz institutioneller Investoren im DAX 30 insgesamt und dem Befund eines mehr als hälftigen Anteilseigentums ausländischer Investoren an diesen Gesellschaften. ${ }^{155}$

Für Vorstandsmitglieder ist die Festlegung einer Altersgrenze durchaus sinnvoll. Der DCGK sieht das als Empfehlung B.5 vor. ${ }^{156}$ Dem entspricht für Aufsichtsratsmitglieder wortgleich die Empfehlung C.2. Der empfohlene Bericht in der EzU doppelt sich bei Nichtbefolgung mit der Erklärung nach $\$ 161$ AktG. ${ }^{157}$ Wann und wie eine solche Altersgrenze eingreifen soll, überlässt der Kodex der Gesellschaft.

\section{Zusammensetzung und Unabbängigkeit (DCGK Teil 2 C)}

\section{a) Zusammensetzung des Aufsichtsrats}

Der DCGK 2020 bringt dazu die drei Grundsätze 10 bis 12, und die fünf Empfehlungen C.1-C.5. Grundsatz 10 erwähnt die deutsche Mitbestimmung anders als der DCGK $2017^{158}$ nur ganz kursorisch und verweist auf die Mitbestimmungsgesetze. Wenn der DCGK 2020 über das deutsche Corporate Governance System informieren will, ist das, wie bereits angemerkt, zu wenig. ${ }^{159}$

Unter den Empfehlungen sind die zur Diversität im Aufsichtsrats C.1 und zur Altersgrenze C.2 bereits oben angesprochen worden. ${ }^{160}$ Wichtig ist die Empfehlung C.1 zum Kompetenzprofil für den Aufsichtsrat insgesamt, ${ }^{161}$ zur Be-

155 Ernst \& Young, Wem gehört der DAX?, Analyse der Aktionärsstruktur der DAXUnternehmen 2017, April 2018, abrufbar unter: https://www.ey.com/Publication/ vwLUAssets/ey-wem-gehoert-der-dax/\$FILE/ey-wem-gehoert-der-dax.pdf (letzter Zugriff: 10.9.2019); IPREO/DIRK, Die Aktionärsstruktur des deutschen Leitindex DAX 30, Juni 2018, S. $7 \mathrm{f}$.

156 Aber ISS, aaO (Fn. 105), p. 15 gegen mandatory retirement ages for directors.

$157 \mathrm{Zu}$ diesem nicht unproblematischen Nebeneinander unten V. 1.

158 DCGK 2017 Präambel Abs. 7, knapp, aber informativ. Ausführlicher Österreichischer Corporate Governance Kodex 2018, aaO (Fn. 56), L 59.

159 Schon oben II. 1. b), auch unten III. 2. a), b) bb). Auch v. Werder, DB 2019, 41, 43. Die Begründung zu Grundsatz 10 erwähnt, dass kürzere Bestellzeiten als die fünf Jahre nach $\ 102$ Abs. 1 AktG wählbar sind und es dafür gute Gründe gibt, nämlich mehr Flexibilität im Hinblick auf das Kompetenzprofil des Aufsichtsrats und Veränderungen der Eigentümerstruktur. Soll mit dieser Aussage unterhalb der Anregung eine weitere Kategorie der Ratschläge an Unternehmen geschaffen werden?

160 Oben III. 1. d) zur Empfehlung B.1 und zur Altersgrenze III. 1. d) zur Empfehlung B.5. Zu Diversität speziell im Aufsichtsrat Норт/Roth, aaO (Fn. 22), $\mathbb{1} 100$ AktG Rdn. $201 \mathrm{ff}$.

161 „Meaningful information on the supervisory board's skill and expertise profile (Kompetenzprofil)” verlangt Glass Lewis, 2019 Guidelines Germany, aaO (Fn. 98), p. 3, 
rücksichtigung bei Wahlvorschlägen und zur Transparenz in der EzU. Die Empfehlung C.3 nur der Offenlegung der Zugehörigkeitsdauer ${ }^{162}$ ist besser als die einer festzulegenden Regelgrenze für die Zugehörigkeit zum Aufsichtsrat wie in DCGK 2017 Ziff. 5.4.1. ${ }^{163}$ Erst recht wäre eine feste Obergrenze für die Bestelldauer wie beim Vorstand für die Aufsichtsratsmitglieder, so im DCGKE $2018^{164}$ auf drei Jahre, zu starr. ${ }^{165}$

Der Grundsatz 12, dass jedes Aufsichtsratsmitglied darauf achten muss, dass ihm für die Wahrnehmung seiner Aufgaben „genügend Zeit“ zur Verfügung steht, wird auch in den meisten ausländischen Kodizes festgehalten, ${ }^{166}$ aber entspricht leider nicht immer der Praxis. Das betrifft nicht nur die Vorbereitung und Anwesenheit bei den Sitzungen, sondern vor allem auch das Overboarding. Die aktienrechtliche Grenze von 10 Mandaten samt Konzernprivileg und Doppelzählung von Aufsichtsratsvorsitzen nach $\ 100$ Abs. 2 Satz 1 bis $3 \mathrm{AktG}$ ist von der Entwicklung offensichtlich überholt, die Anforderungen sind heute deutlich höher, in Krisen des Unternehmens sogar um ein Vielfaches. Das wird auch in der Reformdiskussion so gesehen. ${ }^{167}$ Insgesamt ist die Anzahl der Mehrfachmandate in den 100 größten Unternehmen (stark) rückläufig. ${ }^{168}$ Die Empfehlung C.4 sieht für Aufsichtsratsmitglieder nicht mehr als fünf Aufsichtsratsmandate bei konzernexternen börsennotierten Gesellschaften oder vergleichbare Funktionen unter Doppelzählung eines Vorsitzes vor. ${ }^{169}$ Das entspricht internationalen Standards. ${ }^{170}$

nimmt aber eine ausdrückliche Beurteilung auch der einzelnen Aktionärsvertreter im Aufsichtsrat vor, allerdings ohne direkte Auswirkung auf die Stimmempfehlung, p. 11. Ausführlich Spindler, in: Spindler/Stilz, Komm. z. AktG, 4. Aufl., 2019, $\$ 100$ Rdn. $61 \mathrm{ff}$, besondere Anforderungen für Finanzinstitute.

162 Empfehlung B.3, dazu oben III. 1. d).

163 In der Begründung versehentlich DCGK 2017 Ziff. 5.4.2.

164 DCGK-E 2018 Empfehlung B.1.

165 Ausführlich VGR, aaO (Fn. 19), IV 1. Anders dezidiert aus Investorensicht M. Schmidt/Strenger, Börsen-Zeitung Nr. 233, 4.12.2018, S. 8; Blackrock und STate STREET zum DCGK-E 2018, aaO (Fn. 7).

166 Z.B. UK Corporate Governance Code 2018, aaO (Fn. 30), Principle H und Provision 15. Nach der Vorgängerversion sollte der erwartete Zeitaufwand in die Bestellungsurkunde aufgenommen werden, BECKER/v. WERDER, AG 2016, 761, 769.

167 Норт/Rотн, aaO (Fn. 22), $\$ 100$ AktG Rdn. 68 ff.

168 Monopolkommission, Wettbewerb 2018, XXII. Hauptgutachten der Monopolkommission gemäß $\int 44$ Abs. 1 Satz 1 GWB, 2018, Abschn. 133 (S. 127) mit instruktiver Grafik.

169 Dies gegenüber DCGK 2017 Ziff. 5.4.1 Abs. 5, wonach sich nur der Aufsichtsrat vor seinen Wahlvorschlägen über die zeitliche Verfügbarkeit des jeweiligen Kandidaten zu vergewissern hatte, was zu kurz griff.

170 Oben II. 3.; Норт/Roth, aaO (Fn. 22), $\$ 100$ AktG Rdn. 77; Becker/v. Werder, AG 2016, 761, 769f. So z.B. auch Glass Lewis, 2019 Guidelines Germany, aaO (Fn. 98), p. 5; ISS, aaO (Fn. 105), p. 9 et seq. Der Österreichische Corporate Governance Kodex 
Eine strengere Vorgabe für Vorstandsmitglieder enthält die Empfehlung C.5. ${ }^{171}$ Danach soll ein Vorstandsmitglied nicht mehr als zwei Aufsichtsratsmandate in konzernexternen börsennotierten Gesellschaften oder vergleichbare Funktionen und keinen Aufsichtsratsvorsitz in einer konzernexternen börsennotierten Gesellschaft inne haben. ${ }^{172}$ Die Begründung weist auf die damit verbundene Arbeitsbelastung hin, weicht dies aber mit dem Hinweis auf, das sei nur „regelmäßig“ so. Dieser Hinweis war in der Begründung zu DCGK-E 2018 B.6 noch nicht enthalten und ist offenbar eine Reaktion auf die teils scharfe Kritik in der Konsultation.

\section{b) Unabhängigkeit von Aufsichtsratsmitgliedern}

Die Unabhängigkeit von Aufsichtsratsmitgliedern ist aktienrechtlich nicht vorgeschrieben, ${ }^{173}$ das Unabhängigkeitserfordernis für den Finanzexperten nach $\$ 100$ Abs. 5 a.F. AktG. wurde gegen Kritik und internationale Vorbilder gestrichen. ${ }^{174}$ Künftig sieht $\$ 111 \mathrm{~b}$ AktG i.d.F. ARUG II vor, dass bei der Beschlussfassung über die Zustimmung zu Geschäften mit nahestehenden Personen diejenigen Aufsichtsratsmitglieder ihr Stimmrecht nicht ausüben können, die an dem Geschäft als nahestehende Person beteiligt sind oder bei denen die Besorgnis eines Interessenkonflikts aufgrund ihrer Beziehung zu der nahestehenden Person besteht. In der internationalen Diskussion ist die Frage der Unabhängigkeit von Direktoren zentral, ${ }^{175}$ sie ist auch in der Empfehlung der Europäischen Kommission von 2005 ausführlich geregelt. ${ }^{176}$ Unter diesem

2018, aaO (Fn. 56), C 57 setzt die Grenze bei nicht mehr als 4 Aufsichtsratsmandaten (Vorsitz zählt doppelt) in konzernexternen Aktiengesellschaften an.

171 Die Empfehlung C.5 betrifft den Vorstand und passt deshalb nicht recht unter den Abschnitt $\mathrm{C}$ über die Zusammensetzung des Aufsichtsrats. Richtiger wäre es zu formulieren, dass der Aufsichtsrat keinen entsprechenden Wahlvorschlag ( $\mathbb{} 124 \mathrm{AktG})$ unterbreiten soll.

172 Vgl. demgegenüber UK Corporate Governance Code 2018, aaO (Fn. 30), Provision 15 sentence 4: "Full-time executive directors should not take on more than one non-executive directorship in a FTSE 100 company or other significant appointment."

173 Näher Норт/Rотн, aаO (Fn. 22), $\$ 100$ AktG Rdn. 149, anders im Investmentrecht, Spindler, aaO (Fn. 161), $\$ 100$ AktG Rdn. 66. Das ist auch der Grund, warum der DCGK 2020 zur Unabhängigkeit keinen Grundsatz aufnimmt.

174 Ein Grund war die Kontroverse um die Unabhängigkeit von Arbeitnehmervertretern, Hopt/Roth, aaO (Fn. 22), $\$ 100$ AktG Rdn. 231 ff; dazu auch Merkт, ZHR 179 (2015), 601, 612. Ausführliche Kritik bei SpIndLER, aaO (Fn. 161), $\$ 100$ AktG Rdn. 59a; auch bei Habersack, Münchener Komm. z. AktG, 5. Aufl., 2019, $\$ 100$ Rdn. 68.

175 Норт, ZHR 175 (2011), 444, 472ff, $484 \mathrm{ff}$.

176 Empfehlung vom 15.2.2005, ABIEU L 52/51 mit Anhang II, dazu Hopt, ZIP 2005, 461, $467 \mathrm{ff}$; LANGENBUCher, ZGR 2007, 571, $589 \mathrm{ff}$. Zu dieser Empfehlung und späteren Änderungen Hopt/Roth, aaO (Fn. 22), $\$ 100$ AktG Rdn. 156 ff. 
Einfluss ist heute auch in Deutschland anerkannt, dass die Unabhängigkeit von Aufsichtsratsmitgliedern zur Überwachungseffizienz beiträgt. ${ }^{177}$ Umstritten sind hier aber die Einzelforderungen, namentlich die Unabhängigkeit auch von einem Kontrollaktionär, Definition und Kriterien im Übrigen, Zahl bzw. Anteil der Unabhängigen und das Verhältnis von Unabhängigkeit und Interessenkonflikten. Für die Kodexreform war die Frage der Unabhängigkeit von Aufsichtsratsmitgliedern Hauptaufgabe neben der Vorstandsvergütung. Ergebnis sind zahlreiche Empfehlungen, C.6 bis C.12, die zu Recht ausführlicher und strenger ausfallen als die Vorgaben nach dem DCGK 2017. ${ }^{178} \mathrm{Zu}$ den in anderen Ländern und Kodizes bewährten lead directors bzw. independent director $^{179}$ und einer möglichen Vermittlerrolle zwischen unabhängigen und nicht unabhängigen Aufsichtsratsmitgliedern wird nichts gesagt. ${ }^{180}$

\section{aa) Ziel der Unabhängigkeitsregeln}

Mit den Empfehlungen zur Unabhängigkeit soll eine am Unternehmensinteresse ausgerichtete Überwachung durch Begrenzung von potentiellen Interessenkonflikten sichergestellt werden. ${ }^{181}$ Das ist im Grundsatz international und national ${ }^{182}$ unstreitig. Insoweit geht es vor allem um Minderheitenschutz. ${ }^{183}$ Dass

177 Hopt, ZHR 175 (2011), 444, 474. Dezidiert CalPERS, aaO (Fn. 45), p. 11: „Independence is the cornerstone of accountability.” Das frühere Argument, der deutsche Aufsichtsrat sei schon wegen $\$ 105$ AktG über die Inkompatibilität unabhängig, ist international nicht ernst genommen worden und wird heute nicht mehr vorgebracht.

178 Teil 2 C II und zuvor Begründung in der allgemeinen Erläuterung Teil 1 II 2. Merkwürdig ist, dass die Interessenkonflikte erst unter Zwischenschaltung der Empfehlungen C.13 - C.15 und der Arbeitsweise des Aufsichtsrats unter E selbständig mit Grundsatz 19 und den Empfehlungen E.1 - E.3 geregelt sind. Vorliegend wird deshalb anders gegliedert.

179 UK Corporate Governance Code 2018, aaO (Fn. 30), Provision 12 und Guidance on Board Effectiveness, July 2018, 66-68. Weitere Nachweise bei Hopт, ZHR 175 (2011), 444, 483; Норт/Rотн, аaO (Fn. 22), \$100 AktG Rdn. 198. Für einen senior independent director („Aufsichtsratsältesten“) LEYENS, aaO (Fn. 145), S. $261 \mathrm{f}$. Zu einem für Governance-Fragen zuständigen company secretary UK Corporate Governance Code 2018, ebenda, Principle I und Provision 16; dazu Норт/Rотн, аaO (Fn. 22), $\$ 107$ AktG Rdn. 212; auch The Dutch Corporate Governance Code 2016, 2.3.10.

180 Leyens, aaO (Fn. 145), S. $98 \mathrm{ff}$.

181 Teil 1 II 2 Abs. 1. Unklar bleibt, ob es sich bei dem in Teil 1 II 2 angesprochene Loyalitäts- und Rollenkonflikt um denselben einheitlichen Konflikt handelt oder eher zwischen Loyalität (Treuepflicht) und Rolle unterschieden werden müsste. Einzelheiten zu den neuen Unabhängigkeitsregeln des Kodex bei RubNer/Fischer, NZG 2019, 961.

182 Nur für die Unabhängigkeit von der Gesellschaft und vom Vorstand KocH, aaO (Fn. 3), $\mathbb{1} 100 \mathrm{Rdn} .4$.

183 Begründung zu Empfehlung C.6 Abs. 2. Zum Minderheitenschutz rechtsvergleichend TGS Baltic, Study on Minority Shareholders Protection, Final Report (for the European Commission), January 2018; dazu LecourT, Revue des Sociétés 2018, 677. 
sich die hochgespannten Erwartungen an die Einführung unabhängiger Direktoren nur teilweise erfüllt haben, ${ }^{184}$ sollte dabei allerdings im Auge behalten werden. Bei den potentiellen Interessenkonflikten wird zwischen Gefährdung durch Nähe zur Gesellschaft und zum Vorstand einerseits und durch Stellung als kontrollierender Aktionär oder zu diesem andererseits differenziert, was der unterschiedlichen Aktionärsstruktur (dispersed shareholders/controlling shareholder) entspricht. ${ }^{185}$ Diese Differenzierung spielt auch bei der Festlegung der angemessenen Anzahl unabhängiger Aufsichtsratsmitglieder und bei der Besetzung der Ausschüsse im Aufsichtsrat eine Rolle. ${ }^{186}$

\section{bb) Unabhängigkeit nur von Anteilseignervertretern}

$\mathrm{Ob}$ Arbeitnehmervertreter unabhängig sind, ist bekanntlich umstritten, die zutreffende und wohl überwiegende Meinung hält sie nicht für unabhängig. ${ }^{187}$ Aus der Empfehlung der Europäischen Kommission und der Praxis der US-amerikanischen SEC ergibt sich nichts Gegenteiliges. ${ }^{188}$ Die Corporate Governance Kodizes von Großbritannien und den Niederlanden definieren Arbeitnehmer ausdrücklich als nicht-unabhängig. ${ }^{189}$ Auch die internationalen Stimmrechtsberater betrachten die Arbeitnehmer nicht als unabhängig oder wollen sich nicht in diese deutsche Debatte einmischen. ${ }^{190}$ Der DCGK 2020 vermeidet es, Stellung zu beziehen, und beschränkt seine Empfehlung C.6 „auf Anteilseignerseite“ ${ }^{191}$ Das ist weder in der Sache noch in der Begrün-

184 Hopt, ZHR 175 (2011), 444, 485 f mit Rechtsvergleichung. International GoRdON, The Rise of Independent Directors in the United States, 1950-2005: Of Shareholder Value and Stock Market Prices, 59 Stanford Law Review 1465 (2007); Puchniak/Baum/NotTAGE, Independent Directors in Asia, Cambridge 2017.

185 Die weitere Aufzählung in Teil 1 II 2 des Kodex vermischt aktuelle Interessenkonflikte (Eigeninteresse) und Indikatoren für Unabhängigkeit (Zeitdauer der Zugehörigkeit).

186 So in der Begründung in Teil 1 II 2 Abs. 3: Die Kommission „spricht sich dafür aus“. Ebenso Begründung der Empfehlung C.10.

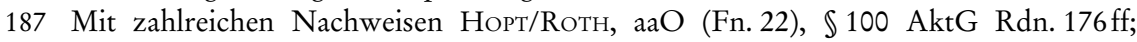
M. Roth, ZHR 176 (2011), 605, 630f; Habersack, aaO (Fn. 174), \100 AktG Rdn. 9, 80, 84; SpINDLER, aaO (Fn. 161), $\$ 100 \mathrm{AktG}$ Rdn. 191. A. A. aus arbeitsrechtlicher Sicht zuletzt SEIFERT, ZfA 2018, 198, $210 f$.

188 Mit näherer Begründung Норт/Rотн, aаO (Fn. 22), $\$ 100$ AktG Rdn. 178 m.w.N.

189 UK Corporate Governance Code 2018, aaO (Fn. 30), Provision 10 first bullet point: "is or has been an employee of the company or group within the last five years"; ebenso The Dutch Corporate Governance Code 2016, provision 2.1.8 i.; auch BECKER/v. WERDER, AG 2016, 761, 770.

190 ISS, aaO (Fn. 105), p. 13, behandelt Arbeitnehmervertreter als nicht unabhängig; GLAss LEwIs, 2019 Guidelines Germany, aaO (Fn. 98), p. 5 lässt die Arbeitnehmervertreter bei den Anforderungen an die Unabhängigkeit unberücksichtigt.

191 Teil 1 II Abs. 2 Satz 2 sowie Begründung zu Empfehlung C.6. So jetzt allerdings auch für Frankreich AFEP/MEDEF, Code de gouvernement d'entreprise des sociétés côtées, 
dung überzeugend. ${ }^{192}$ Dass auch Arbeitnehmer potentiellen Interessenkonflikten (Loyalitäts- und Rollenkonflikten) ausgesetzt sein können, zumal wenn die DCGK-Kommission darunter auch Eigeninteressen fasst, liegt auf der Hand. Dass sie nicht von der Hauptversammlung gewählt werden, was die Kommission zur Begründung anführt, ist insoweit nicht entscheidend. Die Empfehlungen des DCGK sind nicht bindend und könnten sich ohne weiteres auch an die Arbeitnehmervertreter richten. International ist die Aussparung der Thematik keineswegs einsichtig und zudem wenig transparent. ${ }^{193}$

\section{cc) Eine nach Einschätzung der Anteilseignerseite angemessene Anzabl unabhängiger Mitglieder}

Dies sieht die Empfehlung C.6 Abs. 1 vor, wobei nur die Anteilseignerseite entscheiden ${ }^{194}$ und diese die Eigentümerstruktur berücksichtigen soll. Die Empfehlung C.6 Abs. 2 bringt dann eine „Positivdefinition der Unabhängigkeit“ ", ${ }^{195}$ die nicht unproblematisch ist. ${ }^{196}$ In der Sache trifft die Empfehlung hier aber das Richtige: Ein Aufsichtsratsmitglied ist nur dann unabhängig, wenn es sowohl von der Gesellschaft und dem Vorstand als auch von einem kontrollierenden Aktionär unabhängig ist. In beiden Fällen ist der Minderheitenschutz tangiert. ${ }^{197}$ Der Begriff des kontrollierenden Aktionärs wird im DCGK nicht weiter definiert. Das Verständnis der Kommission ist nach der Begründung, dass Kontrolle einen Beherrschungsvertrag oder die absolute Mehrheit der Stimmen oder zumindest eine „nachhaltige Hauptversammlungsmehrheit“ voraussetzt. ${ }^{198}$ Das ist zu unbestimmt. ${ }^{199} \mathrm{Es}$ ist schade, dass sich die Kommission nicht getraut hat,

2018, $\ 8.3$ : „ne sont pas comptabilisés pour établir ces pourcentages“, dann aber \8.5.1: „ne pas être ou ne pas avoir été au cours des cinq années précédentes: - salarié“.

192 Reformbedarf bezüglich der Mitbestimmung mahnt auch KonT, aaO (Fn. 22), Vor $\$ 76$ AktG Rdn. 47 an.

$193 \mathrm{Zu}$ dieser Kritik schon oben II. 1. b), III. 2. a).

194 Anders Ziffer 13 der Empfehlung der Europäischen Kommission von 2015.

195 Ausdruck nach der Begründung zur Empfehlung C.7. Immerhin schränkt die Empfehlung C.6 Abs. 2 ein: „im Sinne dieser Empfehlung als unabhängig“.

196 Dazu unten III. 2. b) dd).

197 Schon oben III. 2. b) aa) Fn. 183 .

198 So auch die ü.L. zum DCGK 2017, dazu SpIndler, aaO (Fn. 161), 100 AktG Rdn. 66a. Die Europäische Kommission verweist in ihrer Empfehlung von 2005, aaO (Fn. 176), auf Art. 1 Abs. 1 der Siebten Richtlinie 83/349/EWG, wonach es auf die Möglichkeit der Bestellung der Mehrheit der Mitglieder des Verwaltungsorgans ankommt (mit Alternativen). Interessant für Frankreich AFEP/MEDEF, Code de gouvernement d'entreprise des sociétés côtées, 2018, $\mathbb{8} 8.7$, mit einer Ausnahmemöglichkeit, „dès lors que ces actionnaires ne participent pas au contrôle de la sociétéc.

199 Kritisch auch VGR, aaO (Fn. 19), IV.2. 
die Frage ebenso wie im WpÜG zu regeln oder wenigstens eine dementsprechende Praxis anzuregen, nämlich Halten von mindestens 30 Prozent der Stimmrechte, was weithin den Präsenzen in den Hauptversammlungen börsennotierter Unternehmen entspricht. ${ }^{200}$ Ein Vorschlag der Kodexkommission vom Januar 2012 hatte sogar schon bei einer Beteiligung von zehn Prozent eine Kontrollmehrheit annehmen wollen. ${ }^{201}$ Zur Funktionsfähigkeit des Unabhängigkeitskriteriums wäre eine Festlegung des DCGK erforderlich gewesen.

\section{dd) Mindestanzahl von der Gesellschaft und vom Vorstand unabhängiger Aufsichtsratsmitglieder, Kriterien-bzw. Indikatorenkatalog}

International wurde die Unabhängigkeit der Direktoren zunächst nur als Unabhängigkeit von der Gesellschaft und dem Management angesehen, was an dem Ursprung der Diskussion in den USA und dem Vereinigten Königreich mit einem weit vorherrschenden Streubesitz liegt. Erst allmählich wurde im Hinblick auf die abweichende Aktionärsstruktur in Kontinentaleuropa auch Unabhängigkeit vom kontrollierenden Aktionär gefordert, dann aber grundsätzlich, also ohne zwischen beiden Arten der Unabhängigkeit zu differenzieren. Das tut der DCGK 2020, wie gesagt, in Empfehlung C.6 Abs. 2 im Grundsatz ebenfalls. In den folgenden Empfehlungen differenziert er dann aber doch und ganz maßgeblich. Das ist aus internationaler Sicht überraschend, erklärt sich aber daraus, dass Deutschland schon mit der Empfehlung der Europäischen Kommission von 2005 im Hinblick auf kontrollierende Aktionäre Schwierigkeiten hatte und dieser insoweit zunächst nicht folgte. Der DCGK 2020 versucht dazu einen komplizierten und wenig transparenten Mittelweg. ${ }^{202}$ Was die Unabhängigkeit von der Gesellschaft und deren Vorstand angeht, soll mehr als die Hälfte der Aufsichtsratsmitglieder unabhängig sein und nur für diese wird nunmehr - wie schon früher erwogen, aber unter dem Eindruck der Kritik damals unterlassen ${ }^{203}$ - ein Indikatorenkatalog aufgestellt (so Empfehlung C.7 Abs. 1 und 2). Das ist ein gutes Stück mehr als im DCGK 2017, wenn auch weniger als das, was institutionelle Investoren und internationale Stimmrechtsberater verlangen. ${ }^{204}$

$200 \rrbracket 29$ Abs. 2 WpÜG; Begr. RegE, BT-Drucks. 14/7034, S. 53; Assmann, in: ders./ Pötzsch/Schneider, Hrsg., WpÜG, 2. Aufl., 2013, $\$ 29$ Rdn. 9. Eine Berechnung nach Stimmmehrheit etwa in den letzten drei Hauptversammlungen, wie in der Reformliteratur teilweise vorgeschlagen, empfiehlt sich wegen der damit verbundenen Unsicherheiten nicht.

201 Vorschläge aus der Plenarsitzung vom 17.1.2012, Ziffer 5.4.2, Abs. 2, 3. Spiegelstrich.

202 Begründung in Teil 1 II 2 Abs. 4.

203 DAV-Handelsrechtsausschuss, NZG 2012, 335, $337 \mathrm{Rdn} .14 \mathrm{ff}$.

204 Zur Director Independence CalPERS, aaO (Fn. 45), p. 11 et seq., 12: möglichst "substantial majority”. Vgl. Glass Lewis, 2019 Guidelines Germany, aaO (Fn. 98), p. 5/6 für den Aufsichtsrat und p. 3 für Ausschüsse. Auch M. Rотн, WM 2012, 1985, 1988 f. 
Der Indikatorenkatalog beschränkt sich abweichend von der Empfehlung der Europäischen Kommission von $2005^{205}$ und von internationalen Kodices ${ }^{206}$ auf folgende Faktoren, die für das Aufsichtsratsmitglied selbst oder einen nahen Familienangehörigen berücksichtigt werden sollen ${ }^{207}: 1$ ) Mitglied des Vorstands in den zwei Jahren vor Ernennung, im Ergebnis wie die Karenzzeit für den Vorstand nach $\ 100$ Abs. 2 Nr. 4 AktG, ${ }^{208}$ 2) wesentliche geschäftliche ${ }^{209}$ Beziehung mit der Gesellschaft oder einem von dieser abhängigen Unternehmen ${ }^{210}$ aktuell oder im Jahr bis zur Ernennung, ${ }^{211}$ 3) naher Familienangehöriger eines Vorstandsmitglieds ${ }^{212}$ und 4) Aufsichtsratsmitglied seit mehr als 12 Jahren. ${ }^{213}$ An-

205 Oben Fn. 158, insoweit nicht geändert durch die Empfehlung der Europäischen Kommission vom 30.4.2009, ABlEU L 120/28, 31, Anhang III.8; auch abgedruckt bei Норт/ Rотн, aaO (Fn. 22), $\$ 100$ AktG Rdn. 157. Diese Empfehlung enthält insbesondere Regelungen über die Verbindung zum Abschlussprüfer; dazu Норт/Rотн, аaO

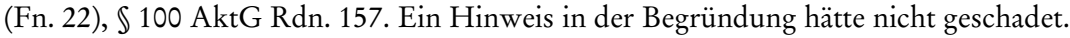
Der DCGK 2020 enthält aber Regeln über die Zusammenarbeit mit dem Abschlussprüfer, unten III. 4. c).

206 Z.B. UK Corporate Governance Code 2018, aaO (Fn. 30), Provision 10 mit sieben erheblich weiter reichenden Kriterien.

207 DCGK-Empfehlung C.7 Abs. 2 mit Begründung sowie Allgemeine Erläuterung in Teil 1 II 2 Abs. 3.

208 International wird meist ein längerer Zeitraum angenommen, in den USA beispielsweise drei Jahre nach Ausscheiden, nach der Empfehlung der Europäischen Kommission sogar fünf Jahre, für ehemalige Arbeitnehmer drei Jahre. Auch Hорт/Rотн, aаO

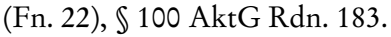

209 Persönliche Beziehungen werden anders als nach dem DCGK 2017 Ziffer 5.4.2 Satz 2 und anders als auch zur Unabhängigkeit vom kontrollierenden Aktionär in Empfehlung C.9 Abs. 2 nicht erwähnt. Ob dies, etwa im Hinblick auf die Erfassung von nahen Familienangehörigen durch den dritten Indikator, Absicht war, ist nicht erkennbar. Dazu auch Hорт/Roth, aaO (Fn. 22), $\$ 100$ AktG Rdn. 190 ff.

210 Der Konzernbezug ist eine wesentliche Verbesserung gegenüber dem DCGK 2017, dazu kritisch schon Норт/Rотн, aaO (Fn. 22), $\$ 100$ AktG Rdn. 185.

211 Näher DCGK Empfehlung C.7 Abs. 2, 2. Spiegelstrich mit Begründung.

212 Nach der Begründung wie die in Definition IAS 24. Auch $\$ 111$ a Abs. 1 Satz 2 AktG i.d.F. ARUG II verweist auf die internationalen Rechnungslegungsstandards in ihrer jeweils geltenden Fassung. Das wird man auch für die Empfehlung C.7 Abs. 2, 3. Spiegelstrich so sehen.

21312 Jahre wird auch international als bezüglich der Unabhängigkeit lange Bestelldauer angesehen, z.B. Glass Lewis, 2019 Guidelines Germany, aaO (Fn. 98), p. 6: lengthy average board tenure; CalPERS, aaO (Fn. 45), p. 16 unter d. Director Tenure. Bemerkt wird nur, dass die Dauer der Zugehörigkeit zum Aufsichtsrat „ein international weit verbreitetes Kriterium der Unabhängigkeit“ ist. Dazu auch Норт/Rотн, aаO (Fn. 22), $\$ 100$ AktG Rdn. 188f; Becker/v. Werder, AG 2016, 761, 770. Der Fondsverband BVI geht von 10 Jahren aus; M. Schmidt/Strenger, Börsen-Zeitung Nr. 233, 4.12.2018, S. 8. UK Corporate Governance Code 2018, aaO (Fn. 30), neun Jahre, vgl. Provision 10, für den chair sogar neun Jahre als Bestelldauergrenze, Provision 19. Auch DVFA, aaO (Fn. 137), unter 11): internationale best practice neun bis zehn Jahre. 
ders als international eher üblich wird damit aber die Unabhängigkeit nicht ausgeschlossen und auch nicht eine widerlegbare Vermutung aufgestellt („Negativkatalog“), sondern es werden nur zu berücksichtigende Indikatoren genannt, dies weil die Beurteilung subjektiv sei und eine Gesamtschau durch den Aufsichtsrat erfordere. ${ }^{214}$ Die DCGK-Kommission bezeichnet das als „pflichtgemäßes Ermessen“, was nahelegt, dass es sich ihrer Ansicht nach nicht um die Ausübung der business judgment rule mit ihren fünf positiven Tatbestandsvoraussetzungen nach $\mathbb{9} 93 \mathrm{Abs}$. 1 Satz $2 \mathrm{AktG}$ handeln soll, sondern um eine allgemeine Ermessensentscheidung unter $\ 93$ Abs. 1 Satz 1 AktG. ${ }^{215}$ Zugleich ist damit impliziert, dass die Frage nach der Einhaltung der Ermessensgrenzen voller gerichtlicher Kontrolle unterliegt. Wird ein Aufsichtsratsmitglied trotz Vorliegens eines der Indikatoren als unabhängig angesehen, soll das nach Empfehlung C.8 in der EzU begründet werden. Nicht ganz klar ist, ob und wann eine Abweichung nach $\$ 161 \mathrm{AktG}$ erklärt und begründet werden muss. Nach Empfehlung C.6 kommt es auf die Einschätzung allein der Anteilseignerseite an, ${ }^{216}$ der empfohlen wird, die Indikatoren zu „berücksichtigen“. Tut sie das, und etwas anderes ist kaum vorstellbar, liegt hinsichtlich C.7 Abs. 2 keine Abweichung vom Kodex vor und es bedarf nur der Begründung in der EzU. Der Kodex zielt offenbar darauf ab, dass selbst dann keine begründete Abweichungserklärung abzugeben ist, wenn objektiv Umstände vorliegen, die einen Interessenkonflikt i.S.v. C.7 Abs. 1 Satz 2 begründen können, solange nur die Anteilseignerseite ihre Auffassung in der EzU begründet. Dies entzieht der Entsprechenserklärung Signalwirkung, ist für das Regelungsmodell Comply or Explain insgesamt misslich und ein Rückschritt gegenüber dem DCGK 2017. Ungewöhnlich ist, dass die DCGK-Kommission dazu ausdrücklich darauf hinweist, dass es für die Annahme von Unabhängigkeit trotz Vorliegens eines Indikators „durchaus gute Gründe geben“ kann. Wenn oben vermisst worden ist, dass auch in der Begründung des Kodex nicht von einer Abweichungskultur die Rede ist, ${ }^{217}$ so weist die Kommission jedenfalls für diesen speziellen Fall der Sache nach auf eine solche hin.

214 Begründung in Teil 1 II 2 Abs. 3.

215 Zur weiten Auslegung des Begriffs der unternehmerischen Entscheidung unter $\ 93$ Abs. 1 Satz 2 und Satz 1 näher Норт/Rотн, aaO (Fn. 22), $\$ 93$ AktG Rdn. 80ff, 116 f. Demgegenüber wird im Schrifttum zum Teil auf das objektive Vorliegen der Unabhängigkeit verwiesen; КосH, aaO (Fn. 3), $\$ 100$ AktG Rdn. 7; PAschos/Goslar, NZG 2012, 1361, 1364, aber misslich, da unsicher.

216 Empfehlung C.6 Abs. 1: "auf Anteilseignerseite eine nach deren Einschätzung angemessene Anzahl unabhängiger Mitglieder“.

217 Oben II. 1. b) aa). 


\section{ee) Mindestanzahl vom kontrollierenden Aktionär unabbängiger Aufsichtsratsmitglieder}

Während der DCGK 2020 für die Unabhängigkeit von der Gesellschaft und deren Vorstand eine Mehrheit von Unabhängigen vorsieht, will er für die Unabhängigkeit von einem kontrollierenden Aktionär, international ungewohnt ${ }^{218}$ und anders als die Empfehlung der Europäischen Kommission von $2005^{219}$ und die Leitlinien wichtiger Stimmrechtsberater, ${ }^{220}$ nach der Größe des Aufsichtsrats differenzieren: mindestens zwei Unabhängige in einem Aufsichtsrat mit mehr als sechs Mitgliedern, sonst mindestens einer. ${ }^{221}$ Die Empfehlung C.9 enthält sodann eine Positivdefinition der Unabhängigkeit, die von der für die Unabhängigkeit des Aufsichtsratsmitglieds oder eines nahen Familienangehörigen von der Gesellschaft und dem Vorstand ganz erheblich abweicht. Genannt werden die Eigenschaft als kontrollierender Aktionär (selbst oder Familienangehöriger) oder als Angehöriger des geschäftsführenden Organs desselben sowie eine persönliche oder geschäftliche Beziehung zum kontrollierenden Aktionär, die einen wesentlichen und nicht nur vorübergehenden Interessenkonflikt begründen kann. Anders als bei der Unabhängigkeit von der Gesellschaft und ihrem Vorstand gibt es keine zeitliche Vorerfassung von zwei Jahren und keine Erstreckung auf vom kontrollierenden Aktionär abhängige Unternehmen, eine bloß verantwortliche Funktion beim kontrollierenden Aktionär ohne Organeigenschaft ist nicht angesprochen und der wesentliche Interessenkonflikt wird nicht erfasst, wenn er nur vorübergehend ist. ${ }^{222}$ Mit diesen mindestens vier Aufweichungen läuft das Konzept der Unabhängigkeit vom kontrollierenden Aktionär

218 In Frankreich und Israel wird statt eines überwiegend unabhängigen board nur ein Drittel unabhängiger Direktoren verlangt, OECD Corporate Governance Factbook 2019, aaO (Fn. 47), Table 4.7, p. 147. In den USA braucht eine börsennotierte Gesellschaft, bei der eine Person mehr als 50 Prozent der Stimmrechte bei der Wahl der Direktoren hat, die Unabhängigkeitsregeln nicht zu befolgen, ebenda und M. Rотн, ZHR 175 (2011), 605, 630. Zum Ganzen Beвснuк/Hamdani, Independent Directors and Controlling Shareholders, University of Pennsylvania Law Review 165 (2017) 1271; Ferrarini/FilipPelli, Indepedent directors and controlling shareholders, in: Thomas/ Hill, eds., Research Handbook on Shareholder Power, 2015, p. 269.

219 Oben Fn. 176; dazu Leyens, aaO (Fn. 2), $\$ 161$ AktG Rdn. 113 und schon Leyens, aaO (Fn. 145), S. 45, 303, 316; LuTTER/BAYER/J. SCHMidT, Europäisches Unternehmens- und Kapitalmarktrecht, 6. Aufl., 2018, $\$ 13$ Rdn. 13.52 m.w. N.

220 Z.B. ISS, aaO (Fn. 105), p. 13, aber auch Differenzierung nach widely-held und nonwideley held companies, p. 8; Glass Lewis, 2019 Guidelines Germany, aaO (Fn. 98), p. 6, 11 .

221 Demgegenüber z. B. für Frankreich AFEP/MEDEF, Code de gouvernement d'entreprise des sociétés côtées, 2018, $\mathbb{\$} 8.3$ : au moins un tiers. Die (interne) Berufung auf das bei mehr Unabhängigen entstehende Übergewicht der Arbeitnehmerseite zieht dann nicht mehr, wenn diese (richtigerweise) als nicht unabhängig behandelt werden, dazu oben III. 2. b) bb).

222 Vgl. Empfehlung C.7 Abs. 2, 1. und 2. Spiegelstrich. 
in der Praxis, die sich leicht darauf einstellen kann, weitestgehend leer und verfehlt seinen Zweck. ${ }^{223}$ Insgesamt reicht diese Empfehlung deutlich weniger weit als international üblich und auch als von der Europäischen Kommission empfohlen. ${ }^{224}$ Immerhin gilt die Empfehlung C.8 nicht auch für C.9 und C.10, eine Begründung in der EzU reicht also nicht aus.

\section{ff) Funktionsbezogene Unabhängigkeit, ehemalige Vorstandsmitglieder und Verbältnis zu wesentlichen Wettbewerbern}

Die Empfehlungen C.10 bis C.12 ergänzen die Regeln zu den beiden zuvor unterschiedenen Unabhängigkeitsfallgruppen. Die Empfehlung C.10 behandelt die funktionsbezogene Unabhängigkeit. Die Vorsitzenden des Aufsichtsrats, des Prüfungsausschusses und des Vergütungsausschusses sollen unabhängig von Gesellschaft und Vorstand sein, der Vorsitzende des Prüfungsausschusses soll auch unabhängig vom kontrollierenden Aktionär sein. Für den Nominierungsausschuss verbleibt es bei den allgemeinen Unabhängigkeitsregeln. Internationale Empfehlungen gehen weiter. ${ }^{225}$ Nach Empfehlung C.11 sollen dem Aufsichtsrat nicht mehr als zwei ehemalige Vorstandsmitglieder angehören, ${ }^{226}$ eine Regelung, die, weil nicht wie international üblich in die Indikatorenliste aufgenommen, bei Abweichung zum Begründungszwang und nicht bloß zu C.8 und in die EzU führt.

De lege lata gibt es keine Inkompatibilität bei engen Beziehungen zu einem Wettbewerber. Versuche der Literatur, die Zulässigkeit solcher Beziehungen nach den allgemeinen Regeln einzuschränken, scheitern bereits an der Unbestimmtheit des Kriteriums der Konkurrenzsituation. ${ }^{227}$ Hier setzt die Empfehlung C.12 an.

223 Ebenso v. Werder, DB 2019, 1721, 1726.

224 OECD Corporate Governance Factbook 2019, aaO (Fn. 47), Table 4.7, p. 147. Vgl. Kriterienkatalog bei CalPERS, aaO (Fn. 45), p. 13, u. a. unter g): „Has not had any of the relationships described above with any parent or subsidiary of the Company.“ Nach Ziffer 13.1 der Empfehlung der Europäischen Kommission gilt ein Mitglied der Unternehmensleitung als unabhängig, wenn es in keiner geschäftlichen, familiären oder sonstigen Beziehung zur Gesellschaft, ihrem Mehrheitsaktionär oder deren Geschäftsführung steht, die einen Interessenkonflikt begründet, der sein Urteilsvermögen beeinflussen könnte; unter Hinweis auf den Fall Volkswagen Hорт/Rотн, aаO (Fn. 22), $\$ 100$ AktG Rdn. 174f, anders Koch, aaO (Fn. 3), $\$ 100$ AktG Rdn. 4: mit deutschen Grundvorstellungen unvereinbar.

225 Rechtsvergleichend Hopt, ZHR 175 (2011), 444, 472ff. Vgl. auch CalPERS, aaO (Fn. 45), p. 12: "Committees who perform the audit, director nomination and executive compensation functions should consist entirely of independent directors." Dabei ist aber die deutsche quasi-paritätische Mitbestimmung nicht berücksichtigt.

226 So schon DCGK 2017 Ziff. 5.4.2 Satz 3. Strenger Glass Lewis, 2019 Guidelines Germany, aaO (Fn. 98), und ISS, aaO (Fn. 105).

227 Dazu und zu weiteren Gründen Hopt/Roth, aaO (Fn. 22), $\$ 100$ AktG Rdn. 138; HABERSACK, aaO (Fn. 174), $\mathbb{1} 100$ AktG Rdn. 89. 
Danach sollen Aufsichtsratsmitglieder keine Organfunktion oder Beratungsaufgaben bei wesentlichen Wettbewerbern des Unternehmens (also konzernweit) ausüben und nicht in einer persönlichen Beziehung zu einem wesentlichen Wettbewerber (auch konzernweit zu verstehen) stehen. Die Empfehlung überzeugt als eine flexiblere, Abgrenzungsschwierigkeiten vermeidende Lösung.

\section{c) Wablen zum Aufsichtsrat}

Hierzu enthalten die Empfehlungen C.13-C.15 wie schon der DCGK $2017^{228}$ einige wichtige Regeln für die Offenlegung in Wahlvorschlägen zum Aufsichtsrat. Etwas kleinteilig wirkt die neu hinzugefügte Vorgabe, dass dem Kandidatenvorschlag ein Lebenslauf mit bestimmten Angaben beigefügt werden soll. Wie schon nach dem DCGK $2017^{229}$ soll die Wahl der Anteilsvertreter im Aufsichtsrat angesichts prominenter Gegenbeispiele bei deutschen DAX-Gesellschaften als Einzelwahl durchgeführt werden. ${ }^{230}$ Das erlaubt den Aktionären eine präzisere, zielgenaue Wahl ihrer Vertreter bei der Überwachung der Vorstände.

\section{Interessenkonflikte bei Vorstand und Aufsichtsrat (DCGK Teil 2 E)}

Die Interessenkonflikte werden getrennt von der Unabhängigkeitsfrage und erst nach ausführlicher Behandlung der Funktions- und Arbeitsweise des Aufsichtsrats und zudem für Vorstand und Aufsichtsrat gemeinsam behandelt, was angesichts des Zusammenhangs von Unabhängigkeit und Interessenkonflikten und auch international überrascht. ${ }^{231}$ Der Grundsatz 19 hält fest, dass Vorstands- und Aufsichtsratsmitglieder dem Unternehmensinteresse verpflichtet sind und bei ihren Entscheidungen weder persönliche Interessen verfolgen noch Geschäftschancen für sich nutzen dürfen. Das entspricht zwar $\$ \mathbb{S} 76,93$ AktG und der Rechtslage zu den Geschäftschancen, ${ }^{232}$ greift aber, wenn schon

228 DCGK 2017 Ziffer 5.4.1 Abs. 6-8. Dazu Hopt/Roth, aaO (Fn. 22), $\mathbb{1} 100$ AktG Rdn. 169.

229 DCGK 2017 Ziffer 5.4.3.

230 Ebenso Glass Lewis, 2019 Guidelines Germany, aaO (Fn. 98), p. 10 zum slate voting. Ähnlich ISS, aaO (Fn. 105), p. 8 zum bundling of proposals to elect directors, directors sind aber auch Vorstandsmitglieder.

231 Schon oben unter II. 2. b) Fn. 160, auch I. 3. b). Überzeugender DCGK 2017 Ziffer 4.3 für Vorstandsmitglieder und Ziffer 5.5 für Aufsichtsratsmitglieder, dort immerhin nach Zusammensetzung (mit Unabhängigkeit) und Vergütung, Ziffer 5.4. International z.B. CalPERs (Fn. 45), p. 12: "Independence also requires a lack of conflict between the director's personal, financial, or professional interests, and the interests of the shareholders."

232 Zur Geschäftschancenlehre (corporate opportunities) u. a. Норт/Rотн, aаO (Fn. 22), $\$ 93 \mathrm{AktG}$ Rdn. $250 \mathrm{ff}$ für Vorstandsmitglieder und $\$ 100 \mathrm{AktG}$ Rdn. 280 und $\$ 116$ 
mit einem eigenen Grundsatz die Gesetzeslage wiedergegeben werden soll, deutlich zu kurz. Die Treupflicht der Organmitglieder reicht weiter und der für die Behandlung von Interessenkonflikten maßgebliche Prioritätsgrundsatz beschränkt sich - in unterschiedlicher Reichweite für Vorstands- und für Aufsichtsratsmitglieder (Nebenamt) - nicht auf den Konflikt mit Eigeninteressen, sondern betrifft auch den Konflikt bei der Wahrnehmung von Interessen Dritter. ${ }^{233}$ Der Grundsatz 19 hätte deshalb richtigerweise die zutreffende Formulierung in DCGK 2017 Ziffer 4.3.2 mindestens der Sache nach beibehalten müssen. ${ }^{234}$ Dass die Interessenkonflikte beim Aufsichtsrat schon wegen der typischen Nebenberuflichkeit ganz anders liegen als beim Vorstand, reflektiert Grundsatz 19 ebenfalls nicht. Zutreffend wird hingegen im Hinblick auf $\ 88$ AktG festgestellt, dass nur Vorstandsmitglieder während ihrer Tätigkeit einem umfassenden Wettbewerbsverbot unterliegen.

Die Empfehlungen E.1 bis E.3 beginnen, merkwürdigerweise abweichend von Grundsatz 19, mit den Aufsichtsratsmitgliedern und fahren erst dann mit den Vorstandsmitgliedern fort. Inhaltlich entsprechen sie den Empfehlungen in DCGK 2017, so etwa Empfehlung E.1, dass jeweils erst der Aufsichtsratsvorsitzende und bei einem Vorstandsmitglied auch der Vorsitzende bzw. Sprecher des Vorstands informiert werden soll. ${ }^{235}$ Empfehlung E.1 Satz 3 besagt richtig, dass wesentliche und nicht nur vorübergehende Interessenkonflikte in der Person des Aufsichtsratsmitglieds zur Beendigung des Mandats führen sollen. ${ }^{236}$ Vorstandsmitglieder sollen, über $₫ 88$ Abs. 1 AktG zu den Wettbewerbsverboten und Vorstandsdoppelmandaten hinausgehend, Nebentätigkeiten, ins-

AktG Rdn. 163 für Aufsichtsratsmitglieder. $\mathrm{Zu}$ den Interessenkonflikten von Aufsichtsratsmitgliedern Норт/Roth, ebenda, $\mathbb{1} 100$ AktG Rdn. 267ff; НAbersack, aaO (Fn. 174), $\mathbb{1} 100$ AktG Rdn. 92 ff. Zum Ganzen Kumpan, Der Interessenkonflikt im deutschen Privatrecht, 2014.

233 Норт/Roth, aаO (Fn. 22), $\$ 93$ AktG Rdn. 224ff, $229 \mathrm{ff}$, und $\$ 116$ AktG Rdn. $142 \mathrm{ff}$, $144 \mathrm{ff}$.

234 DCGK 2017 Ziffer 4.3.2: "Vorstandsmitglieder und Mitarbeiter dürfen im Zusammenhang mit ihrer Tätigkeit weder für sich noch für andere Personen von Dritten ungerechtfertigte Vorteile fordern oder annehmen oder Dritten ungerechtfertigte Vorteile gewähren.“

235 Die Empfehlung E.2 formuliert, dass das konfligierte Vorstandsmitglied auch die anderen Vorstandsmitglieder informieren soll, während die Begründung dem widersprechend formuliert, dass es geboten, aber auch ausreichend ist, dass der Vorsitzende bzw. Sprecher unterrichtet wird und dieser nach pflichtgemäßem Ermessen entscheidet, ob und ggf. wann und wie die anderen Vorstandsmitglieder zu informieren sind. Besser wäre es gewesen, dies wie in E.1 für das konfligierte Aufsichtsratsmitglied in der Empfehlung selbst klarzustellen.

236 So aber schon de lege lata Hорт/Rотн, aaO (Fn. 22), \$100 AktG Rdn. 309, \$116 AktG Rdn. 177; zur Prävention und Repression von Interessenkonflikten Hopt, FS P. Doralt, 2004, S. 213. Der DCGK nimmt zu den Streitfragen bezüglich der Niederlegung und der Abberufung nach $\$ 103$ AktG zu Recht keine Stellung. 
besondere konzernfremde Aufsichtsratsmandate, nur mit Zustimmung des Aufsichtsrats übernehmen, so überzeugend Empfehlung E.3.

4. Funktions- und Arbeitsweise des Aufsichtsrats, insbesondere Zusammenarbeit mit dem Vorstand und Abschlussprüfer, Information, Ausschüsse (DCGK Teil 2 D)

\section{a) Zusammenarbeit mit dem Vorstand und Information}

In Abschnitt D über die Arbeitsweise des Aufsichtsrats ${ }^{237}$ fasst der Grundsatz 13 richtig die vertrauensvolle Zusammenarbeit von Vorstand und Aufsichtsrat zum Wohle des Unternehmens, die Wichtigkeit einer offenen Diskussion in und zwischen den beiden Organen und den Grundsatz einer umfassenden Wahrung der Vertraulichkeit zusammen. Der Grundsatz 15 beschreibt, $\mathbb{\$} 90$ AktG zusammenfassend, die Informationsversorgung als Aufgabe des Vorstands, aber auch als eigenverantwortliche Sache des Aufsichtsrats. ${ }^{238}$ Eine Informationsordnung kann, wie die DCGK-Kommission begründet, nützlich sein. Die Regierungsbegründung des KonTraG hat sie weitergehend als „sinnvoll und geboten“" angesehen. ${ }^{239}$ Der DCGK 2017 hatte dementsprechend empfohlen, dass der Aufsichtsrat die Informations- und Berichtspflichten des Vorstands näher festlegen soll. ${ }^{20}$ Dass die DCGK-Kommission diese Empfehlung zurückzieht, ist angesichts der zentralen Bedeutung der Information für die Überwachung durch den Aufsichtsrat und den Umgang mit den international nicht überall verstandenen Eigenheiten des zweistufigen Modells wenig überzeugend und auch nicht daraus zu rechtfertigen, dass die Informationsordnung als Arbeitsweise des Aufsichtsrats nach $\$ 289 \mathrm{f}$ Abs. 2 Nr. 3 HGB in der EzU offengelegt wird, aber eben nur wenn sie besteht. ${ }^{241}$ Grundsatz 16 adressiert den Aufsichtsratsvorsitzenden und wird durch Empfehlung D.6 ergänzt, wonach dieser mit dem Vorstandsvorsitzenden bzw. -sprecher regel-

237 Die Gliederung des Abschnitts ist unbefriedigend. Sie beginnt mit der Geschäftsordnung, springt vom Aufsichtsrat zum Vorstand und dann wieder zurück zum Aufsichtsrat und seinen Ausschüssen, geht wieder zum Vorstand mit der Informationsversorgung, behandelt dann Sitzungen und Beschlussfassung des Aufsichtsrats, fährt mit der Zusammenarbeit mit dem Abschlussprüfer fort und endet mit der Aus- und Fortbildung und Selbstbeurteilung.

238 Zur Information der Aktionäre und zum Investorendialog oben III. 1. b).

239 RegE KonTraG, BTDrucks. 13/9712, S. 15; für eine gesetzliche Regelung HommeLhoff/Mattheus, AG 1998, 249, 254.

240 DCGK 2017 Ziffer 3.4. Satz 3.

241 Ausführlich zur Informationsordnung Норт/Rотн, aaO (Fn. 22), $\mathbb{1 1 1}$ AktG Rdn. 137 ff. Positiv auch Habersack, aaO (Fn. 174), $\mathbb{1 1 1}$ AktG Rdn. 80; LeYens, aaO (Fn. 145), S. $145 \mathrm{ff}$ mit Formulierungsvorschlag zum DCGK, S. 435. 
mäßig Kontakt halten und mit ihm Fragen der Strategie, der Geschäftsentwicklung, der Risikolage, des Risikomanagements und der Compliance des Unternehmens beraten soll. Zur vorstandsunabhängigen Information ${ }^{242}$ schweigt der Kodex anders als etwa CalPERS. ${ }^{243}$ Über das hinaus, was Grundsatz 16 für den Aufsichtsratsvorsitzenden schon als de lege lata verbindlich bezeichnet, ist zu Stellung, Funktion und Aufgaben des Aufsichtsratsvorsitzenden nichts weiter gesagt, obschon dies in $\$ 107 \mathrm{AktG}$ nur ganz ansatzweise geregelt ist, hier wäre mehr möglich und sinnvoll gewesen. ${ }^{244}$ Auch die mittlerweile ganz überwiegend anerkannte und in größeren Gesellschaften geübte Praxis eines Aufsichtsratsbüros ${ }^{245}$ hätte angesprochen werden können. ${ }^{246}$

\section{b) Ausschüsse, insbesondere Prüfungsausschuss}

Grundsatz 14 resümiert $\ 107$ Abs. 3 und 4 AktG derart, die Bildung von Ausschüssen fördere bei größeren Gesellschaften regelmäßig die Wirksamkeit der Arbeit des Aufsichtsrats. Das ist sicher richtig, auch wenn es jedenfalls so nicht im Gesetz steht. Man mag sich auch fragen, was „größere Gesellschaften“ sind. Vier Empfehlungen D.2 bis D.5 folgen. Die allgemeine Empfehlung zur Ausschussbildung betont zutreffend, dass die spezifischen Gegebenheiten des Unternehmens und die Anzahl der Aufsichtsratsmitglieder zu berücksichtigen sind. Dass die Ausschüsse „fachlich qualifiziert“ sein sollen, versteht sich von selbst. Die namentliche Nennung von Ausschussmitgliedern und Ausschussvorsitzenden in der EzU fördert die Transparenz. International werden heute, mit Ausnahmen für kleinere Gesellschaften, als gute Corporate Governance

242 M.w. N. Hopt, ZGR 2019, 507, 529ff. Positiv auch Habersack, aaO (Fn. 174), $\ 111$ AktG Rdn. 79. Zuletzt Kort, FS E. Vetter, 2019, S. 341.

243 CalPERS, aaO (Fn. 45), p. 11: 2. Informed Directors, a. Board Access to Management: "The board should have a process by which all directors can have access to senior management.” Auch OECD Corporate Governance Factbook 2019, aaO (Fn. 47), p. 54: Verbesserung durch Zugang der non-executive board members „to certain key managers within the company”, z.B. internal auditor, chief risk officer.

244 Vgl. demgegenüber z. B. UK Corporate Governance Code 2018, aaO (Fn. 30), Principle F, Provision 9 und ausführlich Guidance on Board Effectiveness, July 2018, 61. Siehe weiter The Dutch Corporate Goverance Code 2016, 2.3.6; CalPERS, aaO (Fn. 45), p. 12 et seq. ausführlich zur Board Chairman Leadership und den entsprechenden Aufgaben. Dazu umfassend Норт/Roth, aaO (Fn. 22), \111 AktG Rdn. 84212, zum privatautonomen Regelungsspielraum Rdn. 171-195. Auch Habersack, aaO (Fn. 174), $\ 107$ AktG Rdn. $44 \mathrm{ff}$.

245 Näher Норт/Roth, aaO (Fn. 22), $\mathbb{1} 111$ AktG Rdn. 803 ff, aber auch Rdn. 530; LeYens, $\mathrm{aaO}$ (Fn. 145), S. 366.

246 Sogar für ein Budgetrecht des Aufsichtsrats Theisen, AG 2018, 589; dazu auch Bulgrin, AG 2019, 101; Schnorbus/Ganzer, BB 2019, 258, 266 ff. Zuletzt Strohn, FS K. Schmidt, 2019, Bd. II, S. 461. 
ein Nominierungsausschuss, ein Vergütungsausschuss und ein Prüfungsausschuss verlangt. Letzterer ist in $₫ 107$ Abs. 3 AktG samt seinen Aufgaben näher geregelt und ist Gegenstand der Empfehlungen D.3 und D.4, dazu sogleich. Empfehlung D.5 sieht nicht unproblematisch einen ausschließlich mit Vertretern der Anteilseigner besetzten Nominierungsausschuss vor. ${ }^{27}$ Von inhaltlichen Vorgaben zum Vergütungsausschuss ${ }^{248}$ sieht das Gesetz ab, verlangt aber bei Bestehen des Ausschusses nach $\$ 87 a$ Abs. 1 Satz 2 Nr. 10 AktG i.d.F. ARUG II Angaben zur Einbindung in das Verfahren der Vergütungsüberprüfung. Der DCGK 2020 erwähnt den Vergütungsausschuss immerhin in Empfehlung C.10 und geht offenbar von seiner Einrichtung aus. Eine Empfehlung zur Einrichtung des Ausschusses, eventuell abgestuft, hätte angesichts der Wichtigkeit und Komplexität der Vorstandsvergütung nahegelegen. ${ }^{249}$ Zur Bildung und zu den Aufgaben von Ausschüssen allgemein (Prüfungs-, Nominierungs-, Vergütungsausschuss) sagt der DCGK damit (zu) wenig, auch wenn dazu in der EzU zu berichten ist. ${ }^{250}$

Die Einrichtung eines Prüfungsausschusses, der besonders wichtig ist ${ }^{251}$, sieht Empfehlung D.3 vor ${ }^{252}$, und zählt auch sodann die verschiedenen Aufgaben auf, insbesondere Prüfung der Rechnungslegung, der Überwachung des Rechnungslegungsprozesses, der Wirksamkeit des internen Kontrollsystems, des Risikomanagementsystems und des internen Revisionssystems sowie der Abschlussprüfung und der Compliance. ${ }^{253}$ Die Empfehlung D.3 Satz 2 definiert

247 Anders $\$ 25 \mathrm{~d}$ Abs. $11 \mathrm{KWG}$ für CRR-Institute: „aus seiner Mitte“, dazu HenNing/ Gissing, AG 2018, 925, 934. Zum Nominierungsausschuss allgemein und zu den Streitfragen um die Besetzung ohne Arbeitnehmervertreter Норт/Rотн, aаO (Fn. 22), $\$ 100$ AktG Rdn. 568 ff, 577. Sehr weitgehend UK Corporate Governance Code 2018, aaO (Fn. 30), Provision 20: „Open advertising and/or an external search consultancy should generally be used for the appointment of the chair and non-executive directors.", dies mit Berichtspflichten im Jahresbericht.

248 Zum Personal- bzw. Vergütungsausschuss Норт/Rотн, аaO (Fn. 22), \100 AktG Rdn. $579 \mathrm{ff}$. Vergütungsausschüsse sind in Deutschland weniger üblich als in anderen europäischen Ländern, Glass Lewis, 2019 Guidelines Germany, aaO (Fn. 98), p. 10. Für CRR-Institute $₫ 25 \mathrm{~d}$ Abs. $12 \mathrm{KWG}$.

249 ISS, aaO (Fn. 105), p. 20 als eines von Five Global Principles: 4. Maintain an independent and effective compensation committee, näher p. 21; auch Österreichischer Corporate Governance Kodex, aaO (Fn. 56), C 43; UK Corporate Governance Code 2018, aaO (Fn. 30), Provisions 32 et seq., ausführliche Angaben über die Arbeit des Vergütungsausschusses nach Provision 41.

250 Demgegenüber mit detaillierten Empfehlungen zum Audit Committee, Nomination Committee und Compensation Committee z.B. CalPERS, aaO (Fn. 45), p. 17 et seq.

251 Ausführlich zum Prüfungsausschuss Норт/Rotн, aaO (Fn. 22), \107 AktG Rdn. 498567.

252 Nur „soweit kein anderer Ausschuss oder das Plenum damit betraut ist“.

253 Vgl. zu den Aufgaben des audit committee detaillierter UK Corporate Governance Code 2018, aaO (Fn. 30), Provision 25. 
den Umfang der Rechnungslegung (einschließlich CSR-Berichterstattung). Nach der wichtigen Empfehlung D.4 soll der Vorsitzende besondere Kenntnisse und Erfahrungen in der Anwendung von Rechnungslegungsgrundsätzen und internen Kontrollverfahren haben und mit der Abschlussprüfung vertraut sein. Das geht sehr zu Recht deutlich über die Vorgaben des $\ 100 \mathrm{Abs} .5 \mathrm{AktG}$ für kapitalmarktorientierte Gesellschaften und besondere Kreditinstitute und andere Finanzmarktinstitute hinaus. Dort muss mindestens ein Mitglied des Aufsichtsrats über Sachverstand auf den Gebieten Rechnungslegung oder Abschlussprüfung haben. Tatsächlich müsste und wird in der Regel beides oder keines von beiden vorliegen, jedenfalls war die frühere kumulative Regelung besser. ${ }^{254} \$ 100$ Abs. 5 AktG verlangt auch keine Unabhängigkeit mehr, eine problematische und international schwer vermittelbare deutsche Reform. ${ }^{255}$ Umso wichtiger ist, dass die Empfehlung D.4 Unabhängigkeit voraussetzt und überdies empfiehlt, dass der Aufsichtsratsvorsitzende nicht zugleich den Vorsitz im Prüfungsausschuss innehaben soll. Was Unabhängigkeit hier bedeutet, wird nicht gesagt, ergibt sich aber - aufbaumäßig wenig transparent - aus der Empfehlung C.10 Satz 2, ${ }^{256}$ wonach der Vorsitzende des Prüfungsausschusses in beiderlei Hinsicht unabhängig sein soll, von der Gesellschaft und dem Vorstand und auch vom kontrollierenden Aktionär. Das ist sachlich richtig, aber bleibt hinter den internationalen Standards guter Corporate Governance zurück, die eine zumindest überwiegende, möglichst sogar vollständig unabhängige Besetzung des Prüfungsausschusses vorsehen. ${ }^{257}$

\section{c) Zusammenarbeit mit dem Abschlussprüfer}

Der Abschnitt D. III. über die Zusammenarbeit mit dem Abschlussprüfer ist gegenüber dem DCGK 2017 deutlich verschlankt und hinsichlich der Empfehlungen zurückgenommen, was im internationalen Vergleich überrascht. ${ }^{258}$ Neben anderen Empfehlungen sind insbesondere Empfehlungen, die vom IDW Prüfungsstandard PS 345 ausführlich behandelt werden, weggefallen. ${ }^{259}$

254 Норт/Rотн, aaO (Fn. 22), $\mathbb{1} 100$ AktG Rdn. 231 ff, allgemeiner zum Finanzexperten nach $\$ 100$ Abs. 5 AktG ebenda, $\$ 100$ AktG Rdn. $231 \mathrm{ff}$.

255 Schon oben III. 2. b) am Anfang bei Fn. 174.

256 Formal zeigt sich hier wiederum eine Schwäche der Gliederung und mangels Verweisung auch eine solche der Transparenz.

257 Норт/Roth, aаO (Fn. 22), $\$ 107$ AktG Rdn. 514 ff. Zur Frage der Unabhängigkeit auch vom kontrollierenden Aktionär schon oben III. 2. ee).

258 Allein am Vorhandensein gesetzlicher Regelungen kann das nicht liegen, weil das Abschlussprüferrecht weitgehend EU-einheitlich ist.

259 So die Abgabe der Unabhängigkeitserklärung nach DCGK 2017 Ziffer 7.2.1 und die auftragsgemäße Erweiterung der Berichtspflichten nach Ziffer 7.2.3. Vgl. IDW Prü- 
Empfehlungen an den Aufsichtsrat für die Zusammenarbeit mit dem Abschlussprüfer wie in den meisten Leitlinien von Stimmrechtsberatern ${ }^{260}$ fehlen ganz. Grundsatz 17 betont die Aufgabe des Abschlussprüfers, den Aufsichtsrat bzw. den Prüfungsausschuss bei der Überwachung der Geschäftsführung zu unterstützen, und benennt die Informationsfunktion der Abschlussprüfung für den Kapitalmarkt. Die Empfehlungen D.9 und D.10 betreffen, wie schon nach DCGK 2017, zusätzliche Informationsvereinbarungen mit dem Abschlussprüfer. ${ }^{21}$ Die Empfehlung D.11, wonach der Prüfungsausschuss regelmäßig eine Beurteilung der Qualität der Abschlussprüfung vornehmen soll, ${ }^{262}$ ergänzt $\$ 107$ Abs. 3 Satz 2 AktG, wonach sich der Prüfungsausschuss, wenn ein solcher bestellt ist, unter anderem ${ }^{263}$ auch mit der Überwachung der Abschlussprüfung, hier insbesondere der Auswahl und der Unabhängigkeit des Abschlussprüfers und der vom Abschlussprüfer zusätzlich erbrachten und aus Sicht der Vermeidung von Interessenkonflikten möglicherweise gefährlichen Leistungen, ${ }^{264}$ befasst. ${ }^{265}$

\section{d) Geschäftsordnung, Sitzungen und Beschlussfassung, Aus- und Fortbildung, Selbstbeurteilung}

Empfehlung D.1 sieht wie schon der DCGK 2017 und weithin üblich eine Geschäftsordnung des Aufsichtsrats vor, die auch auf der Internetseite der Gesellschaft zugänglich gemacht werden soll. Nach Empfehlung D.7 zu Sitzungen und Beschlussfassung soll der Aufsichtsrat regelmäßig auch ohne den Vorstand tagen. ${ }^{266}$ Das ist der Überwachungsaufgabe des Aufsichtsrats zuträglich und ist gegenüber DCGK 2017 Ziffer 3.6, wo nur von „bei Bedarf“ die Rede war, eine klare

fungsstandard: Auswirkungen des Deutschen Corporate Governance Kodex auf die Abschlussprüfung (IDW PS 345), Stand 10.7.2017, unter Ziffern 4 und 5.

260 Tabelle Audit Committee Quarterly IV/2018, 16.

261 Die Empfehlungen D.9 und D.10 entsprechen denen des DCGK 2017 Ziffer 7.2.3 Abs. 1 und 2.

262 IDW PS 345; wichtig ist dazu ISA 720 zur EzU (prüferische Durchsicht), dazu Arbeitskreis Corporate Governance Reporting der Schmalenbach-Gesellschaft für Betriebswirtschaft e.V., DB 2016, 2130, 2018, 2125.

263 Ausführlich wiedergegeben in Empfehlung D.3, oben III. 4. b).

264 Leyens, aaO (Fn. 81), S. $617 \mathrm{ff}$.

265 Dazu Hopt/Roth, aaO (Fn. 22), $\mathbb{} 107$ AktG Rdn. 534f; Gundel/Lanfermann, WPPraxis 2019, 187. Zur Beurteilung der Qualität der Abschlussprüfung bemerkt die Begründung, dass sich die Beurteilung auf die Würdigung objektiv beurteilbarer Indikatoren (sog. Audit Quality Indicators) und, soweit verfügbar, auf Ergebnisse der Inspektion durch die Abschlussprüferaufsicht beschränkt.

266 Das Gesetz besagt dazu nichts, Норт/Rотн, aaO (Fn. 22), $\$ 107$ AktG Rdn. 453 ff, 455 am Ende. 
Verbesserung. ${ }^{267}$ Eine Verbesserung enthält auch Empfehlung D.8, wonach im Bericht des Aufsichtsrats angegeben werden soll, an wie vielen Sitzungen von Aufsichtsrat und Ausschüssen die einzelnen Mitglieder jeweils teilgenommen haben, was auch international empfohlen wird. ${ }^{268}$ Die Begründung hält zutreffend eine umfassende Offenlegung der individuellen Sitzungsteilnahmen für besser als die Transparenzschwelle von $50 \%$ wie im DCGK 2017 Ziffer 5.4.7, auch die institutionellen Investoren bestehen heute darauf. Dass auch eine Teilnahme über Telefon- oder Videokonferenz zählt, ist völlig in Ordnung, „sollte“ aber nicht die Regel sein, die Kommission traut sich hier nur eine Anregung, eine Empfehlung wäre mutiger gewesen. Der Selbstbehalt bei der D\&O-Versicherung auch für den Aufsichtsrat nach DCGK 2017Ziffer 3.8 ist gestrichen worden, intern wird das nicht ganz ohne Grund mit der Möglichkeit der Eigenversicherung des Selbstbehalts, unter Umständen aus erhöhten Bezügen, gerechtfertigt. International interessante, aber wegen möglicher Nebenwirkungen nicht ganz unproblematische Empfehlungen wollen, dass bei verbleibenden Meinungsverschiedenheiten diese im Sitzungsprotokoll festgehalten werden. ${ }^{269}$

$\mathrm{Zu}$ Aus- und Fortbildung, die nach der lex lata bisher Sache der Aufsichtsratsmitglieder selbst ist, ${ }^{270}$ geht die Empfehlung D.12 zu Recht, wenngleich nur sehr zögerlich, ${ }^{271}$ weiter. Die Gesellschaft soll die Mitglieder des Aufsichtsrats bei ihrer Amtseinführung sowie Aus- und Fortbildungsmaßnahmen angemessen unterstützen und darüber im Bericht des Aufsichtsrats berichten. Dies fordert auch das neuere Schrifttum. ${ }^{272}$ Finanzinstitute ${ }^{273}$ müssen nach $\mathbb{2} 25 \mathrm{~d}$

267 Anspruchsvoller CalPERS, aaO (Fn. 45), p. 12: mindestens einmal pro Jahr, unter Leitung des unabhängigen board chair oder lead independent director. Dazu schon LeYENS, aaO (Fn. 145), S. 435 ff Nr. 4.

268 Becker/v. Werder, AG 2016, 761, 769. CalPERS, aaO (Fn. 45), p. 11 ist strenger: mindestens $75 \%$ ige Teilnahme.

269 UK Corporate Governance Code 2018, aaO (Fn. 30), Provision 8: concerns about the operation of the board or the management of the company that cannot be resolved. Auch AFEP/MEDEF, Code de gouvernement d'entreprise des sociétés côtées, 2018, $\$ 10.4$. Das könnte allerdings dazu führen, dass Meinungsverschiedenheiten nicht mehr so offen diskutiert werden oder zur Vermeidung von Haftung stets ein Widerspruch zu Protokoll gegeben wird. Im UK führt nicht der Vorsitzende, sondern der unabhängige company secretary das Sitzungsprotokoll. Vergleichend Leyens, aaO (Fn. 145), S. 95 ff, $254 \mathrm{ff}, 437 \mathrm{Nr} .15$.

270 So Grundsatz 18.

271 Deutlicher der Swiss Code (Fn. 53) Ziffer 13 S. 11: „Der Verwaltungsrat sorgt für eine aufgabenbezogene Einführung neu gewählter Mitlgieder und eine zweckmässige Weiterbildung. “ Zum Verhältnis Verwaltungsrat/Aufsichtsrat in der Schweiz HopT, ZGR 2019, 507, 517.

272 Норт/Roth, aаO (Fn. 22), $\mathbb{} 113$ AktG Rdn. 114 ff; Косн, aаO (Fn. 3), $\$ 113$ AktG Rdn. 2e.

273 Genauer in $\$ 25 \mathrm{~d}$ Abs. $4 \mathrm{KWG}$; ähnlich auch für die Versicherungswirtschaft, KocH, $\mathrm{aaO}$ (Fn. 3), $\$ 113$ AktG Rdn. 2e. 
Abs. 4 KWG angemessene personelle und finanzielle Ressourcen einsetzen, um Aufsichtsratsmitgliedern die Einführung in ihr Amt zu erleichtern und die Fortbildung zu ermöglichen, die zur Aufrechterhaltung der erforderlichen Sachkunde notwendig ist. ${ }^{274}$ Teilweise wird dazu eine Ausstrahlungswirkung auch auf Nichtfinanzinstitute befürwortet, jedenfalls aber für Fortbildungsmaßnahmen eine stärkere Inpflichtnahme der Gesellschaft als bisher befürwortet. ${ }^{275}$ Das entspricht auch für Nichtfinanzinstitute europäischen und internationalen Standards. ${ }^{276}$ So empfiehlt beispielsweise CalPERS den Gesellschaften eine förmliche Einführung für alle neuen Direktoren und die Ermöglichung regelmäßiger Auffrischung ihrer Fähigkeiten und Kenntnisse. ${ }^{277}$

Die Empfehlung D.13 zur Selbstbeurteilung vermeidet den Ausdruck Effizienzprüfung wie in DCGK 2017 Ziff. 5.6 und sieht eine regelmäßige Selbstbeurteilung (Selbstevaluation) des Aufsichtsrats insgesamt und seiner Ausschüsse vor. Darüber soll in der EzU berichtet werden. ${ }^{278}$ Eine Beurteilung auch der einzelnen Aufsichtsratsmitglieder ist, obschon durchaus sinnvoll, nicht vorgesehen. ${ }^{279}$ Vor allem hatte noch der DCGK-E 2018 empfohlen, im Abstand von höchstens drei Jahren die Selbstbeurteilung extern unterstützen zu lassen. ${ }^{280}$ Dass die Kommission sich von der Kritik, man könne das schon selbst und brauche keine externe Beratungsindustrie, ${ }^{281}$ hat beeindrucken lassen, ist bedauerlich. Internationalen Erwartungen entspricht eher eine Fremdbeurteilung mindestens alle drei Jahre. ${ }^{282}$ Auch Mittellösungen wären denkbar gewesen. ${ }^{283}$ Eine

274 Dazu Binder, ZGR 2018, 88, $113 \mathrm{ff}$.

$275 \mathrm{Koch}, \mathrm{aaO}$ (Fn. 3), $\mathbb{1} 13$ AktG Rdn. 2e; vgl. auch Leyendecker-Langner/HuthmaCHER, NZG 2012, 1415, $1416 f$.

276 Rechtsvergleichend Becker/v. Werder, AG 2016, 761, 766f; Hopt/Roth, aaO

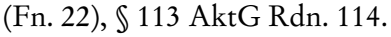

277 CalPERS, aaO (Fn. 45), p. 11.

278 Dazu unten V. 1.

279 Demgegenüber CalPERS, aaO (Fn. 45), p. 16; Норт/Rотн, aаO (Fn. 22), $\$ 111$ AktG Rdn. 223. So für Frankreich, Italien, Großbritannien und die USA BECKER/v. Werder, AG 2016, 761, 768; SеIвт, DB 2003, 2107, 2109. Dass die Ergebnisse vertraulich sein sollen, wird von der Begründung zu Recht hervorgehoben.

280 DCGK-E 2018 Ziff. A.15 Satz 2. Richtige Begründung bei Nonnenmacher, Der Aufsichtsrat 1/2019, 11.

281 Polemisch Kley, aaO (Fn. 8), S. 31: neue Kostentreiber, Horden von Trittbrettfahrern.

282 Z.B. für Frankreich AFEP/MEDEF, Code de gouvernement d'entreprise des sociétés côtées, 2018, \$ 9.3; UK Corporate Governance Code 2018, aaO (Fn. 30), Provision 21: "The chair should consider having a regular externally facilitated board evaluation. In FTSE 350 companies this should happen at least every three years." Näher Hopt/ Roth, aaO (Fn. 22), $\$ 111$ AktG Rdn. $221 \mathrm{ff}$. Viel weitergehend BAInbridge/HenderSEN, Outsourcing the Board, Cambridge 2018. Demgegenüber die Streichung begrüßend BDI-Reihe Wirtschaftsrecht, Ausgabe 2/2019, S. 7.

283 VGR, aaO (Fn. 19), III 3: z. B. externe Unterstützung auf Wunsch eines Aufsichtsratsmitglieds oder Beschlussfassung darüber alle drei Jahre. 
proaktive deutsche Haltung wäre sicher besser als darauf zu warten, bis die internationalen Stimmrechtsberater und Investoren das in den Hauptversammlungen durchsetzen.

\section{Die Vergütung von Vorstand und Aufsichtsrat}

\section{Vergütung des Vorstands (DCGK Teil 2 G I)}

Die meiste Kritik am DCGK-E 2018, vor allem die der nationalen und internationalen Investoren, Stimmrechtsberater und ihrer Verbände bzw. Dachorganisationen, richtete sich gegen die Vorschläge zur Vorstandsvergütung. ${ }^{284}$ Kritik kam auch aus dem Arbeitskreis Leitlinien für eine nachhaltige Vorstandsvergütung. ${ }^{285}$ Besonders die Corporate Governance Leitlinien der Stimmrechtsberater und institutionellen Investoren enthalten detaillierte Regeln zur Vergütung. ${ }^{286}$ Der DCGK 2020 versucht, dem Rechnung zu tragen. Der letzte Teil des DCGK 2020 G. behandelt beides, Vergütung von Vorstand und Aufsichtsrat, fasst die Gesetzeslage nach dem ARUG II $^{287}$ jeweils in einem knappen Grundsatz 23 und 24 zusammen, bringt dazu 18 Empfehlungen und Anregungen, 16 für den Vorstand und zwei für den Aufsichtsrat, und schließt mit einem Hinweis auf den Vergütungsbericht beider Organe ohne weitere Empfehlung zur Gestaltung des Berichts. ${ }^{288}$ Dabei fällt auf, dass der Kodex zur Vergütung bei weitem die meisten Empfehlungen aufweist, deutlich mehr als zum zweiten großen Reformanliegen, der Unabhängigkeit von Aufsichtsratsmitgliedern. Das entspricht der scharfen Kritik der Öffentlichkeit an überzogenen Vorstands-

284 Die diesbezüglichen Stellungnahmen der Kapitalmarktakteure zusammenfassend KRAMARSCh/Siepmann/DörRwÄChter, Der Aufsichtsrat 2019, 66. Grundsätzlich positiv aber z.B. Böcking/Bunde/Schmidt/Wagner, DB 2019, 137.

285 Oben Fn. 102. Ausführlich angesprochen in Glass Lewis, 2019 Guidelines Germany, aaO (Fn. 98), p. 1 f.

286 ISS, aaO (Fn. 105), Compensation Guidelines, p. 20-24; Glass Lewis, 2019 Guidelines Germany, aaO (Fn. 98), p. 13-15; CalPERS, aaO (Fn. 45), The Link Between Pay and Performance, p. 21-28: Executive, Director, and Employee Compensation.

$287 \int \mathbb{\int}$ 87, 87 a und 120a AktG für Vorstandsmitglieder und $\$ 113$ AktG für Aufsichtsratsmitglieder, speziell für börsennotierte Gesellschaften $\$ \int 87$ Abs. 1 Satz 2, 87a, 120a und 113 Abs. 3 AktG jeweils i.d.F. ARUG II; LÖBBE/FISCHBACH, AG 2019, 373; zum RefE BACHMANn/Pauschinger, ZIP 2019, 1; BAYer, DB 2018, 3034. Weitere flankierende Regelungen bei Koch, aaO (Fn. 3), $\$ 87$ AktG Rdn. 1. Zu Sonderregeln für den Finanzdienstleis-

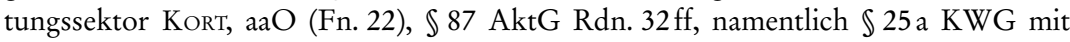
InstitutsvergütungsVO samt Auslegungshilfe der BaFin, 15.2.2018; ANZINGER, ZGR 2019, 39; HerZ, NZG 2018, 1050 und EuZW 2019, 60, 63, und \$S 23 ff, 25 VAG.

288 Dazu auch die Allgemeinen Erläuterungen Teil 1 (4) und II 3. Die Frage der Einrichtung eines Vergütungsausschusses kommt zu kurz, dazu schon oben III. 4. b). 
bezügen ${ }^{289}$ und der Reaktion des Gesetzesgebers darauf mit dem ARUG II. Um Besorgnis und Kritik an diesem großen Empfehlungspaket abzumildern, betont die Kommission gleich zu Eingang zutreffend, dass die Empfehlungen nicht für laufende Vorstandsverträge gelten und erst bei Verlängerung derselben einschlägig werden. ${ }^{290}$ Bei der Beurteilung der Vergütungsregeln des DCGK 2020 ist vor allem zu beachten, dass die Vergütungspraxis und ihre Regulierung international und national enorme Unterschiede aufweisen, ${ }^{291}$ was einheitliche Regeln erheblich erschwert.

Der DCGK gliedert seine Empfehlungen und Anregungen in fünf Schritte: Festlegung des Vergütungssystems, Festlegung der konkreten Gesamtvergütung, Festsetzung der Höhe der variablen Vergütungsbestandteile, Leistungen bei Vertragsbeendigung und sonstige Regelungen.

\section{a) Zielsetzung und inhaltliche Neufassung}

Die DCGK-Kommission sieht als Ziel der Vergütungsregelung, ${ }^{292}$ richtige Anreize für das Vorstandshandeln zu schaffen, mit angemessener Vergütung auf gesellschaftliche Akzeptanz zu achten und klar und verständlich zu erklären, wieviel das einzelne Vorstandsmitglied erhält und wofür die Vergütung gewährt wird. Das Konzept folgt nach der Kommission einem Top-Down-Ansatz. Neben einer Ziel-Gesamtvergütung bei hundertprozentiger Zielerreichung steht eine Maximalvergütung (Gesamt-Cap), ${ }^{293}$ beides soll im Peer Group-Vergleich

289 Aufgenommen schon in der Begründung zu Abs. 2 der Präambel, die ausdrücklich die gesellschaftliche Verantwortung für die Akzeptanz der Vorstandsvergütung in der Öffentlichkeit anspricht.

290 Das versteht sich von selbst, STOLL, NZR 2014, 48 ff; Kort, aaO (Fn. 22) $\mathbb{\$} 87$ AktG Rdn. 530; КосH, aaO (Fn. 3), $₫ 87$ AktG Rdn. 17 a.E.

291 Seyfahrt, Vorstandsrecht, 2016, 55 V Rdn. 86-153; Allen \& Overy, Analyse der Vorstands- und Aufsichtsratsgehälter der DAX-30-Unternehmen 2017, 2018, trotz Standardisierung zum Teil erhebliche Unterschiede in den Systemen; PWC, Vergütungsstudie 2018; für 2014-2017 Böcking U. A., Der Konzern 2019, 15. International Randall/Hill, eds., Research Handbook on Executive Practice, 2012; Ferrarini/Ungureanu, Executive Remuneration. A Comparative Overview, ECGI Law Working Paper No. 268/2014. Rechtsvergleichend auch FleIscher, aaO (Fn. 3), $\$ 87$ AktG Rdn. 7 ff; DERs., RIW 2010, 497.

292 Dazu Allgemeine Erläuterungen Teil 1 (4) und Teil 1 II 3.

293 Diese Höchstgrenze bezieht sich auf die gesamte Vergütung (Gesamt-Cap), weitere Caps hinsichtlich einzelner Bestandteile wie offenbar noch nach DCGK 2017 Ziffer 4.2.3 Abs. 2 Satz 6 sind nicht vorgesehen und haben in der Praxis auch zu Schwierigkeiten vor allem bei Nebenleistungen geführt, $\mathrm{KocH}, \mathrm{aaO}$ (Fn. 3), $\$ 87$ AktG Rdn. 17 m. w. N. Aber ISS, aaO (Fn. 105), p. 21: „1.3.1. Any short- or long-term compensation component must include a maximum award limit." CalPERS, aaO (Fn. 45), p. 22: nicht nur Cap nach oben, sondern auch Grenze nach unten. 
und im Vergleich zur Vergütung der Führungskräfte und der Belegschaft auch der Öffentlichkeit vermittelbar sein. ${ }^{294}$ Das Vergütungssystem umfasst neben fixen Komponenten (wie insbesondere Festgehalt, ${ }^{295}$ Ruhestands- und Altersvorsorge ${ }^{296}$ sowie Nebenleistungen ${ }^{297}$ ) auch variable Komponenten ${ }^{298}$. Mit der leistungsabhängigen, kurz- und langfristigen Komponente wird der wesentliche materielle Anreiz als Motivation ex ante und Belohnung ex post gesetzt, um die Ziele der Geschäftspolitik zu verfolgen. Die Kommission ist sich bewusst, dass die Zielerreichung nicht unbedingt exakt messbar ist, sie muss aber auf jeden Fall verifizierbar sein, was bei kurzfristiger variabler Vergütung vor allem mit operativen Metriken und bei der langfristigen variablen Vergütung mit den Erfolgen in der Umsetzung der Unternehmensstrategie messbar sein soll. ${ }^{299}$ Die langfristig variablen Vergütungsbeiträge sollen überwiegend in Aktien der Gesellschaft angelegt oder von der Gesellschaft aktienbasiert gewährt werden. Soweit die Zielsetzung und kurze Zusammenfassung der Vorstandsvergütungsregeln des Kodex, nunmehr im Einzelnen.

294 Empfehlungen G.3, G. 4.

295 Die Festvergütung der DAX-Vorstände machte 2018 32,9 \% der Vergütung (ohne Pensionszusagen) aus, Boni 36,7 \%, DSW-Vorstandsvergütungsstudie 2019, FriedL, Pressekonferenz 11.6.2019. Zur Frage einer reinen Festvergütung unten IV. 1. b) a.E.

296 Versorgungszusagen waren im DCGK 2017 Ziffer 4.2.3 Abs. 3 noch ausdrücklich angesprochen. Jedoch gelten dafür die allgemeinen Regeln: $₫ 87$ Abs. 1 Satz 4 AktG verweist auf $₫ 87$ Abs. 1. Satz 1 AktG und $₫ 87$ Abs. 2 Satz 2 AktG restringiert die Möglichkeit von Herabsetzungen nach $₫ 87$ Abs. 2 Satz 1 AktG. Zur Angemessenheit von Versorgungszusagen und zum Abschluss der Vergütungszusage als allein maßgeblicher

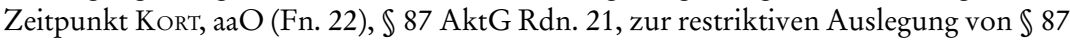
Abs. 2 Satz 2 AktG ebenda Rdn. 28. Kritisch gegen Pensionszahlungen an Vorstände überhaupt TüNGLER, DSW-Vorstandsvergütungsstudie 2019, DSW-Pressekonferenz 11.6.2019; in der Praxis Tendenzen dazu, aber noch kein Trend, PWC, Vergütungsstudie 2018, S. 26; BöCKING U.A., Der Konzern 2019, 15, 20. Vgl. auch UK Corporate Governance Code 2018, aaO (Fn. 30), Provision 38: Only basic salary should be pensionable. The pension contributions rates for executive directors, or payments in lieu, should be aligned with those available to the workforce.

297 Kritisch zu solchen perquisites CalPERS, aaO (Fn. 45), p. 27.

298 Zusammensetzung der gewährten Gesamtvergütung für DAX-Vorstände: 26 \% Festvergütung, $23 \%$ kurzfristige variable Vergütung, $34 \%$ langfristig variable Vergütung, $3 \%$ Nebenleistungen und 14 \% Versorgungsaufwand, PwC, Vergütungsstudie 2018, S. 15.

299 Typische Finanzparameter sind z.B. EBIT, ROCE, EBITDA, Allen \& Overy, aaO (Fn. 291), S. 4. Vgl. auch CalPERS, aaO (Fn. 45), p. 23 et seq.: Establishing Performance Metrics, Multiple Performance Metrics, Performance Hurdles. Praxisrelevante Parameter bei Ihrig/Wandt/WitTgens, ZIP Beil Heft 40/2012, S. 10. 


\section{b) Festlegung des Vergütungssystems}

Die Empfehlung G.1 enthält in fünf Spiegelstrichen zunächst eine Aufzählung, was im Vergütungssystem insbesondere festgelegt werden soll. Dem liegt nach der Begründung eine dreistufige Vorgehensweise zugrunde: Festlegung eines Vergütungssystems, Festlegung der individuellen konkreten Ziel- und Maximalvergütung für das bevorstehende Geschäftsjahr und Festsetzung der Höhe der variablen Bestandteile und damit der Ist-Gesamtvergütung für das abgelaufene Geschäftsjahr. Die genannten Festlegungen decken sich teilweise mit den für börsennotierte Gesellschaften in $₫ 87$ a Abs. 1 Satz $2 \mathrm{Nr} .1 \mathrm{ff}$ AktG i.d.F. ARUG II genannten, dort handelt es sich aber um Mindestangaben, hier um Empfehlungen. Die Empfehlung spricht in Spiegelstrich 2 nur davon, dass die relativen Anteile von fester Vergütung und (kurzfristig und langfristig) variablen Vergütungsbestandteilen im Vergütungssystem festgelegt werden sollen, eine Empfehlung gegen eine reine Festvergütung liegt darin nicht. ${ }^{300}$

\section{c) Festlegung der konkreten Gesamtvergütung}

Nach der Empfehlung G.2 soll der Aufsichtsrat für jedes Vorstandsmitglied auf der Basis des Vergütungssystems (Empfehlung G.1) dessen konkrete Zielund Maximalvergütung festlegen. ${ }^{301}$ Das ist die Basis für die Beurteilung der Zielerreichung am Ende des Geschäftsjahrs gemäß Empfehlung G.9.

Nach $\ 87$ Abs. 1 Satz 1 AktG dürfen die Gesamtbezüge die übliche Vergütung nicht ohne besondere Gründe übersteigen. Deshalb und mit Blick auf die angestrebte gesellschaftliche Akzeptanz soll die konkrete Gesamtvergütung in eine doppelte Relation - Üblichkeit horizontal und vertikal ${ }^{302}$ -

300 So aber CalPERS, aaO (Fn. 45), p. 27: Combination of Cash and Equity. Ebenso noch DCGK 2017 Ziffer 4.2.3 Abs. 2 Satz 2; dazu kritisch KorT, aaO (Fn. 22), $\$ 87$ AktG Rdn. 512; Kосн, aaO (Fn. 3), $\$ 87$ AktG Rdn. 7.

301 Der Zusatz in der Empfehlung, dass diese beiden Größen in angemessenem Verhältnis zu den Aufgaben und Leistungen des Vorstandsmitglieds sowie zur Lage der Gesellschaft stehen und die übliche Vergütung nicht ohne besondere Gründe übersteigen darf, deckt sich bis auf „Unternehmenslage“ mit $\$ 87$ Abs. 1 Satz 1 AktG, insoweit ohne Änderung durch ARUG II. Zur Lage der Gesellschaft, insbesondere der Relevanz von Konzernbeziehungen, KorT, aaO (Fn. 22), \87 AktG Rdn. 65 ff, 102. Übersicht zu den Beurteilungsgesichtspunkten $\mathrm{Koch}$, aaO (Fn. 3), $\$ 87$ AktG Rdn. 4 f. Eine Höchstgrenze für die Gesamtvergütung (also einschließlich der fixen Vergütung) ist schon seit 2014 überwiegende Praxis im DAX-30, Allen \& Overy, aaO (Fn. 291), S. 5.

302 Dazu unter $\mathbb{8} 87$ Abs. 1 Satz 1 AktG ausführlich KorT, aaO (Fn. 22), $₫ 87$ AktG Rdn. $82 \mathrm{ff}, 90 \mathrm{ff}$ und zum DCGK 2017 Ziffer 4.2.2. Abs. 2 Satz 2 Rdn. $96 \mathrm{ff}$. Die DAX-Vorstände haben 2018 wie im Vorjahr das 52-fache ihrer Mitarbeiter verdient, DSW-Vorstandsvergütungsstudie 2019; FRIEDL, DSW-Pressekonferenz 11.6.2019. 
gesetzt werden, und zwar nach Empfehlung G.3 durch Wahl einer geeigneten Vergleichsgruppe anderer Unternehmen, ${ }^{303}$ also ein Peer Group Alignment ${ }^{304}$, und nach Empfehlung G.4 zur Vergütung des oberen Führungskreises und der Belegschaft insgesamt ${ }^{305}$ und dieses auch in der zeitlichen Entwicklung. Das wird schon unter $\ 87$ Abs. 1 Satz 1 AktG (übliche Vergütung) angenommen, ${ }^{306}$ entspricht $\$ 162$ Abs. 1 Satz 2 Nr. 2 AktG i.d.F. ARUG II und ist auch hinsichtlich des Vertikalvergleichs mehr oder weniger akzeptiert. ${ }^{307}$ Die Wahl der Vergleichsgruppe, die Abgrenzung des Führungskreises und die Einzelheiten des Vergleichs liegen im Ermessen des Aufsichtsrats. Offenlegung wird nur für den Peer Group-Vergleich, nicht auch für die unternehmensinterne Pay Ratio empfohlen. Offenlegung auch der Pay Ratio wird zwar international teilweise empfohlen, ${ }^{308}$ wäre aber sehr problematisch. ${ }^{309}$

Aufsichtsräte bedienen sich heute hinsichtlich der Komplexität der Vergütungsvorschriften, insbesondere bei der Entwicklung des Vergütungssystems oder zu den vorgeschriebenen Vergleichen fachkundigen Rats. Dieser kann intern vorhanden sein, oft wird aber auch auf die Hilfe eines externen Vergütungsexperten zurückgegriffen. Letzteres ist rechtlich nicht vorgeschrieben, ${ }^{310}$ und auch die Empfehlung G.5 sieht davon ab. Wenn aber ein externer Vergütungsexperte herangezogen wird, ${ }^{311}$ soll auf dessen Unabhängigkeit vom Vorstand und vom Un-

303 Laut Begründung kommt es dafür auf die Marktstellung der Unternehmen an, also insbesondere Branche, Größe, Land. Nach Auffassung des Rechtsausschusses soll es nur auf die Üblichkeit in Deutschland ankommen, im Anschluss daran auch die Literatur, z. B. Koch, aaO (Fn. 3), $\ 87$ AktG Rdn. 3 m. w. N.; richtigerweise hängt das davon ab, ob die Gesellschaft nach Größe und Tätigkeitsfeld im internationalen Wettbewerb um Führungskräfte steht, so Kort, aaO (Fn. 22), $₫ 87$ AktG Rdn. 84; SPINDler, aaO

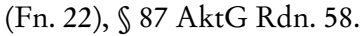

304 Dazu ISS, aaO (Fn. 105), p. 20 and 21, aber ohne Näheres zur peer group. Auch CalPERS, aaO (Fn. 45), p. 22, aber mit der problematischen Empfehlung, die Namen der gewählten Peers zu veröffentlichen.

305 Ebenso CalPERS, aaO (Fn. 45), p. 23 für den CEO. Zu den Problemen Klein, AG 2013, 733, 738f; Schmidt-Bendun, AG 2014, $177 \mathrm{f}$.

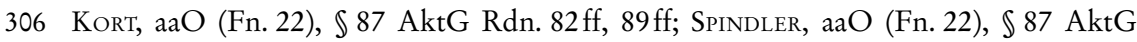
Rdn. 57 ff, $60 \mathrm{ff}$; FleisCher, aaO (Fn. 3), $₫ 87$ AktG Rdn. $15 \mathrm{ff}$.

307 Mit Hinweis auf den Rechtsausschuss Fleischer, aaO (Fn. 3), \87 AktG Rdn. 18; FleISCHER, NZG 2009, 801, 802; restriktiv SPINDLER, aaO (Fn. 22), \8 87 AktG Rdn. 61; kritisch Kort, aaO (Fn. 22), $\mathbb{8} 87$ AktG Rdn. 90 ff, 96; CAHn, FS Hopt, 2010, S. 431, 433 ff.

308 v. WeRDER, DB 2019, 1721, 1724 m.w.N.

309 VGR, aaO (Fn. 19), VI 2.

310 Kort, aaO (Fn. 22), \87 AktG Rdn. 111 ff; Koch, aaO (Fn. 3), $\ 87$ AktG Rdn. 4; zu einem Vergütungsberater kritisch HÜFFER, FS Hoffmann-Becking, 2013, S. 589, 601.

311 Nach v. Werder/Danilow, DB 2108, 1997, 2005 und DB 2019, 41, 47, schalten mehr als $80 \%$ der antwortenden Institute Vergütungsberater ein, nach der Studie des Arbeitskreises Deutscher Aufsichtsrat e. V./HengelerMueller vom September 2019, aaO (Fn. 5), B.4, nur etwas weniger als die Hälfte. 
ternehmen geachtet werden. Unabhängigkeit vom „Unternehmen“ bedeutet, wie das die Europäische Kommission bereits in ihrer Empfehlung von 2009 betont hat, konzernweit. ${ }^{312}$ Dass der externe Vergütungsberater vom Aufsichtsratsvorsitzenden oder dem Vorsitzenden des Aufsichtsrats-Vergütungsausschusses mandatiert wird, wie die Begründung sagt, ist richtig. ${ }^{313}$ Dass er von Zeit zu Zeit gewechselt wird, steht aber weder im Gesetz noch in der Empfehlung, sondern nur in der Begründung; wird dem nicht entsprochen, kann das pflichtwidrig sein, gleichwohl braucht nach $\ 161 \mathrm{AktG}$ nichts erklärt zu werden, was kaum überzeugen kann. ${ }^{314}$ An der Unabhängigkeit fehlt es aber, was nicht gesagt wird, auch bei einem Interessenkonflikt, etwa bei aktuellen oder zu erwartenden Beratungsmandaten des Vorstands zur Vergütung von nachgelagerten Führungsebenen. ${ }^{315}$

\section{d) Festsetzung der Höhe der variablen Vergütungsbestandteile}

Darauf liegt mit den gleich sechs Empfehlungen G.6 bis G.11 ein besonderes Augenmerk des Kodex. Die Empfehlung G.6 beginnt damit, dass der Anteil der langfristig variablen Vergütung den Anteil der kurzfristig variablen Vergütung übersteigen soll. ${ }^{316}$ Das entspricht der Auslegung von $\$ 87$ Abs. 1 Satz 3 Halbsatz $1 \mathrm{AktG}$, wonach variable Vergütungsbestandteile eine mehrjährige Bemessungsgrundlage haben sollen. ${ }^{317}$ Besonderheiten gelten wiederum für Finanzdienstleistungsinstitute ${ }^{318}$ nach $\$ 25$ a Abs. 5 Satz 1 KWG.

312 Präambel Abs. 5, oben II. 1. c). So schon die Europäische Kommission, Ziff. 9.2 Empfehlung der Kommission 2009/385/EG v. 30.4.2009 zur Ergänzung der Empfehlungen 2004/913/EG und 2005/162/EG zur Regelung der Vergütung von Mitgliedern der Unternehmensleitung börsennotierter Gesellschaften, ABlEU L 120 v. 15.5.2009, S. 28. Zu den Anforderungen an die Unabhängigkeit des Vergütungsberaters IHRIG/WANDT/ Wittgens, ZIP Beil Heft 40/2012, S. 25 f.

313 Nach UK Corporate Governance Code 2018, aaO (Fn. 30), Provision 35 ist allein der Vergütungsausschuss zuständig.

314 KorT, aaO (Fn. 22), \87 AktG Rdn. 113. Zur Relevanz des Rats eines Vergütungsexperten für die Pflichtwidrigkeit sind die Grundsätze zur Beratung in Rechtsfragen relevant, im Einzelnen str., näher Норт/Rотн, aaO (Fn. 22), $\$ 93$ AktG Rdn. 110, 139 ff.

315 Leyens, aaO (Fn. 81), S. $614 \mathrm{ff}, 629 \mathrm{ff}$.

316 Short Term Incentives (STI), Long Term Incentives (LTI). Bei den DAX-30-Unternehmen schon derzeit bzw. Verhältnis etwa 50 \%, Allen \& Overy, aaO (Fn. 291), S. 4.

317 KorT, aaO (Fn. 22), $\ 87$ AktG Rdn. 141: die langfristige variable Vergütung muss ihrerseits bereits die kurzfristige variable Vergütung überwiegen, dies jedenfalls zusammen mit der Festvergütung. Heranzuziehen ist nach KorT ebenda auch $₫ 87$ Abs. 1 Satz 2 AktG. Demgegenüber großzügiger ISS, aaO (Fn. 105), p. 21: „avoid disproportionate focus on short-term variable elements". In der Praxis ist das Verhältnis langfristig/kurzfristig $60 \mathrm{zu} 40$ üblich, Нohenstatt/Seibt, ZIP 2019, 11, 13.

318 Nach $\$ 25$ a Abs. 5 Satz 2 KWG darf die variable Vergütung für Mitarbeiter und Geschäftsleiter vorbehaltlich eines Beschlusses nach Satz 5 jeweils 100 Prozent der fixen Vergütung für jeden einzelnen Mitarbeiter oder Geschäftsleiter nicht überschreiten. 
Empfehlung G.7 handelt von der Festlegung der Leistungskriterien. Diese soll der Aufsichtsrat für das bevorstehende Geschäftsjahr für jedes Vorstandsmitglied und für alle variablen Vergütungsbestandteile festlegen. Sie sollen sich an operativen, vor allem aber an strategischen Zielsetzungen orientieren. Dabei soll klar sein, inwieweit individuelle Ziele der einzelnen Vorstandsmitglieder oder Ziele für alle Vorstandsmitglieder zusammen maßgeblich sind. Die Begründung zählt dazu vier Gruppen von typischen Leistungskriterien der langfristig variablen Vergütung auf - langfristige finanzielle Erfolge, nichtfinanzielle Erfolge als Voraussetzung späterer finanzieller Erfolge, Unternehmensstrategie und Messgrößen für die absolute oder relative Aktienrendite - und gibt dazu jeweils Beispiele. Die Empfehlung G.7 samt Begründung orientiert sich offensichtlich an $\$ 87$ a Abs. 1 Satz 2 Nr. 4 AktG i.d.F. ARUG II und konkretisiert diesen. Es ist richtigerweise Sache des Aufsichtsrats zu entscheiden, welche finanziellen und nichtfinanziellen Leistungskriterien bzw. Erfolgsparameter ${ }^{319}$ zugrunde gelegt werden.

Dass eine nachträgliche Änderung der Ziele oder der Vergleichsparameter (sog. repricing) ausgeschlossen sein soll, wie Empfehlung G.8 festhält, ${ }^{320}$ liegt auf der Hand, sonst macht das ganze Anreizsystem keinen Sinn, enge Ausnahmen müssen möglich bleiben und sind es, soweit es die Kodexregulierung anbelangt ohnehin, weil eine Aktualisierungserklärung unter Angabe der Nichtbefolgung mit Begründung möglich ist. ${ }^{321}$ Das gilt grundsätzlich auch für Empfehlung G.9, wonach der Aufsichtsrat nach Ablauf des Geschäftsjahrs Zielerreichung und Höhe der individuellen Vergütungsbestandteile für dieses Jahr festsetzen soll, was auch $\$ 87$ a Abs. 2 Satz 1 AktG i.d.F. ARUG II entspricht. Die Prüfung der Zielerreichung unbedingt jedes Jahr ist allerdings nicht einfach und wenig flexibel und wird auch in der Praxis vielfach anders gehandhabt (z. B. prozentual zur Festvergütung). ${ }^{322}$ Die Zielwerte können ex post ausgewiesen werden. ${ }^{323}$

319 Beispiele bei Koch, aaO (Fn. 3), $\int 87$ AktG Rdn. 12. Die Mehrheit der befragten Unternehmen verwendet sowohl quantitative Finanzkennziffern wie Key Performance Indicators (KPIs) als auch konkrete qualitative Kriterien, Arbeitskreis Deutscher Aufsichtsrat e. V./HengelerMueller, aaO (Fn. 5), B.6.

320 Auch schon DCGK 2017 Ziffer 4.3.3 Abs. 2 Satz 8; zustimmend KorT, aaO (Fn. 22), \87 AktG Rdn. $232 \mathrm{ff}$.

321 Dazu noch sogleich im Zusammenhang mit Empfehlung G.11. Repricingfälle in der Praxis bei Ihrig/Wandt/Wittgens, ZIP Beil Heft 40/2012, S. $12 \mathrm{f}$.

322 VGR, aaO (Fn. 19), VI 2; v. Werder, DB 2019, 41, 47 und 2019, 1721, 1727, hat Zweifel an der Motivierungswirkung. Aus Investorensicht kritisch M. SCHMidt/Strenger, Börsen-Zeitung Nr. 233, 4.12.2018, S. 8: "Jahresscheibe“ der falsche Ansatz. Aus der DCGK-Kommission wird entgegengehalten, der Vorstand berichte ohnehin jedes Jahr über den Stand der Strategieerreichung.

323 So Begründung zu Empfehlung G.9. Das dient der Geheimhaltung und wird von den Unternehmen begrüßt, von institutionellen Investoren dagegen eher kritisiert, HoHENSTATT/SEIBT, ZIP 2019, 11, 17. 
Empfehlung G.10 hält fest, dass langfristig variable Vergütungsbeiträge überwiegend ${ }^{324}$ in Aktien der Gesellschaft angelegt ${ }^{325}$ oder entsprechend aktienbasiert ${ }^{326}$ gewährt werden sollen ${ }^{327}$ und dass das Vorstandsmitglied über diese Gewährungsbeiträge erst nach vier Jahren verfügen können soll, ${ }^{328}$ was die Gesellschaft dann auch in geeigneter Weise kontrollieren muss. ${ }^{329}$ International wird das manchmal durch Hedging-Verbote ergänzt, ${ }^{330}$ häufig erwarten internationale Investoren einen Aktienbesitz relativ zum Fixgehalt, etwa 300 oder $500 \%$ des Brutto-Fixgehalts. ${ }^{331}$ Auch in der Unternehmenspraxis finden sich zunehmend shareholdership guidelines (Aktienhaltevorschriften), die teilweise auch offengelegt werden. ${ }^{332}$ Die Gewährung von restricted sha-

324 Damit werden andere Gestaltungsformen wie Bonus-Malus-Systeme nicht ganz ausgeschlossen, vgl. DörRwächter, DB 2018, 2977, 2979. Aber fast ein Viertel der Befragten lehnen Aktien als Bestandteil des Vergütungskonzepts für Vorstände bewusst ab, Arbeitskreis Deutscher Aufsichtsrat e. V./HengelerMueller, aaO (Fn. 5), B.8.

325 Anreizorientierte Vergütungszusagen wie zum Beispiel Aktienbezugsrechte sind in $\ 87$ Abs. $1 \mathrm{AktG}$ ausdrücklich angesprochen. Ob sie gewährt und wie sie verteilt werden, entscheidet im Rahmen einer bedingten Kapitalerhöhung die Hauptversammlung ( $\mathbb{S} 192$ Abs. 2 Nr. 3, 193 Abs. 2 Nr. 4 AktG, dort auch Mindestwartefrist von vier Jahren).

326 Phantom stocks (virtuelle Aktien in Nachbildung von Aktien) und stock appreciation rights (SARs, Wertsteigerungsrechte). Da es sich hier um rein schuldrechtliche Gestaltungen handelt, sind $\$ \mathbb{S} 71 \mathrm{ff}$ und $\$ \mathbb{S} 192 \mathrm{ff} A \mathrm{ktG}$ nicht anwendbar. Näher RIECKERS, in: Spindler/Stilz, Komm. z. AktG, 4. Aufl., 2019, \192 Rdn. 57; KorT, aaO (Fn. 22), \87 AktG Rdn. 247; Claussen, FS Horn, 2006, S. 313, $319 \mathrm{ff.}$

327 Kritisch aus Investorensicht M. Schmidt/Strenger, Börsen-Zeitung Nr. 233, 4.12.2018, S. 8.

328 So Empfehlung G.10 Satz 1 und 2. Nach der Begründung kann das Bestandteil einer Share Ownership Guideline sein. Zu Empfehlung G.10 Satz 3 die Begründung. Dort auch der Hinweis auf den Verzicht von Mustertabellen, da $\$ 162$ AktG i.d.F. ARUG II einen aussagekräftigen Vergütungsbericht vorschreibe. So auch die Begründung zu Grundsatz 25. Dazu unten IV. 2. a.E.

329 Auch v. WeRdER, DB 2019, 1721, 1727 (Investitionscontrolling).

330 So CalPERS, aaO (Fn. 45), p. 24, weil damit das alignment of interest konterkariert wird. Das kann vertraglich im Anstellungsvertrag oder in der Optionsabrede vereinbart werden, man wird aber auch eine eine solche Abrede als der organschaftlichen Treuepflicht zuwiderlaufend ansehen können, vgl. KorT, aaO (Fn. 22), \$87 AktG Rdn. 241; Fleischer, aaO (Fn. 3), $\$ 87$ AktG Rdn. 43. Ausdrücklich $\ 8$ Abs. 2 InstitutsVergV, Compliance-Struktur gegen Absicherungs- und sonstige Gegenmaßnahmen der Mitarbeiter; auch $\$ 4$ Abs. 4 VersVergV.

331 Arbeitskreis Leitlinien für eine nachhaltige Vorstandsvergütung, aaO (Fn. 102), Ziffer 1.8. E, der Arbeitskreis selbst begnügt sich mit mindestens einer Brutto-Jahresvergütung bis spätestens nach 4 Jahren. Interessant ist sein Vorschlag in Ziffer 1.9., im Unternehmen Compliance-Prozesse zu implementieren, um die sich aus vertraglichen Bestimmungen ergebenden Aktieninvestments des Vorstands insiderrechtssicher zu gewährleisten, z.B. automatische Kaufprozesse zu festen Stichtagen.

332 Böcking/Bundle/Schmidt/Wagner, DB 2019, 137, 143 m.w.N., im Median sollen $200 \%$ der Fixvergütung in Aktien investiert und gehalten werden. 
res $^{333}$ entspricht dem Grundsatz der nachhaltigen und langfristigen Entwicklung der Gesellschaft nach $\$ 87$ Abs. 1 Satz 2 AktG i.d.F. ARUG II. ${ }^{334}$ Die Empfehlung G.10 spricht von Aktien der Gesellschaft und schließt damit nach der eigenen Definition ${ }^{335}$ Aktien der Obergesellschaft aus. Da jedenfalls für den Vertragskonzern die letztere Möglichkeit anerkannt ist und mittlerweile die wohl ü.L. sie auch für den faktischen Konzern für zulässig hält, ${ }^{336}$ erscheint die Empfehlung unnötig eng. Zumindest hätte man einen Hinweis in der Begründung erwartet. International wird teilweise empfohlen, dass der Vergütungsausschuss share ownerhip guidelines für die Zeit nach dem Ausscheiden entwickelt. ${ }^{337}$

Das Vergütungssystem nach $\mathbb{8} 87$ a AktG i.d.F. ARUG II enthält sehr anspruchsvolle Vorgaben. Es ist deshalb wichtig, dass der Aufsichtsrat vorübergehend von dem Vergütungssystem abweichen kann, wenn dies im Interesse des langfristigen Wohlergehens der Gesellschaft notwendig ist. Das sieht $\$ 87$ a Abs. 2 Satz 2 AktG i.d.F. ARUG II mit weiteren Anforderungen ausdrücklich vor. Die Empfehlung G.11 folgt dem. Der Aufsichtsrat soll danach die Möglichkeit haben, außergewöhnlichen Entwicklungen in angemessenem Rahmen Rechnung zu tragen. Darüber sind dann nach $\$ 162$ Abs. 1 Satz 2 Nr. 5 AktG i.d.F. ARUG II im Vergütungsbericht Angaben zu machen, und die Notwendigkeit der Abweichungen ist zu erläutern. Die Begründung stellt klar, dass das sowohl zu einer Erhöhung als auch zu einer Verminderung der (kurz- oder langfristigen) variablen Vergütung führen kann und dass das z.B. bei allgemein ungünstigen Marktentwicklungen nicht möglich sein soll. ${ }^{338}$

Die Möglichkeit des Aufsichtsrats, bei Verschlechterung der Lage der Gesellschaft eine unbillige Weitergewährung der Bezüge nach $\$ 87$ Abs. 1 AktG durch Herabsetzung der Bezüge auf die angemessene Höhe zu vermeiden, ist

333 Restricted Share Units (RSU). Koch, aaO (Fn. 3), $\int 87$ AktG Rdn. 28; Krieger/S. H. SCHNEIDER, FS Hellwig, 2010, S. 181.

334 Die Formulierung "nachhaltige und langfristige Entwicklung der Gesellschaft" soll zum Ausdruck bringen, dass die Vergütung auch soziale und ökologische Gesichtspunkte in den Blick zu nehmen hat; Begr. ARUG II, BT-Drucks. 19/15153, Vorabfassung vom 13.11.2019, S. 62.

335 Zur Wahl der Begriffe Gesellschaft/Unternehmen Präambel Abs. 5, oben II. 1. c).

336 Rieckers, aaO (Fn. 326), \$192 AktG Rdn. 61a, 61b; Goette, FS Hopt, 2010, S. 689, $698 \mathrm{ff}$; Ihrig/Wandt/WitTGENs, ZIP Beil Heft 40/2012, S. 15 f; weitere Nachweise bei Koch, aaO (Fn. 3), $\$ 87$ AktG Rdn. 14. Differenzierend KorT, aaO (Fn. 22), $\$ 87$ AktG Rdn. 204. Auch Reichert/Balke, FS Hellwig, 2010, S. 285, $291 \mathrm{ff.}$

337 UK Corporate Governance Code 2018, aaO (Fn. 30), Provision 36 sentence 3: formal policy for post-employment shareholding requirements encompassing both unvested and vested shares.

338 Die Begründung RegE ARUG II, BT-Drucks. vom 29.4.2019, S. 75, erwähnt die Finanzkrise 2008/2009 und Unternehmenskrisen und gibt weitere positive und negative Beispiele. 
schon in $\ 87$ Abs. 2 AktG vorgesehen, aber als Abweichung vom Grundsatz pacta sunt servanda eng auszulegen. ${ }^{339} \$ 87 \mathrm{Abs}$. $2 \mathrm{AktG}$ wird auch durch den neuen $\$ 87$ a Abs. 2 Satz 2 AktG i.d.F. ARUG II nicht berührt. ${ }^{340}$ Die Empfehlung G.11 Satz 2 betrifft demgegenüber nur die variable Vergütung. Diese soll in begründeten Fällen, so auch international, ${ }^{341}$ einbehalten oder zurückgefordert werden können (Clawback). ${ }^{342}$ Dass das rechtlich möglich ist, wird durch \87a Abs. 1 Nr. 6 AktG i.d.F. ARUG II bestätigt. ${ }^{343}$ Begründete Fälle sind wie in $\$ 87$ Abs. 2 AktG jedenfalls Insolvenz, ${ }^{344}$ aber je nachdem auch schon eine gravierende, existenzbedrohende Krise. ${ }^{345}$ Selbstverständlich geht das nicht ohne weiteres, sondern muss im jeweiligen Anstellungsvertrag vereinbart sein. Die Praxis sieht Clawbacks auf dem Vormarsch ${ }^{346}$ und hat dazu verschiedene Typen von Clawback-Klauseln entwickelt, die an Fehlverhalten, nachträgliche Verschlechterung der Lage der Gesellschaft oder andere Kriterien anknüpfen. ${ }^{347}$ Die Clawback-Klauseln sind zulässig, unterliegen aber wie alle AGB der Inhaltskontrolle. ${ }^{348}$ Die Entscheidung des Aufsichtsrats über die Herabsetzung fällt, soweit nicht der engere $\ 87 \mathrm{AktG}$ einschlägig ist, ${ }^{349}$ unter die business judgment rule nach $\mathbb{9} 93$ Abs. 1 Satz 2 AktG. Zu den Möglichkeiten

339 BGHZ 207, 190 Rdn. 24 = NJW 2016, 2136. Die Bedeutung der Norm wird durch variable Vergütungen, die mit ihren Parametern negativen Entwicklungen der Gesellschaft bereits Rechnung tragen, in der Praxis eingeschränkt, BGHZ 207, 190 Rdn. 54; OLG Stuttgart NZG 2015, 194 Rdn. 36; KосH, aaO (Fn. 3), $\$ 87$ AktG Rdn. 24, 27. Ob bzw. inwieweit der Aufsichtsrat bei seiner Entscheidung nach $₫ 87$ Abs. 2 AktG einen Ermessens- oder Beurteilungsspielraum hat, ist umstritten, bejahend die h.L., verneinend $\mathrm{Kосн,} \mathrm{aаO} \mathrm{(Fn.} \mathrm{3),} \$ 87$ AktG Rdn. 27. Zum Ganzen einschränkend RaitZsCh, NZG 2019, 495.

340 Begründung RegE ARUG II, aaO (Fn. 338), zu \87a Abs. 2 Satz 2 AktG, S. 73.

341 Seyfahrt, WM 2019, 521, 569.

342 Kritisch als für die Praxis kaum hilfreich, klare Hinweise vermissend VGR, aaO (Fn. 19), VI 2; auch Hohenstatt/Seibt, ZIP 2019, 11, 17 f.

343 Begründung RegE ARUG II zu $\int 87$ a Abs. 5 AktG, S. 82. Nach $\ 87$ Abs. 2 Satz 2 AktG können sogar Ruhegehälter in den ersten drei Jahren nach Ausscheiden herabgesetzt werden, zum Streit dazu Fleischer, aaO (Fn. 3), $\$ 87$ Rdn. 69.

344 BGHZ 207, 190 Rdn. 38.

345 Vgl. m. w. N. КосH, aaO (Fn. 3), $\$ 87$ AktG Rdn. 25.

346 Arbeitskreis Deutscher Aufsichtsrat e. V./HengelerMueller, aaO (Fn. 5), B.9; auch Favoccia/Siepelt, FAZ 28.8.2019, Nr. 199, S. 16.

347 Schockenhoff/NußBaum, AG 2018, 813, 817 ff; Löw, NZA 2017, 1365, auch zu UK; RaITZsCh, ZIP 2019, 104. Für gross negligence und Kausalität CalPERS, aaO (Fn. 45), p. 24; ähnlich Arbeitskreis Leitlinien für eine nachhaltige Vorstandsvergütung, aaO (Fn. 102), Ziffer $1.10 \mathrm{zu}$ Auszahlungskürzung (Malus) und Vergütungsrückforderung (clawback).

348 OLG Frankfurt, 18.4.2018, BeckRS 2018, 9111; KorT, aaO (Fn. 22), \$87 AktG Rdn. 135; Habersack, NZG 2018, 127, 133.

349 Spindler, aaO (Fn. 22), $\ 87$ Rdn. 184, 179. 
der Gesellschaft, variable Vergütungsbestandteile zurückzufordern, muss der Aufsichtsrat künftig im Vergütungsbericht Angaben machen. ${ }^{350}$

\section{e) Leistungen bei Vertragsbeendigung}

Die Empfehlungen G.12 und G.13 und die Anregung G.14 betreffen die Leistungen bei Vertragsbeendigung. Zu Empfehlung G.12 stellt die Kommission klar, dass die Vertragsbeendigung keinen Einfluss auf die Bemessung und die Fälligkeit der variablen Vergütung haben darf. Nur so kann die Langfristigkeit von variablen Vergütungsbestandteilen im Einklang mit $\int \mathbb{S} 87$ Abs. 1 Satz 2, 87a Abs. 1 Satz 2 Nr. 2 AktG i.d.F. ARUG II (auch Grundsatz 23 Abs. 3) erhalten werden.

Empfehlung G.13 Satz 1 sieht bei vorzeitiger Beendigung der Vorstandstätigkeit einen Abfindungs-Cap in Höhe des Werts von zwei Jahresvergütungen vor. ${ }^{351}$ Das wird in der Praxis und teils auch in der Literatur kritisch beurteilt. ${ }^{352}$ Nach Empfehlung G.13 Satz 2 soll bei einem nachvertraglichen Wettbewerbsverbot die Abfindungszahlung auf die Karenzentschädigung angerechnet werden. Mit der Abfindung soll also, so die Begründung, das Wettbewerbsverbot für den Zeitraum, für den die Abfindung gewährt wird, abgegolten sein. ${ }^{353}$

Für den Fall einer Change of Control-Klausel ${ }^{354}$ beschränkt sich die Kommission hingegen auf eine bloße Anregung G.14 und räumt gleichzeitig das Miss-

350 \87a Abs. 1 Satz 2 Nr. 6 AktG i.d.F. ARUG II. Die Hauptversammlung muss dann ein Votum zum Vergütungssystem und zum Vergütungsbericht abgeben, $\mathbb{1} 120$ a i.d.F. ARUG II.

351 Zur Berechnung ist nach der Begründung die Gesamtvergütung des abgelaufenen Geschäftsjahrs und ggf. die voraussichtliche Gesamtvergütung für das laufende Geschäftsjahr maßgeblich. Auch ISS, aaO (Fn. 105) p. 21: 24 months‘ pay oder weniger gemäß „market best practices“. Zu Abfindungscaps Ihrig/WANDT/WitTGENs, ZIP Beil Heft 40/2012, S. 15 f. Rechtstatsächlich und rechtspolitisch BAYER/MEIER-WeHrsdorfer, AG 2013, 477.

352 Sünner, AG 2014, 115; Kort, aaO (Fn. 22), $\$ 87$ AktG Rdn. 258 ff. Vgl. auch Hoffmann-Becking, ZIP 2007, 2101, 2105; КосH, aaO (Fn. 3), $\$ 87$ AktG Rdn. 8. Keine Abfindung bei vorzeitigem Ausscheiden aus von dem Vorstandsmitglied zu vertretenden wichtigen Grund, so ausdrücklich Österreichischer Corporate Governance Kodex, $\mathrm{aaO}$ (Fn. 56), C 27a. Gegen Abfindungen bei Ausscheiden auf eigenen Wunsch, TüNGLER, DSW-Vorstandsvergütungsstudie 2019, DSW-Pressekonferenz 11.6.2019; auch bei Wechsel innerhalb des Konzerns, AFEP/MEDEF, Code de gouvernement d'entreprise des sociétés côtées, 2018, $\mathbb{2} 24.5 .1$ al. 4. Das kann aber nicht ohne Ausnahme gelten, IHRIG/WANDT/WiTTGENS, ZIP Beil Heft 40/2012, S. $16 \mathrm{f}$.

353 Für Frankreich ähnlich AFEP/MEDEF, Code de gouvernement d'entreprise des sociétés côtées, 2018, \$23.

354 Definiert als Zusagen für Leistungen aus Anlass der vorzeitigen Beendigung des Anstellungsvertrags durch das Vorstandsmitglied infolge eines Kontrollwechsels. \87a 
verständnis aus, sie habe mit der Empfehlung in DCGK 2017 Ziff. 4.2.3 Abs. 5 (nicht mehr als $150 \%$ des Abfindungscaps) solche Klauseln empfohlen. Zwar ist es dann konsequent, von einer Empfehlung mit einem solchen Höchstbetrag abzusehen, aber nicht auch, bloß noch eine einzige Anregung zu geben. Denn die Gesellschaft kann nunmehr solche Leistungen, und zwar auch über diesen Betrag hinaus, sofern sie angemessen sind, ${ }^{355}$ ohne Erklärung nach $\ 161$ AktG gewähren. Im Ergebnis ist das eher ein Rückschritt. Darüber, ob Change of Control-Klauseln auf jeden Fall abzulehnen sind oder ob sie nicht doch eher, auch etwa im Hinblick auf die Rechtsprechung des Bundesgerichtshof in Sachen Mannesmann, ${ }^{356}$ für bestimmte Fälle sinnvoll sein können, ${ }^{357}$ besteht Streit. ${ }^{358} \mathrm{Da}$ sie eine Vergütung für loyales Verhalten des Vorstandsmitglieds insbesondere bei Übernahmeangeboten, also keine Verteidigung nur im Interesse des Amtserhalts, darstellen (sollen), können sie jedenfalls nach dem Ausscheiden nicht mehr nach $\ 87$ Abs. 2 AktG gekürzt werden. ${ }^{359}$

\section{f) Sonstige Regelungen, Anrechnung bei konzerninternen und -externen Aufsichtsratsmandaten}

Die Empfehlungen G.15 und G.16 betreffen konzerninterne und konzernfremde Aufsichtsratsmandate von Vorstandsmitgliedern. ${ }^{360}$ Die Vergütung für erstere soll angerechnet werden, und zwar, wie die Begründung sagt, auf die

Abs. 1 Satz 2 Nr. 8 lit. b AktG i.d.F. ARUG II spricht breiter von etwaigen „Zusagen von Entlassungsentschädigungen“, worunter auch Change of Control-Leistungen fallen, Begründung RegE ARUG II, aaO (Fn. 338), S. 74.

355 Fleischer, aaO (Fn. 3), $\$ 87$ AktG Rdn. 53.

356 BGH NJW 2006, 522 zu den (nachträglichen) appreciation awards, nicht zu change of control-Leistungen, KоRT, aaO (Fn. 22), $\$ 87$ AktG Rdn. 319ff, 325. In der Literatur wird diese Entscheidung zu Recht kritisiert, Косн, aaO (Fn. 3), $\$ 87$ AktG Rdn. 6 ff m.w.N.

357 CalPERS, aaO (Fn. 45), p. 26 verlangt nur, dass change-in-control payments „doubtetriggered" sein sollen, nämlich erst anfallen, wenn der Kontrollwechsel tatsächlich eingetreten ist und wenn die Vorstand deshalb ausgeschieden ist. Der Arbeitskreis Leitlinien für eine nachhaltige Vorstandsvergütung, aaO (Fn. 102), Ziffer 1.12 will sie auf bis zu drei Jahresgesamtvergütungen (allerdings nicht mehr als die Restlaufzeit des Anstellungsvertrags) begrenzen. Auch DÖRRWÄCHTER, DB 2018, 2977, 2981; HOHENSTATT/ Seibt, ZIP 2019, 11, 19; Bachmann, aaO (Fn. 3), Rdn. 1019 ff.

358 Bork, Change of Control-Klauseln, 2009, S. 97 ff; KorT, aaO (Fn. 22), \87 AktG Rdn. 322; KосH, aaO (Fn. 3), $\ 87$ AktG Rdn. 9.

359 Krieger, Liber amicorum M. Winter, 2011, S. 369, $384 \mathrm{ff}$; KorT, aaO (Fn. 22), \87 AktG Rdn. 424; Spindler, aaO (Fn. 22), $\$ 87$ Rdn. 204; Koch, aaO (Fn. 3), $\$ 87$ AktG Rdn. 29.

$360 \mathrm{Zu}$ Aufsichtsratsfunktionen in Konkurrenzunternehmen KorT, aaO (Fn. 22) \88 AktG Rdn. $49 \mathrm{ff}$. $\mathrm{Zu}$ vertraglichen Regelungen der Nebentätigkeit und Herausgabepflichten dabei KorT, ebenda, $\mathbb{} 84$ AktG Rdn. $430 \mathrm{ff}$. 
Festvergütung für die Vorstandstätigkeit. $\mathrm{Ob}$ und wie bei konzernfremden Aufsichtsratsmandaten anzurechnen ist, soll der Aufsichtsrat entscheiden. Dabei kommt es nach der Begründung darauf an, inwieweit die Tätigkeit im Interesse des Unternehmens oder des Vorstands liegt.

\section{Vergütung des Aufsichtsrats (DCGK Teil 2 G II)}

Die Vergütungsproblematik ist bei den Aufsichtsratsmitgliedern deutlich weniger akut als bei Vorstandsmitgliedern, denn die Bezüge der Aufsichtsratsmitglieder stiegen bei weitem nicht so stark wie die der Vorstandsmitglieder, sondern blieben auf einem tendenziell eher zu niedrigen Niveau. Erst in jüngerer Zeit ist ein gewisser Anstieg der Vergütung auch bei Aufsichtsratsmitgliedern $\mathrm{zu}$ verzeichnen, ${ }^{361}$ vor allem funktionsgebunden, aber auch allgemein. Dementsprechend beschränkt sich der DCGK 2020 auf einen Grundsatz 24, der $\$ 113 \mathrm{AktG}^{362}$ zu verkürzt wiedergibt, ${ }^{363}$ und darunter auf zwei Empfehlungen G.17 und G.18.

Empfehlung G.17 trägt, insoweit deutlicher als DCGK 2017 Ziff. 5.4.6 Abs. 1 Satz 2, dem höheren zeitlichen Aufwand der verschiedenen Funktionsträger ${ }^{364}$ im Aufsichtsrat Rechnung und empfiehlt eine angemessene Differenzierung bei der Vergütung des Vorsitzenden und stellvertretenden Vorsitzenden des Aufsichtsrats sowie des Vorsitzenden und der Mitglieder von Ausschüssen. Das ist in der Praxis bereits weitgehend üblich. ${ }^{365}$

361 Dazu empirische Daten bei Theisen/Probst, DB 2012, 1553; Zahlen für 2017 bei Allen \& OverY, aaO (Fn. 291), S. 6 und weiter; für 2018 in FAZ Nr. 100 30.4.2019, S. 20, Vergütungsabstand zwischen Vorstands- und Aufsichtsratsvorsitzenden das 15-Fache. Zuletzt Studie des Arbeitskreises Deutscher Aufsichtsrat e.V./Hengeler Mueller vom September 2019, aaO (Fn. 5). Zu Vergütung und Kosten des Aufsichtsrats M. Rотн, FS E. Vetter, 2019, S. 629.

362 Für den Finanzdienstleistungssektor gelten nach $\$ 25 \mathrm{~d}$ KWG wiederum strengere Anforderungen.

363 Einmal mehr zeigt sich hier das Problem einer Gesetzeswiedergabe. Die Aussage, die Mitglieder des Aufsichtsrats „erhalten eine Vergütung ...“, ist so nicht richtig. Nach $\$ 113$ Abs. 1 Satz 1 AktG ist die Gewährung nur fakultativ („kann“) und nach $\$ 113$ Abs. 1 Satz 3 AktG „soll“ sie nur in einem angemessenen Verhältnis zu den Aufgaben der Aufsichtsratsmitglieder und der Gesellschaft stehen.

364 Nur eine solche funktionsgebundene Differenzierung ist zulässig, wegen des Gleichbehandlungsgrundsatzes für Aufsichtsratsmitglieder dagegen nicht eine qualifikationsbezogene, Hopt/Roth, aaO (Fn. 22), $\$ 113$ AktG Rdn. 95; Mertens/Cahn, Kölner Komm. z. AktG, 3. Aufl., 2013, $₫ 113$ Rdn. 9 f.

365 Allen \& Overy, aaO (Fn. 291), S. 8. Mit Prozentangaben aus Literatur und Praxis Hopt/Roth, aaO (Fn. 22), $\mathbb{1} 113$ AktG Rdn. 95, in der Praxis das 2,5-fache für den Aufsichtsratsvorsitzenden und 1,5-fache für seinen Stellvertreter, BöcKING ET AL., Der 
Nach der Anregung G.18 Satz 1, insoweit neu gegenüber DCGK 2017 Ziff. 5.4.6 Abs. 2 Satz 1, sollte die Vergütung von Aufsichtsratsmitgliedern in einer Festvergütung bestehen, wohin bei den DAX-30-Unternehmen seit 2013 auch ein deutlicher Trend geht. ${ }^{366}$ Wird dennoch eine erfolgsorientierte Vergütung zugesagt, soll sie nach der Empfehlung G.18 Satz 2 auf eine langfristige Entwicklung der Gesellschaft ausgerichtet sein. ${ }^{367}$ Eine Anregung, dass Aufsichtsräte keine Pensionszusagen erhalten sollten, so viele Stimmrechtsberater, ${ }^{368}$ fehlt, was angesichts von zunehmend mehr Berufsaufsichtsräten durchaus vertretbar ist. Die Anregung einer Festvergütung trägt dem Umstand Rechnung, dass die Anreizwirkung einer variabler Vergütung für bessere Überwachung wenig plausibel ist und eher die Gefahr besteht, dass Vorstand und Aufsichtsrat am gleichen Strang ziehen (mutual backscratching). ${ }^{369}$ Europäisch und international wird das weitergehender als die Unabhängigkeit grundsätzlich ausschließend angesehen. ${ }^{370}$ Outside directors in anglo-amerikanischen boards erhalten regelmäßig nur eine Festvergütung. ${ }^{371}$ Strenge Maßstäbe legt beispielsweise ISS auch für Kontinentaleuropa und Deutschland an. ${ }^{372}$ Ob die Mobilcom-Entscheidung des BGH aktienkursbasierte Vergütungssysteme für Aufsichtsratsmitglieder allgemein für unzulässig erklärt, ist umstrit-

Konzern 2018, 1, 2 = BöCKING/PWC, Vergütungsstudie 2017, S. 50, 53, in der Literatur für den Aufsichtsratsvorsitzenden Forderungen nach dem 3- oder 4-fachen.

366 Allen \& Overy, aaO (Fn. 291), S. 5 f, teilweise verbunden mit einer (freiwilligen) Verpflichtung zum Eigeninvestment in Aktien des Unternehmens (share ownership guidelines).

367 So schon DCGK 2017 Ziff. 5.4 Abs. 2 Satz 2. Ähnlich restriktiv Glass Lewis, 2019 Guidelines Germany, aaO (Fn. 98), p. 14 et seq. Zur Formulierung „nachhaltige und langfristige Entwicklung der Gesellschaft“ in $\ 87$ Abs. 1 Satz 2 AktG i.d.F. ARUG II schon oben IV. 1. d) Fn. 334.

368 Tabelle Audit Committee Quarterly IV/2018, 16.

369 Hopt/Roth, aaO (Fn. 22), $\mathbb{1} 113$ AktG Rdn. 52ff; Mertens/Cahn, aaO (Fn. 364), $\$ 113$ AktG Rdn. 18. Nach $\$ 25$ d Abs. 5 Satz 1 KWG darf die Ausgestaltung der Vergütungssysteme für Mitglieder des Verwaltungs- oder Aufsichtsorgans im Hinblick auf die wirksame Wahrnehmung der Überwachungsfunktion des Verwaltungs- oder Aufsichtsorgans keine Interessenkonflikte erzeugen. $\$ 25 \mathrm{~d}$ Abs. 5 Satz 2 KWG schließt variable Vergütungsbestandteile für die Tätigkeit im Verwaltungs- oder Aufsichtsorgan generell aus.

370 Z.B. UK Corporate Governance Code 2018, aaO (Fn. 30), Provision 34 sentence 3: "Remuneration for all non-executive directors should not include share options or other performance-related elements." Näher Норт/Rотн, aаO (Fn. 22), $\mathbb{1} 113$ AktG Rdn. 54 m.w. N.

371 Leyens, RabelsZ 67 (2003) 57, 74. So anscheinend auch der Trend für Aufsichtsratsmitglieder in Deutschland, Preen/Pacher/Bannas, DB 2014, 1633.

372 ISS, aaO (Fn. 105), p. 22 u. a. gegen: „the granting of stock options, performance-based equity compensation (including stock appreciation rights and performance-vesting restricted stock), and performance-based cash to non-executive directors." sowie gegen "retirement benefits for non-executive directors". 
ten und wäre auch zu pauschal. ${ }^{373}$ Solche Vergütungsformen können durchaus sinnvoll sein, ${ }^{374}$ zumal der Aufsichtsrat angesichts seiner Überwachungsaufgabe ex ante und seiner Beratungsfunktion zunehmend auch mitunternehmerische Verantwortung trägt. ${ }^{375}$

Nach Grundsatz 25 erstellen Vorstand und Aufsichtsrat jährlich nach den gesetzlichen Bestimmungen einen Vergütungsbericht, wie nunmehr ausführlich in $\$ 162 \mathrm{AktG}$ i.d.F. ARUG $\mathrm{II}^{376}$ vorgeschrieben. ${ }^{377}$ Angesichts dessen und der im Entwurf vom 1.3.2019 vorliegenden Leitlinien der Europäischen Kommission, ${ }^{378}$ auf die auch die Begründung hinweist, ist dieser Grundsatz überflüssig, zumal er auch nicht durch weitere Empfehlungen konkretisiert wird.

In der Begründung wird ferner der Wegfall der bisherigen Kodex-Mustertabellen ${ }^{379}$ gerechtfertigt. ${ }^{380}$ Die Kodex-Kommission weist darauf hin, dass die in den Vergütungsbericht nach $\$ 162 \mathrm{AktG}$ aufzunehmenden Angaben über die bisherigen Kodex-Mustertabellen hinausgehen, etwa hinsichtlich der Leistungsindikatoren für jedes einzelne Vorstandsmitglied. ${ }^{381}$ Aber das erfasst den Mehrwert von Kodex-Mustertabellen für einen Vergleich zwischen verschie-

373 BGHZ 158, 122, $125 \mathrm{ff}=$ AG 2004, 265 zur Frage von stock options für Aufsichtsratsmitglieder; Röнricht, in: Gesellschaftsrecht in der Diskussion, 2004, 2005, S. 1, 16: „nicht aus derselben Quelle trinken“, zur selben Quelle „same source“ bereits HopT, Journal of Corporate Law Studies 2003, 221, 236; kritisch Hoffmann-Becking, ZHR 169 (2005), 155, $179 \mathrm{ff}$.

374 Claussen, FS Röhricht, 2005, S. 63, 72 ff; durchaus erwägenswert nach KocH, aaO (Fn. 3), $₫ 113$ AktG Rdn. 12; vgl. auch GeERken, Erfolgsabhängige Aufsichtsratsvergütung, 2015.

375 Allgemeiner zum Funktionswandel des Aufsichtsrats Hopt, ZGR 2019, 507.

376 Bisher nur fakultativ nach $\$ 120$ Abs. 4 AktG. Vgl. auch die individualisierten Offenlegungsvorschriften der $\$ 285$ Nr. 9 lit. a HGB im Anhang und für den Konzernanhang $\$ 314$ Abs. 1 Nr. 6 lit. a HGB für Vorstandsmitglieder; zu Verteidigung und Kritik $\mathrm{KocH}, \mathrm{aaO}$ (Fn. 3), $\$ 87$ AktG Rdn. 35. Nach $\$ 289$ a Abs. 2 HGB ist bei Börsennotierung im Lagebericht auch auf die Grundzüge des Vergütungssystems der Gesellschaft für die in $\ 285 \mathrm{Nr}$. 9 HGB genannten Gesamtbezüge einzugehen, entsprechend $₫ 315 \mathrm{a}$ Abs. 2 HGB zum Konzernlagebericht für $\ 314$ Abs. 1 Nr. 6 HGB.

377 Grundsatz 25 wirkt unter der Überschrift II. Vergütung des Aufsichtsrats angehängt und sollte zumindest eine eigene Überschrift haben. Sachlich könnte er auch unter F. Transparenz und externe Berichterstattung stehen.

378 Guidelines on the standardised presentation of the remuneration report under Directive 2007/36/EC, as amended by Directive (EU) 2017/828 as regards the encouragement of long-term shareholder engagement, Communication from the Commission, 01/03/ 2019, DG Just/A.3. Kritisch MutTer, AG Report 8/2019, R112: detailversessen.

379 DCGK 2017 Ziffer 4.2.5 und Anhänge. Zu den bisherigen Mustertabellen eher kritisch Klein, AG 2013, 733, 740 f; zu Problemen damit WandT, AG 2015, 303.

380 Dazu schon Begründung zu Empfehlung G.10.

381 \162 Abs. 1 Satz 2 Nr. 1 AktG i.d.F. ARUG II. 
denen ${ }^{382}$ Unternehmen über die Jahre hinweg nicht ausreichend. ${ }^{383}$ Jedoch stehen Leitlinien der EU-Kommission zur Vergütungsberichterstattung nach ARUG II unmittelbar bevor. ${ }^{384}$ Sie sind zwar rechtlich nicht bindend, die EU-Kommission stützt sich aber auf die Richtlinie ${ }^{385}$ und interpretiert diese.

\section{Zwischenergebnis zur Vergütung von Vorstand und Aufsichtsrat}

Das zweite Hauptanliegen der Reform war die Vergütung der Organe. Grundsätzlich Festvergütung und Differenzierung nach Funktionen sind für den Aufsichtsrat ohne weiteres einsichtig. Das gilt nicht ohne weiteres auch für das umfangreiche, auf das ARUG II abgestimmte und noch abzustimmende Empfehlungsprogramm zur Vorstandsvergütung. Die Varianz der von den Stimmrechtsberatern erwarteten und in der Praxis verbreiteten Vergütungssysteme ist ganz erheblich. Der DCGK 2020 empfiehlt demgegenüber ein Modell mit einem ganz bestimmten Ablauf und inhaltlich wie zeitlich weitgehenden Vorgaben, was bei jeder Abweichung zu Erklärungen und Begründungen zwingt. Dieses Modell ist interessant und sollte weiter diskutiert werden, aber es ist doch ein „Novum“, das bislang noch nicht durchweg als best practice etabliert ist. ${ }^{386}$ Auch wenn man in der Industrie jedenfalls im Vergleich zum DCGK-E 2018 mit den modifizierten Anforderungen offenbar leben kann, ${ }^{387}$ wäre insgesamt mehr Flexibilität möglich und in der Praxis willkommen gewesen, ${ }^{388}$ etwa durch Beschränkung der Empfehlungen auf einige

382 Eine vergleichende Darstellung bezüglich der Gesellschaft selbst sieht $\ 162$ Abs. 1 Satz 2 Nr. 2 AktG i.d.F. ARUG II vor.

383 Kritisch zum Wegfall deshalb TüngLER, DSW-Vorstandsvergütungsstudie 2019, DSWPressekonferenz 11.6.2019; aus Investorensicht (Kommission Corporate Governance im Verband der Investment Professionals DVFA) M. Schmidt/STrenger, Börsen-Zeitung Nr. 233, 4.12.2018, S. 8; DÖRRWäChTER, DB 2018, 2977, 2981.

384 Guidelines, aaO (Fn. 378).

385 Art. 9b Abs. 6 der Richtlinie.

386 Böcking/Bundel/Schmidt/Wagner, DB 2019, 137, wenngleich positiv in der Sache. Der weit überwiegende Teil der Befragten überprüft die Umsetzung der strategischen Planung jährlich, das Vorstandsvergütungssystem wird dagegen nur von je einem Viertel anlassbezogen bzw. jährlich überprüft, eine relative Mehrheit überprüft es nur alle zwei bis fünf Jahre, Studie von 2019 des Arbeitskreises Deutscher Aufsichtsrat e.V./ HengelerMueller, aaO (Fn. 5), B.7. Auch die Anlage in Aktien wird von einem erheblichen Anteil der Befragten bewusst abgelehnt, aaO (Fn. 324). So auch das Fazit der Studie, aaO (Fn. 5), C: „die Diskussion um die Vorstandsvergütung ist aber keineswegs abgeschlossen. Eine ultimative Formel scheint noch nicht in Sicht."

387 BDI-Reihe Wirtschaftsrecht, Ausgabe 2/2019, S. 7.

388 Etwa Dörrwächter, DB 2018, 2977, 2979 ff; VGR, aaO (Fn. 19), VI 1. Aus Investorensicht (Kommission Corporate Governance im Verband der Investment Professionals DVFA) M. Schmidt/STrenger, Börsen-Zeitung Nr. 233, 4.12.2018, S. 8. Zur brei- 
Kernpunkte und im Übrigen bloße Anregungen. Richtig oder jedenfalls mit kleineren Modifikationen gut vertretbar sind beispielsweise die Empfehlungen zum horizontalen und auch zum vertikalen Vergleich, zum repricing, zum Vergütungsexperten, zu außergewöhnlichen Entwicklungen, zum Clawback, zum Abfindungscap samt Anrechnung auf die Karenzentschädigung und zum Change of Control. Aber der DCGK muss sich eben künftig im Wettbewerb mit den Vorschlägen anderer durchsetzen. ${ }^{39}$ Das bedarf weiterer Überzeugungsarbeit.

\section{Transparenz und externe Berichterstattung (DCGK Teil 2 F)}

\section{1. Überführung des Corporate Governance Berichts in die Erklärung zur Unternehmensfübrung sowie weitere externe Berichterstattung}

Der DCGK 2020 enthält in einem eigenen Abschnitt F über Transparenz und externe Berichterstattung ${ }^{390}$ drei Grundsätze 20 bis 22 und fünf Empfehlungen F.1 bis F.5. Dass Transparenz und Offenlegung (disclosure) für das Vertrauen der Aktionäre und anderen Stakeholdern und für den Kapitalmarkt entscheidend ist, ist allgemein anerkannt ${ }^{391}$ und ist auch empirisch belegt. ${ }^{392}$ Die Information in der Aktiengesellschaft liegt im Markt-, öffentlichen und Unternehmensinteresse. ${ }^{393}$ Am wichtigsten ist Grundsatz 22, wonach

ten Kritik zum Thema Vorstandsvergütung im DCGK-E 2018, vor allem auch der Stimmrechtsberater und institutionellen Investoren, KRAMARSCH/SiEPMANN/DÖRRwächter, Der Aufsichtsrat 2019, 66, „too prescriptive“. Auch HohenstatT/Seibt, ZIP 2019, 11, 13 ff; v. Werder, DB 2019, 41, 46f. Zur Vergütungspraxis bei den DAX-30Unternehmen 2017 Allen \& Overy, aaO (Fn. 291), PWC, Vergütungsstudie 2018; zu den erheblichen nationalen und internationalen Unterschieden oben Nachweise in Fn. 267. Zur unterschiedlichen Praxis bei variablen Vergütungsbestandteilen IHRIG/ WANDT/WitTGENs, ZIP Beil Heft 40/2012, S. 11 f. Zu den erheblichen Unterschieden bei den Stimmrechtsberatern und institutionellen Investoren Tabelle Audit Committee Quarterly IV/2018, 16.

389 Zutreffend Lutter, aaO (Fn. 9), S. 33; Hommelhoff, BB Heft 1/2 2019, Erste Seite.

390 Teil 2 F, die Platzierung vor Abschnitt G Vergütung von Vorstand und Aufsichtsrat ist merkwürdig, da gerade dort die Transparenz und externe Berichterstattung eine besondere Rolle spielen. Übergreifende Fragen zum Corporate Governance Reporting und zur Reformdiskussion bei Leyens, aaO (Fn. 2), $\mathbb{} 161$ AktG Rdn. 23b-23g.

391 Statt vieler Kraakman et al., aaO (Fn. 147), p. 246 et seq. mit Begründung, warum mandatory disclosure wichtig ist.

392 Leuz, Different Approaches to Corporate Reporting Regulation: How Jurisdictions Differ and Why, abrufbar unter: http://ssrn.com/abstract_id=1581472 (letzter Zugriff: 1.10.2019).

393 Das ist auch das Thema des ZGR-Symposium 2020 mit Veröffentlichung in ZGR 2020 Heft 2/3. Zum System der Aktionärsinformation LeYens, ZGR 2019, 544. 
Aufsichtsrat und Vorstand über die Corporate Governance der Gesellschaft in der jährlichen EzU nach $\ 289 \mathrm{f}$ HGB berichten, die dadurch zum zentralen Instrument der Berichterstattung über die Corporate Governance wird. Die Abschaffung des bisherigen Corporate Governance Berichts nach DCGK 2017 Ziffer 3.10 soll die Unternehmen entlasten. ${ }^{394}$ Manche Gegenstände des früheren Corporate Governance Berichts gehören nach dem DCGK 2020 in die EzU. ${ }^{395}$ Die Praxis wird auch künftig auf das an vielen Stellen zu findende Nebeneinander von Berichtsinhalten und dadurch bedingte Dopplungen mit der Zusammenführung von Angaben und Erläuterungen in einem einzigen Dokument reagieren müssen, ${ }^{396}$ was ein Schritt zu dem in der Betriebswirtschaftslehre geforderten Integrated Reporting ist. ${ }^{397}$ Zur Entlastungswirkung ist zu bemerken, dass manche der früheren Inhalte des Corporate Governance Berichts letztlich nur in die EzU verschoben worden sind. ${ }^{398}$

Ein nach wie vor nicht aufgegriffenes Petitum ist die Anleitung der Berichterstattung. Dies betrifft zum einen die aus Sicht der Unternehmen wie auch dem Ziel einer Abweichungskultur kritische Begründung einer Nichtbefolgung. Die Empfehlung der Europäischen Kommission von 2014 zur Steigerung der Berichtsqualität und die dortigen Überlegungen sind bei der Regierungskommission auf Generalablehnung gestoßen, vom britischen Financial Reporting Council wurden sie begrüßt. ${ }^{399} \mathrm{Zum}$ anderen fehlt eine Anleitung des Aufsichtsrats im Umgang mit seiner von Grundsatz 22 angenommen gemeinsamen Berichterstattung mit dem Vorstand in der EzU. Der Kodex formuliert, was vom Gesetz nicht vorgesehen, aber auch nicht ausgeschlossen ist. ${ }^{400}$ Gerade nach

394 Ausführlich dazu Allgemeine Erläuterungen Teil 1 II 4. Allerdings hatte das doppelte Signal im Corporate Governance Bericht und der EzU möglicherweise eine größere Wirkung. Die Überführung in die EzU entspricht der Forderung des Arbeitskreises Corporate Governance Reporting der Schmalenbach-Gesellschaft für Betriebswirtschaft e.V., DB 2018, 2125, dort auch Vorschlag einer Mustergliederung der EzU, ebenda S. 2127. Dies begrüßend auch v. Werder, DB 2019, 41, 43.

395 Erläuterungen in der EzU fordert der DCGK 2020 in B.2, B.5/C.2, C.8, D.13, F.4. Außerdem soll der Aufsichtsrat in seinem Bericht an die Hauptversammlung $(\mathbb{} 171$ Abs. 2 Satz $1 \mathrm{AktG}$ ) verschiedene Erläuterungen aufnehmen, so D.8, D.12, E.1. Sonst muss Nichtbefolgung erklärt werden.

396 So die Begründung Teil 1 II 4.

397 Arbeitskreis Integrated Reporting der Schmalenbach-Gesellschaft für Betriebswirtschaft e.V., ZfbF Sonderheft 72 (2017) 337; Freidank/Müller/Velte, Hrsg., Handbuch Integrated Reporting, 2015.

398 Schon oben Fn. 395.

399 Regierungskommission DCGK, Stellungnahme zur Empfehlung der EU-Kommission vom 9. April 2014 zur Qualität der Berichterstattung über die Unternehmensführung („Comply or Explain“), 30.1.2015, 4; Financial Reporting Council, Stephen Haddrill responds to Commission Recommendation on the quality of corporate governance reporting, Press Release, 9.4.2014. Zum Ganzen Leyens, ZEuP 2016, 388, 411.

400 Leyens, FS E. Vetter, 2019, S. 397, 407 f. 
Wegfall des gemeinsam verantworteten Corporate Governance Berichts wäre eine Positionierung zu erwarten gewesen, also etwa dem Vorschlag des Arbeitskreises Corporate Governance Reporting folgend, eine Empfehlung zur Übernahme von Mitverantwortung des Aufsichtsrats durch Mitunterzeichnung der EzU. ${ }^{401}$

Grundsatz 21 mit den beiden Empfehlungen F.2 und F.3 betrifft die Unterrichtung von Anteilseignern und Dritten insbesondere durch den Konzernabschluss und den Konzernlagebericht einschließlich CSR-Berichterstattung sowie durch unterjährige Finanzinformationen.

Während die Empfehlung F.5 zu nicht mehr aktuellen Erklärungen und ihrer Internet-Zugänglichmachung mindestens fünf Jahre lang die Transparenz ohne großen Aufwand verbessert, ${ }^{402}$ ist die Empfehlung F. $4^{403}$ folgenreicher. Danach haben Aufsichtsrat und Vorstand von börsennotierten, spezialgesetzlich regulierten Gesellschaften in der EzU anzugeben, welche Empfehlungen des Kodex auf Grund vorrangiger gesetzlicher Bestimmungen nicht anwendbar waren. Das betrifft vor allem Kreditinstitute und Versicherungsunternehmen, aber auch andere staatlicher Zulassung bedürfende und überwachte Gesellschaften. Danach sind z.B. Kreditinstitute künftig gehalten, die zahlreichen, für sie geltenden Besonderheiten zur Corporate Governance, etwa zum Aufsichtsrat nach $\ 25 \mathrm{~d}$ KWG, soweit sie zu Abweichungen vom Kodex führen, darzustellen. Inwieweit das zu umfangreichen Erläuterungen in der EzU führt, bleibt abzuwarten. Ein eigener Bankenkodex könnte sinnvoller sein. ${ }^{404}$

\section{Gleichbehandlung der Aktionäre bei Informationen}

Aktionäre sind unter gleichen Voraussetzungen gleich zu behandeln. Dieser allgemeine Gleichheitsgrundsatz für Aktionäre ist in $\$ 53$ a AktG niedergelegt und richtet sich an die Aktiengesellschaft. Die Schwierigkeiten liegen in der

401 Arbeitskreis Corporate Governance Reporting der Schmalenbach-Gesellschaft für Betriebswirtschaft e.V., DB 2019, $317 \mathrm{f}$. So auch die Begründung im DCGK, Allgemeine Erläuterungen Teil 1 II 4; dazu auch Arbeitskreis Corporate Governance Reporting der Schmalenbach-Gesellschaft für Betriebswirtschaft e.V., DB 2018, 2125, 2126. Zum Fall nicht überwindbarer Uneinigkeit zwischen den Organen Leyens, aaO (Fn. 2), $\mathbb{1} 161$ AktG Rdn. $177 \mathrm{ff}$. Zum Aufsichtsrat als (mit-)erklärendem Organ in $\$ 161$ Abs. 1

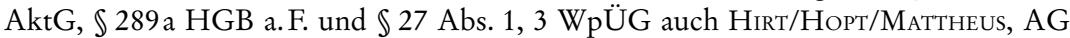
2016, 725, 732.

402 Wichtig ist das für den Vergleich in Vergütungstabellen. Der Vergütungsbericht und der Vermerk über seine Prüfung sind nach $\$ 162$ Abs. 4 AktG i.d.F. ARUG II zehn Jahre lang auf der Internetseite der Gesellschaft kostenfrei öffentlich zugänglich zu machen.

403 Schon oben II. 1. c).

404 Schon oben II. 1. c) und Норт, WM 2019, 1771. 
Konkretisierung, nicht nur weil es sich um eine (zwingende) gesetzliche Generalklausel handelt, sondern weil die entscheidende, komplexe Frage die nach den gleichen Voraussetzungen ist. ${ }^{405} \ 53$ a AktG gilt allgemein, auch für die Gleichbehandlung der Aktionäre bei Informationen unter gleichen Voraussetzungen. Der Grundsatz 20 wiederholt das lediglich. Die Empfehlung F.1 spezifiziert wie schon im DCGK 2017 Ziffer 6.1 Satz 2 dazu, dass die Gesellschaft den Aktionären unverzüglich sämtliche wesentlichen neuen Tatsachen, die Finanzanalysten und vergleichbaren Adressaten mitgeteilt worden sind, zur Verfügung stellen soll. ${ }^{406}$ Das ist zu Recht mehr, als was $\ 131 \mathrm{AktG}$ mit einem bloßen Auskunftsrecht des einzelnen Aktionärs vorsieht. Für Informationen an Finanzanalysten in speziellen Analystengesprächen oder Roadshows ist das ohne weiteres einleuchtend, denn ungleiche Voraussetzungen sind dann grundsätzlich nicht gegeben. Beim Investorendialog des Aufsichtsrats, den der DCGK 2020 in Anregung A.3 aus dem DCGK 2017 aufgenommen hat, ist das jedoch komplizierter ${ }^{407}$ und hätte näher angesprochen werden sollen. ${ }^{408}$

405 Eine Ungleichbehandlung ist nach der Formel des BGH zulässig, „wenn sie sachlich berechtigtistund damitnichtden CharakterderWillkürträgt",also dasErgebnis sachgerechter Abwägung darstellt, BGHZ 120,141 (Leitsatz und 150f) = AG 1993, 134. Eine unterschiedliche Behandlung von Unternehmensaktionären und von Kleinaktionären kann danach angesichts ihrer unterschiedlichen Interessen und Bedeutung für das Unternehmendurchausberechtigtsein, BGHZ120,141,151 f = AG1993,134 fürden Bezugsrechtsausschluss von Kleinaktionären vom Genussrechtsbezug bei einer ertragsschwachen BankAG, wenn die Genussrechte keine ertragreiche Kapitalanlage darstellen. Auch HopT, ZGR 1997, 1, 16,26; VERSE, Der Gleichbehandlungsgrundsatz im Recht der Kapitalgesellschaften, 2006, S. $536 \mathrm{ff}$. Auch die Vorabinformation wesentlich beteiligter Gesellschafter über einemöglicheKapitalerhöhungfürdasUnternehmen odersonst, umsichihrerUnterstützung bei grundlegenden Unternehmensentscheidungen zu versichern, ist, wenn im Unternehmensinteresse liegend, rechtlich zulässig. ZuletztZeTZsche, AG2019,701.

406 Insiderinformationen müssen Emittenten, wenn sie von diesen unmittelbar betroffen sind, so bald wie möglich bekannt geben (Art. 17 Abs. 1 MAR). Zu Investor Relations und informationeller Gleichbehandlung FleisCHer, ZGR 2009, 505.

407 Leyens, ZGR 2019, 544, $575 \mathrm{ff}, 579$. Rechtsvergleichend Hopt, The Dialogue between the Chairman of the Board with Investors, Revue Trimestrielle de Droit Financier (RTDF) 2017 no. 3, 97,100 etseq.; weitere NachweisebeiHopt,ZGR 2019,507,526. Möglichkeiten wären danach Ankündigung auf der Website, Webcasting, Angebot telefonischer Teilnahme, Informationssitzungen, die allen Aktionären offenstehen, umgehende Veröffentlichung auf der Website, Presseveröffentlichung. Ganz strikt z. B. für Frankreich AFEP/ MEDEF, Code degouvernement d'entreprise des sociétés côtées, 2018, \4.2: „Toute communication doit permettre à chacun d'accéder en même temps à la même information. “

408 Oben III. 1. b). 


\section{Zusammenfassung und Thesen}

1. Der DCGK 2020 ist ein beachtliches Werk zu einer guten deutschen Corporate Governance, das sich auch international im Wettbewerb mit den Leitlinien der Stimmrechtsberater und institutionellen Investoren durchaus sehen lassen kann. Der Kritik am DCGK-E 2018, soweit berechtigt, hat die Neufassung weitgehend Rechnung getragen. Die Änderungen zum DCGK 2017 sind insgesamt gelungen. Es bleibt aber eine ganze Reihe von Monita, vor allem zur Unabhängigkeit, zu den Ausschüssen, zur Selbstbeurteilung und zur Vergütung. Dazu ist, auch wenn man die deutschen Besonderheiten in Rechnung stellt, der internationale Stand noch nicht voll erreicht. Gute Corporate Governance ist jedoch nicht statisch, sondern entwickelt sich weiter. Der Kodex wird dazu in den nächsten Jahren im Dialog mit den Adressaten und der Öffentlichkeit kontinuierlich gefordert sein. Denkanstöße dazu auf der Basis eines internationalen Vergleichs finden sich in dieser Abhandlung.

2. Der Hinweis auch auf Unternehmerethik bleibt berechtigt. Den internationalen Anlegern neben dem deutschen zweistufigen System vor allem auch die (quasi-paritätische) Mitbestimmung verständlicher $\mathrm{zu}$ machen, ist dagegen nicht gelungen. Zur Bedeutung des Kodex auch für nicht kapitalmarktorientierte Gesellschaften war der DCGK 2017 besser. Dass zu Konzernen und institutionellen Investoren wenig und zu Stimmrechtsberatern nichts gesagt wird, ist jedenfalls nicht selbstverständlich.

3. Die Neueinführung von Grundsätzen zur lex lata schwächt den richtigen Verzicht auf die in der Verkürzung problematische und den Kodex aufblähende Beschreibung geltenden Aktienrechts wie im DCGK 2017 wieder ab.

4. Im Abschnitt Leitung und Überwachung sind die Anregungen zum Investorendialog des Aufsichtsrats, zur kürzeren Dauer der Hauptversammlung und zur Einberufung einer außerordentlichen Hauptversammlung im Falle eines Übernahmeangebots beibehalten worden. Das überzeugt aus internationaler und rechtspraktischer Sicht. Vorstandsbestellung nur auf drei Jahre, international sogar oft nur ein Jahr, leuchtet bei Gesellschaften mit Streubesitz ein, bei Familiengesellschaften und Konzernen weniger.

5. Eines der beiden Hauptanliegen der Reform war die Unabhängigkeit im Aufsichtsrat. Die Empfehlungen gehen in die richtige Richtung. Unabhängige Aufsichtsratsmitglieder sind zwar kein Allheilmittel, aber bei zielführenden Unabhängigkeitskriterien und einem richtig bemessenen Anteil fördern sie gute Überwachung. Dass mehr als die Hälfte der Anteilseignervertreter von der Gesellschaft und vom Vorstand unabhängig sein soll, die Aufstellung eines Indikatorenkatalogs für die Unabhängigkeit und die Entscheidung des Aufsichtsrats dazu sind zu begrüßen. Das gilt auch für die Empfehlungen zur funktionsbezogenen Unabhängigkeit (Vorsitzende des Aufsichtsrats, Prüfungsausschusses und Vergütungsausschusses). Aus europäischer und interna- 
tionaler Sicht ${ }^{409}$ greift die DCGK-Kommission dagegen deutlich zu kurz, was die Unabhängigkeit von einem kontrollierenden Aktionär angeht, dies auch, wenn man die deutschen Besonderheiten in Rechnung stellt. Eine Definition der Kontrolle wäre wünschenswert gewesen. Die Beschränkung der Unabhängigkeitsempfehlungen auf Anteilseignervertreter ist eine klar verfehlte Konzession an nationale Politik und Partikularinteressen.

6. International und europäisch hätte es nahegelegen, sich mehr mit den Ausschüssen wie dem Vergütungsausschuss, der vorstandsunabhängigen Information, der Aus- und Fortbildung, der Selbstbeurteilung (mindestens als Anregung: unter externer Hilfe alle drei Jahre) und dem Aufsichtsratsvorsitzenden zu befassen. Auch vermisst man einen ausdrücklichen Hinweis auf die wichtige Rolle, die dem Vorstand und dem Aufsichtsrat bei der Unternehmenskultur und dem tone from the top, was nicht Vorgabe, sondern Vorleben von oben bedeutet, heute mehr denn je zufällt.. ${ }^{40}$ All das sei für eine spätere Kodexreform ausdrücklich angemeldet.

7. Das zweite Hauptanliegen der Reform war die Vergütung der Organe. Grundsätzlich Festvergütung und Differenzierung nach Funktionen sind für den Aufsichtsrat einsichtig. Das gilt nicht ohne weiteres auch für das umfangreiche, schon auf das ARUG II abgestimmte und eventuell in Einzelheiten noch weiter abzustimmende Empfehlungsprogramm zur Vorstandsvergütung. Der DCGK 2020 empfiehlt hier ein Modell mit einem ganz bestimmten Ablauf und inhaltlich wie zeitlich weitgehenden Vorgaben, was aber bei jeder Abweichung zu Erklärungen und Begründungen zwingt. Hier wäre insgesamt mehr Flexibilität möglich und in der Praxis willkommen gewesen, etwa durch Beschränkung der Empfehlungen auf eine ganze Reihe durchaus berechtigter, oben näher benannter Kernpunkte und im Übrigen bloße Anregungen.

8. Die Überführung des Corporate Governance Berichts in die Erklärung zur Unternehmensführung ist als Erleichterung für die Unternehmen willkommen. Gleichbehandlung der Aktionäre auch bei den Informationen ist richtig, aber angesichts der internationalen Erfahrungen mit dem Bedürfnis nach einem unterjährigen Investorendialog praktisch nicht leicht umsetzbar.

409 BECKER/v. WeRder, AG 2016, 761, $770 \mathrm{ff}$.

410 Z.B. The Dutch Corporate Governance Code 2016, mit einem eigenen Principle 2.5. Culture und fünf Empfehlungen dazu; UK Corporate Governance Code 2018, aaO (Fn. 30), Principle B und Provision 2: „The board should assess and monitor culture.“ und ausführlich Guidance on Board Effectiveness, July 2018, 21 et seq.: Monitoring culture; CalPERS, aaO (Fn. 45), p. 14. Rechtsvergleichend Becker/v. Werder, AG 2016, 761, 772f. Zu corporate culture and values bei Finanzinstituten Nachweise bei Hopt, FS Seibert, 2019, S. 389, 397 f. Ernüchternde Praxisbefunde schon oben Fn. 66. 